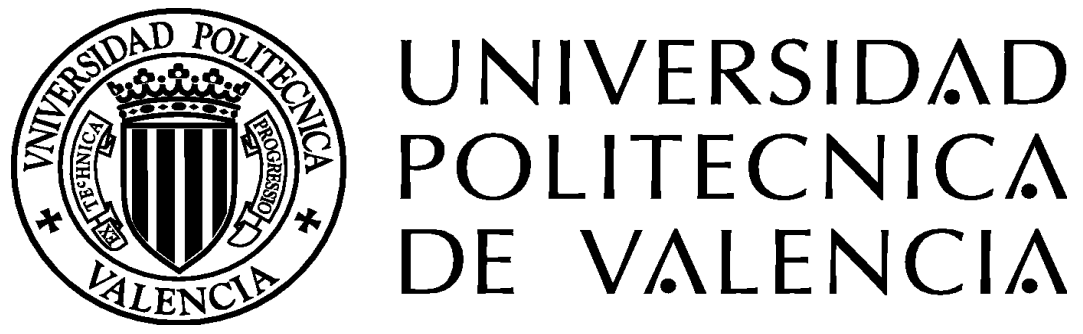

Departamento de Tecnología de Alimentos

\title{
Influencia del procesado en el valor nutritivo y funcional de la uva blanca
}

\section{TESIS DOCTORAL}

\author{
Presentada por: \\ José Carranza Concha
}

Dirigida por:

D ${ }^{a}$ Nuria Martínez Navarrete

$\mathrm{D}^{\mathrm{a}} \mathrm{M}^{\mathrm{a}}$. del Mar Camacho Vidal

Valencia, 2009 
INTRODUCCIÓN 



\section{INTRODUCCIÓN}

\section{I.1 Generalidades de la uva}

La vid es una de las más importantes plantas arbóreas cultivadas en la zona mediterránea. Su cultivo está sometido a una evolución constante, cada día más rápida por la disponibilidad de conocimientos para una mejor gestión de los viñedos. La uva (Vitis vinífera) es el nombre que recibe el fruto que crece formando racimos de la vid común o vid europea. Pertenece al género Vitis de la familia de las Vitáceas, que incluye unas 600 especies de arbustos, por lo general trepadores y que producen frutos en baya, propios de países cálidos y tropicales. Existen innumerables variedades de uvas con grandes diferencias entre sí en la forma, tamaño, tonalidad de los frutos, productividad, calidad, etc. Las variedades europeas se consideran con mejores aptitudes en comparación con las americanas para elaborar vinos de mesa, uva de mesa y pasas, mientras que las últimas se prefieren para obtener jugos y jaleas. La vid tiene especiales facultades para mutar genéticamente y adaptarse a condiciones climáticas y edafológicas diversas. De ahí el gran número de variedades que se conocen. Al parecer, la vid, en su origen fue tinta, siendo la variedad blanca procedente de una mutación posterior. A continuación se describen las variedades objeto de estudio en este trabajo de investigación.

Uva Moscatel: podría ser la más antigua de las cepas, posiblemente antepasada de las otras Vitis vinífera. Probablemente su origen sea 


\section{Capítulo I}

Alejandría y de ahí una de sus denominaciones "MOSCATEL DE ALEJANDRIA". La uva moscatel es una variedad blanca de maduración media y de usos múltiples (uva de mesa, pasificación, mistelas y vinificación). Se considera cepa del Mediterráneo, muy exigente en cuanto al clima, necesitada de sol, suelos húmedos e influjo del mar, dando sus mejores cualidades organolépticas cuanto más próxima está del mar. La variedad moscatel, en cuanto a viticultura, posee una gran rusticidad adaptándose a todo tipo de suelos, si bien las mejores calidades de uva se obtienen en terrenos de suave pendiente y con cantos rodados.

En España se cultivan 22.000 Ha. para vino y 18.000 Ha. para uva de mesa. Se cree que fue introducida en España por los romanos y ya era conocida por los egipcios y griegos expandiéndose de esa manera por todo el mediterráneo. Esta familia cuenta al menos con doscientos representantes e igual número de denominaciones (Moscatel Romano, Moscatel de Valencia, Moscatel Real, etc), algunas, por supuesto, con más calidad que otras. La moscatel de grano menudo o fino es una de las variedades más preciadas de la vinicultura mundial. Se la conoce también con los nombres de Muscat de Frontignan, Muscat de Alsace, Moscazo d'Asti, entre otras denominaciones. No debe confundirse con la Moscatel de Alejandría. Aunque con ella se pueden obtener exquisitos vinos dulces, sobresalen los vinos blancos secos muy aromáticos (rosa, naranja, miel de azahar), de paladar sedoso y crujiente. 
Uva Thompson Seedless (sinónimos: Sultaninia, Kichinich, Kishmish, Sultana): esta variedad de uva es muy antigua y tiene su origen en Asia Menor. Es la variedad apirena más extendida y cultivada en el mundo y se utiliza como parental para nuevas generaciones de material sin semilla. Se emplea principalmente como uva de mesa y para la elaboración de uvas pasas, pero también puede utilizarse para la elaboración de vino. Su principal inconveniente para el mercado del consumo en fresco es el pequeño tamaño de sus bayas. Dadas sus características de apirena y fácil secado se considera excelente para la obtención de pasas. Se estima que más de la mitad de la uva pasa que se produce en el mundo procede de esta variedad.

Uva Imperial Seedlees: la variedad de uva Imperial seedless es de origen californiano. Fue obtenida en 1972 por la empresa SUPERIOR FARMING COMPANY BAKERSFIELD procedente de un cruce de la variedad Cardinal y un genitor apireno. En estos momentos, junto con la Thompson, es una de las variedades sin semilla mas cultivada. Además de uva de mesa, se emplea para la elaboración de pasas, zumos macedonias y conservas en almíbar.

Uva Festival Seedless (sinónimos: Sugraone Brasileña): es una uva apirena de largo diámetro, de un verde tenue muy atractivo y con un suave sabor dulce. Esta uva representa una opción saludable en la dieta y puede ser utilizada para la vinificación si lo que se busca es una uva de sabor suave y baja acidez. El creciente intercambio y demanda de 


\section{Capítulo I}

mercados como la del continente Europeo, Reino Unido, Sudamérica y el mercado local brasileño han hecho de esta uva una de las más importantes. Es producida en Valle de Sao Francisco en Brasil, con un ciclo productivo de 94 días con cosechas concentradas en los meses de septiembre y octubre y en menor volumen en los meses de abril y mayo. http://www.fruitfoodlog.com.br/grapes-sugraone.htm. (3-Nov-2009).

Por otra parte, el grano de uva puede dividirse en tres partes, la piel, la pulpa y las pepitas (figura 1), cada una de ellas con unas características y componentes. La piel, también denominada hollejo, es la parte del fruto que envuelve la pulpa o parte carnosa y constituye del 6 al 10\% de la uva. En el hollejo se encuentran las sustancias colorantes (antocianos, solo se encuentran en uvas tintas), flavonoides, compuestos fenólicos, aromas, sustancias pécticas, taninos y enzimas. En la pulpa se encuentran los principales componentes nutritivos de la uva (agua y azúcares). También se encuentran sales minerales, sustancias nitrogenadas, ácidos libres y ácidos combinados. Las pepitas o semillas están dentro de la pulpa y difieren según las variedades, llegando incluso a encontrarse, como se ha comentado, uvas que no las contienen. Poseen una capa muy dura y tienen gran cantidad de taninos. 


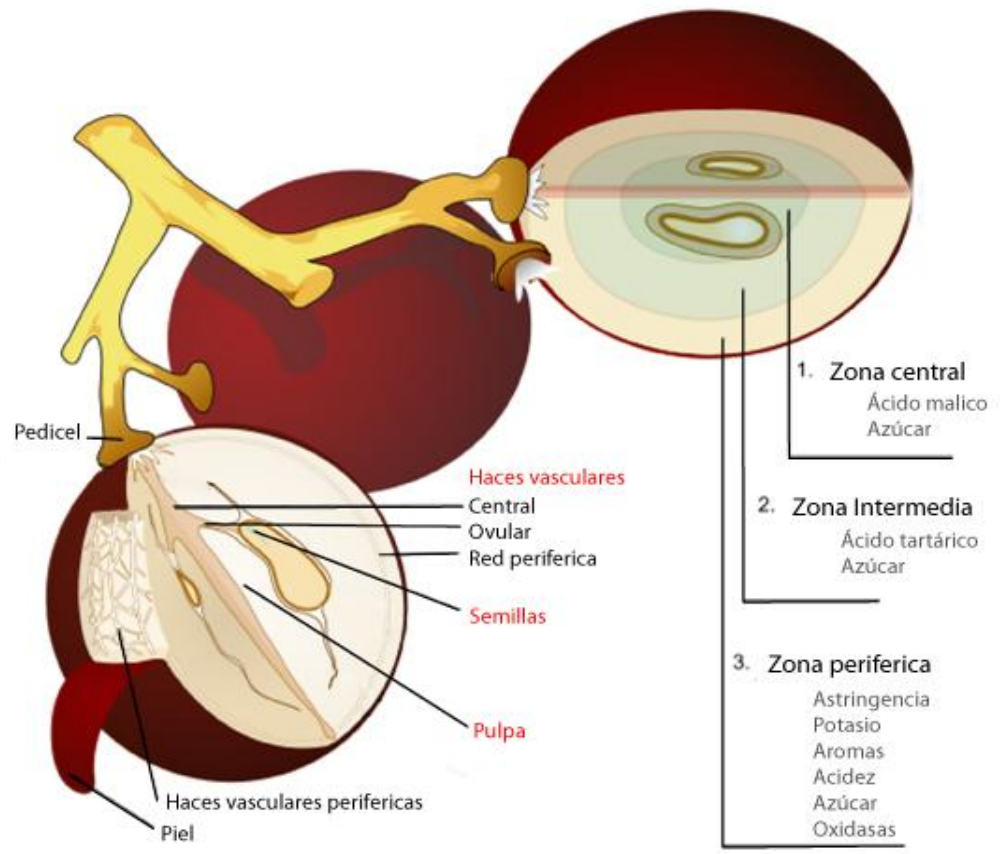

Figura 1. Partes de la uva

El fruto de la vid ha sido muy apreciado por el hombre desde la más remota antigüedad como fruta, por sus buenas características nutritivas, excelente sabor y aroma y como vino por su valor energético y por sus propiedades organolépticas y euforizantes (Primo, 1998). Podemos distinguir 4 tipos de uva en función del uso que se va a dar al producto: uva de mesa, uva para la obtención de pasa, uva para vinificación y para la elaboración de zumos.

a).- Uvas de mesa para el consumo en fresco.

La uva de mesa es aquella que se comercializa habitualmente para su consumo directo en estado fresco. Las uvas de mesa se corresponden con 


\section{Capítulo I}

aquellas variedades que vocacionalmente se aprecian más por las condiciones físicas y estructurales de sus frutos que por las características de los mostos. Deben reunir una serie de características que las hagan aptas para esta propuesta. Así deben tener un aspecto agradable, una buena calidad gustativa y una determinada aptitud para el transporte. Entre las características más importantes a considerar destacan: el tamaño del racimo, el tamaño de los granos, la uniformidad de color de los racimos y la época de maduración. Se tendrá en cuenta también la presencia de semillas (Pérez, 1988).

b).- Uva pasa.

Se entiende como uva pasa a toda uva desecada. Entre los caracteres más importantes a exigir a las uvas pasas destaca la textura carnosa, el tamaño y la presencia o ausencia de semilla. La uva pasa es una alimento de gran valor energético (3340 kcal/kg) y muy rico en azúcares (Pérez, 1988). Existen evidencias de que los antiguos Egipcios ya producían pasas desde los años 2000 a.C. En la actualidad se producen pasas similares en distintas zonas del mundo, sobre todo en California. Las pequeñas pasas de Corinto proceden de unas uvas negras sin semillas, nativas de los alrededores de la ciudad homónima en Grecia. Se identifican por su color oscuro, su pronunciado aroma, carecen de pepitas y son mucho más pequeñas que el resto. Las pasas sultanas más reconocidas se obtienen de las uvas blancas sin semillas que crecen en los alrededores de la ciudad de Esmirna, en Turquía. Son uvas pasas de color claro, sin semillas y extraordinariamente dulces, por lo que son las 
más empleadas en repostería y pastelería. Aunque ambas variedades se producen hoy día en muchos otros lugares, todavía prevalecen con sus antiguas denominaciones. En España, las uvas pasas de Málaga poseen Denominación de Origen, son de gran calidad, proceden de la uva Moscatel y son grandes, dulces y con pepitas.

c).- Uva para la elaboración de vino.

Para este fin se emplean la mayoría de las uvas producidas en el mundo. Se tendrá en cuenta la concentración inicial de azúcares ya que es la que después de la fermentación darán lugar al etanol. Además, cada productor tendrá en cuenta una gran cantidad de variables que posteriormente darán lugar a un vino de unas determinadas características (Pérez, 1988).

d).- Uva para la elaboración de zumos.

Para la producción de zumo han de utilizarse uvas que produzcan zumos que mantengan un sabor adecuado después de pasar por las diferentes etapas del proceso de elaboración, clarificación y conservación (Pérez, 1988).

La composición química de las uvas varía en función de la variedad y el medio ambiente bajo el cual han crecido. Entre los diferentes factores ambientales, la temperatura, la fertilidad de la tierra, la humedad y la luz tienen una marcada influencia (Salunkhe y Kadam, 1995), pero de forma general es rica en agua y azúcares además de que contiene 


\section{Capítulo I}

vitaminas, minerales y otros compuestos saludables que la hacen muy interesante para el consumidor. En la Tabla I se presenta la composición de la uva, como un intervalo de los valores obtenidos de varios autores.

Tabla I. Composición nutricional de la uva por cada $100 \mathrm{~g}$ de fruta.

\begin{tabular}{|c|c|}
\hline Compuesto & Cantidad \\
\hline Agua & $80,1-81,7 \mathrm{~g}$ \\
\hline Calorías & $63-70 \mathrm{cal}$ \\
\hline Carbohidratos & $15,5-18,1 \mathrm{~g}$ \\
\hline Cenizas & $0,5 \mathrm{~g}$ \\
\hline Grasas & $0,1-0,4 \mathrm{~g}$ \\
\hline Proteínas & $0,7 \mathrm{~g}$ \\
\hline Calcio & $4-18 \mathrm{mg}$ \\
\hline Hierro & $0,3-0,5 \mathrm{mg}$ \\
\hline Magnesio & $3-10 \mathrm{mg}$ \\
\hline Fósforo & $13-22 \mathrm{mg}$ \\
\hline Potasio & $185-320 \mathrm{mg}$ \\
\hline Sodio & $2 \mathrm{mg}$ \\
\hline Cobre & $0,1-0,26 \mathrm{mg}$ \\
\hline Manganeso & $0,1 \mathrm{mg}$ \\
\hline Selenio & $0,1 \mathrm{mg}$ \\
\hline Zinc & $0,05-0,1 \mathrm{mg}$ \\
\hline Vitamina A & $66-73 \mathrm{IU}$ \\
\hline Vitamina $\mathrm{C}$ & $4-10,8 \mathrm{mg}$ \\
\hline Vitamina E & $0,2 \mathrm{mg}$ \\
\hline Vitamina $\mathrm{K}$ & $14,6 \mu \mathrm{g}$ \\
\hline Tiamina & $0,1 \mathrm{mg}$ \\
\hline Riboflavina & $0,1 \mathrm{mg}$ \\
\hline Niacina & $0,2-0,3 \mathrm{mg}$ \\
\hline Vitamina B6 & $0,1 \mathrm{mg}$ \\
\hline Ácido Pantotenico & $0,1 \mathrm{mg}$ \\
\hline Fructosa & $7,7 \mathrm{~g}$ \\
\hline Glucosa & $7,3 \mathrm{~g}$ \\
\hline Sacarosa & $0,4 \mathrm{~g}$ \\
\hline Pectina & $280 \mathrm{mg}$ \\
\hline
\end{tabular}

Mataix (2003). Primo (1998). http:// www.nutritiondata.com/ facts/fruits-and-fruit-juices/1920/2 (6-Nov-09) http://frutas.consumer.es/documentos/frescas/uva/intro.php 


\section{I.2 Alteración de la uva y métodos de conservación}

En general, los microorganismos y los procesos bioquímicos son las principales causas de alteración de los alimentos en general y de la uva en particular.

La vía de entrada más importante de los microorganismos al fruto son los cortes en la superficie de éste, causados durante la recolección, manipulación, transporte etc. En el caso de que la uva vaya a ser destinada para su procesado y por ello sea troceada, este será el punto crítico de entrada de microorganismos. Una vez los microorganismos se encuentran en el interior del fruto, la multiplicación y el tipo de microorganismos depende de la naturaleza y composición del fruto. Por ejemplo, los halófilos crecen en condiciones salinas, los osmófilos en medios azucarados, los termófilos a elevadas temperaturas, los psicrófilos a bajas temperaturas, etc. (Escribá, 2000).

Por otra parte, las reacciones bioquímicas que mantienen la vida de las plantas pueden verse alteradas por los enzimas, proteínas muy complejas que las catalizan. La actividad de algunos enzimas aumenta durante la maduración y causa el ablandamiento de los tejidos, lo cual conlleva a que el alimento se deteriore y cambie en cuanto a sus características sensoriales. También se puede producir el pardeamiento enzimático debido a la acción de las polifenoloxidasas, que en presencia de oxigeno oxidan los compuestos fenólicos propios de las frutas. Para evitar este pardeamiento se puede adicionar ácidos (ácido cítrico, ácido málico y ácido fosfórico) que inactivan los enzimas, o utilizar métodos de conservación como el escaldado o la inmersión en almíbares. 
Capítulo I

Otra forma de alteración es la causada por la reacción de Maillard, una de las reacciones más importantes que se da en los alimentos, entre los azúcares y los compuestos de tipo amina. Este tipo de deterioro, responsable de un pardeamiento no enzimático, se produce en gran medida en las frutas deshidratadas (Escribá, 2000).

A continuación se describen brevemente los métodos de conservación más utilizados en alimentos.

\section{I.2.1 Deshidratación de alimentos}

La deshidratación supone la eliminación del agua de un producto alimenticio hasta un nivel en el que el producto desecado es estable durante un período de tiempo determinado (Holdsworth, 1988). Este proceso reduce el peso y el volumen de los alimentos pudiendo conducir a ahorros sustanciales en los costes de transporte y almacenamiento. Sin embargo la deshidratación es un proceso que utiliza grandes cantidades de energía y los costes de este suministro pueden ser relativamente altos comparados con otros métodos de conservación. Durante el secado también pueden ocurrir cambios que perjudiquen la calidad del alimento, como la disminución del tamaño, el cambio en el color y en el sabor, así como la reducción del valor nutricional.

Dependiendo del tipo de producto que se desee obtener, la etapa de deshidratación puede ser más o menos intensa. Así puede interesar desde un procesado mínimo del producto que permite alargar la vida útil afectando lo menos posible a la calidad hasta una deshidratación muy 
intensa que da lugar a otro tipo de alimento, como sería el caso de las pasas.

El secado por aire caliente es, desde hace muchos años, la técnica más común elegida para deshidratar alimentos (Erenturk et al., 2005), pues ha resultado ser suficientemente eficiente y productiva, versátil y de fácil manejo gracias a las nuevas tecnologías. En el secado convectivo, la corriente de aire caliente pasa a través del alimento eliminando el agua de su superficie. Esto crea un gradiente difusional en dicho alimento que provoca la salida del agua desde su interior hacia su superficie (Gowen et al., 2006). Es frecuentemente un proceso lento, que requiere altas temperaturas externas para generar las diferencias de concentración requeridas (Fito et al., 2001). Las principales ventajas que presenta respecto al secado natural son las siguientes:

- La calidad del producto deshidratado es generalmente superior, si se selecciona una buena tecnología del proceso.

- La velocidad de secado suele ser mucho mayor, disminuyendo considerablemente el tiempo de proceso, lo que influye tanto en la calidad como en el coste del producto.

- Las condiciones sanitarias y nutritivas son mejores, al no estar el producto expuesto a la acción directa del sol, la lluvia, el polvo y los insectos.

- La superficie de las instalaciones utilizadas en la deshidratación es varias veces menor, que la utilizada en el secado natural. 
Capítulo 1

Aún así el secado artificial convencional (convectivo) presenta las siguientes desventajas:

- Alto coste de la instalación, tanto por la cámara de secado como por la caldera, hornos o calentadores de aire.

- Alto coste de producción, en caso de que consuma petróleo o electricidad para el calentamiento del aire o el producto.

- Baja eficiencia energética.

- Largos tiempos de secado.

Además de los inconvenientes que acaban de mencionarse, hay que tener en cuenta el más importante, la gran pérdida de calidad ocasionada en los alimentos dependiendo de las condiciones de secado (Erentuk et al, 2005). Los daños causados están directamente relacionados con las elevadas temperaturas y los largos tiempos de proceso que son necesarios para llevar a cabo la deshidratación. Ello conlleva que el secado por aire caliente convencional cause a menudo grandes daños y efectos negativos sobre la textura, color, flavor y valor nutricional de los alimentos. Todas estas desventajas han hecho patente la necesidad de implantar nuevas técnicas de deshidratación de alimentos, como por ejemplo la utilización de la energía microondas (Gowen et al., 2006) o el secado osmótico. 
La deshidratación osmótica, con o sin vacío, se presenta como una alternativa de conservación de frutas. Ha cobrado gran interés debido a las bajas temperaturas de operación usadas $\left(20-50^{\circ} \mathrm{C}\right)$, lo cual evita el daño de componentes termolábiles, en propiedades nutritivas y/o funcionales además de reducir los costes de energía para el proceso (Fito et al., 1995). Este método consiste en sumergir a los alimentos en disoluciones hipertónicas con el objetivo de producir dos efectos principales: flujo de agua y otros componentes (azúcares, vitaminas, pigmentos) desde el producto hacia la disolución hipertónica y flujo de solutos hacia el interior del alimento desde la disolución (Barat et al., 1998, Peiró et al., 2006 y 2007). En consecuencia el producto pierde agua (hasta un 50-60\% en base húmeda), gana sólidos solubles y reduce su volumen (Peiró et al., 2006). Cuando se utiliza azúcar en la preparación de la disolución osmótica, se consiguen beneficios como la inhibición de la enzima polifenoloxidasa además previene la perdida de compuestos volátiles (Zhang et al., 2006). Esta técnica es mas adecuada para un procesado mínimo del producto, ya que una deshidratación muy intensa requiere tiempo proceso muy largo.

Se puede decir que la deshidratación osmótica es un método de conservación de alimentos factible de adaptarse en países con economías emergentes que produzcan frutas que normalmente se consumen frescas por ser productos perecederos y que al someterse a tratamientos de procesado mínimo puedan conservarse y exportarse manteniendo muchas de sus propiedades. Otra de las ventajas es que su desarrollo e 


\section{Capítulo I}

instrumentación no requiere de grandes inversiones ni de equipos complejos o difíciles de fabricar (Genina, 2002).

Por otra parte, para la obtención de frutas deshidratadas se pueden aplicar otros métodos como las microondas. El gran interés en este tipo de técnica de secado se debe a la capacidad de penetración que poseen estas ondas, que calientan no solo la superficie, sino también el interior del alimento, lo que acelera el proceso y puede contribuir a una mejora de la calidad final del producto frente a la obtenida por otras técnicas como el secado por aire caliente (Contreras et al., 2005 y 2007). Sin embargo, aunque el uso doméstico de aparatos microondas está muy extendido en el mundo desarrollado, la aplicación industrial es más bien escasa debido al elevado coste de los equipos y la falta de información sobre la tecnología. No obstante, en los últimos años el uso industrial de esta técnica parece haber aumentado considerablemente (Bilbao, 2002; Martín, 2002).

El método de deshidratación por microondas destaca frente a otros métodos de secado debido, como ya se ha comentado, a su poder de penetración. A pesar de que el calentamiento es mayor en la superficie que en el interior del producto, se disminuye la transferencia de calor por conducción desde la superficie hacia el interior del alimento. Además es más rápido y el calor se genera en las zonas húmedas y no en las zonas secas, de manera que las zonas sin humedad no son calentadas innecesariamente con los efectos negativos para la calidad del producto que ello comporta (Bilbao, 2002; Martín, 2002). 
Por el contrario, los sistemas de deshidratación por microondas, tienen el inconveniente de que es muy difícil conocer la distribución del campo energético, pues resulta modificado por la introducción de una carga en el sistema. Otro inconveniente, es que no pueden introducirse objetos metálicos, pues se crean potenciales eléctricos (entre estos y las paredes) que provocan descargas eléctricas. Lo mismo ocurre entre las paredes metálicas del equipo si la carga es insuficiente, por ello se suelen introducir cargas de agua que absorben el exceso de energía aportado.

Por otra parte, la aplicación combinada de las microondas con el secado por aire caliente e incluso con la deshidratación osmótica puede aportar ciertas ventajas, ya que ha mostrado mejoras en el secado y en la calidad final del producto (Ahrne et al., 2003; Contreras et al., 2005; Funebo et al., 2002; Piotrowski et al., 2004; Prothon et al., 2001; Raghavan \& Silveira, 2001: Torringa et al., 2001).

\subsubsection{Escaldado}

La mayor parte de las verduras y algunas frutas se someten a un proceso de escaldado ante las subsiguientes operaciones de procesado como el enlatado, la congelación o la deshidratación. El escaldado es un tratamiento térmico suave cuyo objetivo suele ser la inactivación de las enzimas que provocarían la reducción de la calidad del producto final. El escaldado consiste en el calentamiento rápido de un producto a una temperatura predeterminada, su mantenimiento durante el tiempo adecuado y a continuación un enfriamiento rápido o su paso inmediato a 


\section{Capítulo I}

la siguiente fase del proceso (Brennan, 2007). El escaldado elimina los gases de los tejidos vegetales, en especial el gas intracelular. Esto es particularmente útil antes del enlatado, ya que ayuda a conseguir el vacío en las latas, evitando la expansión de aire durante el procesado, con la consecuente reducción de la fuerza de los envases y el riesgo de deformaciones en las latas. También actúa como operación final de limpieza y descontaminación. Selman (1987) describió la efectividad del escaldado en la eliminación de residuos de pesticidas o sustancias radioactivas en la superficie de los vegetales, mientras que los constituyentes tóxicos naturalmente presentes (como nitritos o nitratos y oxalatos) se reducen por lixiviación. Además se consigue una reducción muy significativa del contenido en microorganismos, lo que es muy positivo en los alimentos congelados o deshidratados, en los que la microbiota superviviente puede multiplicarse durante la descongelación o la rehidratación.

Las frutas después de escaldarse suelen enlatarse o envasarse en jarabes de sacarosa, aunque cada vez se tiende a utilizar como liquido de gobierno su propio zumo. La concentración de azúcares suele expresarse en grados Brix ( ${ }^{\circ}$ Brix) lo que constituye una medida del porcentaje de azúcar, en peso, con disolución acuosa a $20^{\circ} \mathrm{C}$ (Arthey y Ashurst, 1996) 
OBJETIVO 



\section{OBJETIVO}

El objetivo general de esta Tesis ha sido evaluar el efecto del procesado de uva por métodos alternativos a los tradicionales para la obtención de diferentes productos: uva parcialmente deshidratada, uva en almíbar y uva pasa. En todos los casos se consideró, como alternativa al calentamiento convencional, la aplicación de energía microondas y, en el caso de la uva parcialmente deshidratada, además, el procesado osmótico. Para la comparación de tratamientos se analizaron los macro y micronutrientes de la fruta antes y después de su procesado así como durante su almacenamiento. En el caso de la uva en almíbar se evaluó también el efecto sobre el color y las propiedades mecánicas.

Los objetivos específicos para cada producto se detallan en el correspondiente capítulo. 


\section{MATERIA PRIMA Y MÉTODOS DE ANÁLISIS}



MATERIA PRIMA Y MÉTODOS DE ANÁLISIS

\section{III.- MATERIA PRIMA Y MÉTODOS DE ANÁLISIS}

\section{III.1 MATERIA PRIMA}

III.1.1 Uva

Los experimentos fueron realizados con uva blanca (Vitis vinífera) seleccionada por tamaño, color y estado de maduración de las variedades Moscatel, Thompson seedless, Imperial seedless y Festival adquiridas en supermercados de la ciudad de Valencia y almacenadas en refrigeración hasta el momento de su procesado (máximo 24h).

\section{III.1.2 Disolución Osmótica}

Para llevar a cabo la deshidratación osmótica de la uva se preparó una disolución de sacarosa de 55 'Brix. Para esto se utilizó agua destilada $(45 \% \mathrm{p} / \mathrm{p})$ y azúcar común de grado alimentario $(55 \% \mathrm{p} / \mathrm{p})$, disolviendo el azúcar con agitación continua a $30^{\circ} \mathrm{C}$.

\section{III.2 ANÁLISIS REALIZADOS}

A continuación se describen los métodos utilizados en los análisis de fruta y de los productos de fruta a lo largo de todo el trabajo de investigación.

\section{III.2.1 Humedad $\left(\mathbf{X}_{\mathrm{w}}\right)$}

Las medidas de la humedad se realizaron mediante el método 950.46 de la AOAC (1997). Este método se suele emplear para muestras que contienen azúcares como es el caso de las frutas. La muestra triturada 


\section{Capítulo III}

con arena se introdujo en una estufa de vacío (Selecta) durante 24 horas a $60^{\circ} \mathrm{C}$ y 0,8 bares de presión manteniendo la misma temperatura hasta alcanzar el peso constante. El agua evaporada se calculó a partir del peso de la muestra antes y después del secado en la estufa, referida al peso inicial de la muestra. Esta determinación se llevo a cabo en la fruta tanto en fresco como tratada y se realizó por triplicado.

\section{III.2.2 Ácido ascórbico}

La determinación del contenido en ácido ascórbico (AA) se llevo a cabo mediante el método descrito por la AOAC $(967.21,1997)$ para frutas y vegetales. Se trata de un análisis volumétrico en el que se emplea ácido metafosfórico para inactivar la enzima oxidasa ascórbica; el AA se determina por su acción reductora sobre el colorante azul 2,6 diclorofenol-indofenol.

Para analizar el ácido ascórbico en las muestras de fruta fue necesario homogeneizarlas y posteriormente centrifugarlas. A partir del sobrenadante obtenido se pesaron $10 \mathrm{~g}$ de muestra, adicionándoles $10 \mathrm{ml}$ de una disolución acuosa de ácido metafosfórico al 25\% y se enrasó a 50ml con $\mathrm{H}_{2} \mathrm{O}$ destilada. De la disolución anterior, se tomaron $10 \mathrm{ml}$ y se valoraron con el indicador azul 2,6 diclorofenol-indofenol previamente valorado con una disolución patrón de ácido ascórbico (250ppm), en ambos casos hasta la aparición de un color rosa persistente durante 30 segundos. Todos los reactivos se prepararon con agua destilada fría pero previamente hervida. El resultado se expresa en mg de AA/100g de muestra (Ec. 1). Los análisis se realizaron por triplicado. 


$$
m g \text { de AA } / 100 \mathrm{~g} \text { de muestra }=\frac{V m \cdot\left(\frac{M p}{V p}\right) \cdot V t}{V a \cdot P} \cdot 100
$$

Donde:

$V m=$ Volumen de indicador $(\mathrm{ml})$ consumido en la valoración de la muestra

$M p$ = masa (mg) de ácido ascórbico que tiene el patrón en la alícuota valorada

$V p=$ Volumen de indicador $(\mathrm{ml})$ consumido en la valoración del patrón.

$V t=$ Volumen total de la muestra

$V a=$ Volumen de muestra valorada

$P=$ peso en $(\mathrm{g})$ de la muestra

\section{III.2.3 Acidez total}

La determinación de la acidez total se efectuó de acuerdo con el método 942.15 de la AOAC (1997). A $10 \mathrm{~g}$ de muestra previamente homogeneizada se le añadieron 40ml de agua destilada y se agregaron 23 gotas de fenolftaleína. Para controlar el viraje de la fenolftaleína se colocó un electrodo de $\mathrm{pH}$ en la muestra durante la valoración con $\mathrm{NaOH} 0,1 \mathrm{~N}$ (previamente valorada con $\mathrm{HCl}$ ) hasta alcanzar un $\mathrm{pH}$ de 8,2 coincidiendo con la aparición de un color rosa fuerte durante 30 segundos. 


\section{Capítulo III}

Lo resultados se expresan en mg del ácido mayoritario, en este caso de ácido tartárico (AT), en 100g de muestra. Los análisis se realizaron por triplicado.

\section{III.2.4 Actividad del agua $\left(a_{w}\right)$}

Las determinaciones se llevaron a cabo mediante el uso de un higrómetro de punto de rocío (GBX FA-st lab, Francia) con una sensibilidad de 0,001 , el cual previamente fue calibrado con disoluciones salinas saturadas con $\mathrm{a}_{\mathrm{w}}$ similares a los valores de la materia a analizar (fruta fresca, fruta procesada y almíbar). Para poder realizar la lectura las muestras se homogeneizaron previamente con un Ultra-turrax modelo T25. Los análisis se realizaron por triplicado.

\section{III.2.5 Sólidos solubles}

La determinación de los sólidos solubles ( $\left.{ }^{\circ} \mathrm{Brix}\right)$ se realizó mediante la medida del índice de refracción de las muestras. Para ello se utilizó un refractómetro ATAGO NAR-3T termostatado a $20^{\circ} \mathrm{C}$. Para poder realizar la lectura de los ${ }^{\circ}$ Brix, las muestras se homogeneizaron previamente con un Ultra-turrax modelo $\mathrm{T}-25$ y posteriormente centrifugadas a $10,000 \mathrm{rpm}$ durante $10 \mathrm{~min}$ y $4^{\circ} \mathrm{C}$. Las medidas fueron sobre la fracción liquida de las muestras. Las determinaciones se realizaron por triplicado.

\section{III.2.6 Pectinas}

Las cadenas de pectina están formadas por unidades fundamentales de ácido galacturónico (AGU). Debido a esto su cuantificación es 
utilizada para la determinación de las pectinas en una muestra. La determinación de AGU se llevo a cabo a partir de los sólidos insolubles en alcohol (AIS) mediante el método utilizado por Yu et al. (1996).

a).- Extracción de los sólidos insolubles en alcohol (AIS)

La extracción de los AIS se llevó a cabo de acuerdo con el método de Kitner y Van Buren (1982). 2,5g de muestra previamente homogeneizada fueron introducidos en un tubo de centrifuga previamente pesado, se agregaron $15 \mathrm{ml}$ de etanol absoluto e inmediatamente se agitó con una varilla de vidrio. Posteriormente se colocó la muestra en un baño con agua en ebullición durante 10 minutos. A continuación se enfrío en un baño de agua con hielo. Enseguida se centrifugó durante 10 minutos a $10000 \mathrm{rpm}$ y $4^{\circ} \mathrm{C}$. Finalizada la centrifugación, el sobrenadante se desechó. Al precipitado se le agregó una vez más etanol y se centrifugó bajo las mismas condiciones. Finalmente, el mismo tubo de centrifuga con el precipitado se puso a secar en una estufa a $60^{\circ} \mathrm{C}$ durante 24 horas para evaporar el etanol. El tubo se pesó con los AIS secos. Obtenidos los AIS se procedió a la determinación de la pectina total o de las fracciones pécticas (pectina hidrosoluble y pectina oxalato soluble). La extracción se realizó por triplicado.

\section{b).- Extracción pectina total (PT)}

$5 \mathrm{mg}$ de AIS fueron pesados en una balanza analítica, se agregaron $2 \mathrm{ml}$ de $\mathrm{H}_{2} \mathrm{SO}_{4}$ concentrado y se dejó agitar 1 minuto. Después se 


\section{Capítulo III}

agregaron $0,5 \mathrm{ml}$, gota a gota, de agua destilada y se dejó agitando durante 5 minutos. Al cabo de este tiempo se agregaron otros $0,5 \mathrm{~mL}$ de la misma manera dejándose en agitación durante 30 minutos. Transcurrido este tiempo la dilución resultante se filtró a vació con fibra de vidrio y se enrasó a $25 \mathrm{ml}$ con agua destilada. La disolución se dejó reposar durante 24 horas y se volvió a filtrar antes de su utilización. La extracción se realizó por triplicado.

c)- Extracción de la pectina hidrosoluble (PHS) y la pectina oxalato soluble (POS)

$40 \mathrm{mg}$ de AIS fueron pesados en un tubo de centrifuga, después se agregaron $10 \mathrm{ml}$ de agua destilada y se agitó con una varilla de vidrio. Posteriormente se centrifugó $\left(10000 \mathrm{rpm} / 10 \mathrm{~min} / 4^{\circ} \mathrm{C}\right)$ y se filtró a vacío con papel Whatman $\mathrm{N}^{\circ} .1$. El sobrenadante se recuperó. El residuo se recogió y se le añadieron nuevamente $10 \mathrm{ml}$ de agua destilada, repitiéndose el proceso. El sobrenadante se juntó con el anterior en un matraz de 50ml y se enrasó con $\mathrm{H}_{2} \mathrm{O}$ destilada. La disolución se mantuvo en refrigeración hasta su utilización para la determinación de la PHS (24 horas). El residuo anterior se recogió y se dispersó en $10 \mathrm{ml}$ de una disolución de oxalato de amonio $(0,25 \%)$ y ácido oxálico $(0,25 \%)$. Se agitó con una varilla de vidrio y se calentó a reflujo durante una hora. Posteriormente se centrifugó en las mismas condiciones que la fracción hidrosoluble y se recogió el filtrado. El residuo se dispersó nuevamente en $10 \mathrm{ml}$ de la disolución de ácido oxálico-oxalato de amonio y se repitió el proceso por completo. Finalmente, se combinaron los filtrados y se enrasó a $50 \mathrm{ml}$ con $\mathrm{H}_{2} \mathrm{O}$ destilada. Las muestras se refrigeraron 
hasta su utilización para la determinación de la POS (24 horas). La extracción se realizó por triplicado.

d).- Determinación de pectina total, pectina hidrosoluble y la pectina oxalato soluble.

La determinación es aplicable tanto para la pectina total como para las fracciones pécticas (POS y PHS). Del extracto obtenido para la pectina total y las fracciones pécticas se tomó $1 \mathrm{ml}$, se agregaron $6 \mathrm{ml}$ de una disolución ácida de tetraborato de sodio $(0,025 \mathrm{M})$ manteniendo baja la temperatura con un baño de agua con hielo. Posteriormente, se calentó en un baño de agua a $100^{\circ} \mathrm{C}$ durante 5 minutos y, finalmente, se dejó enfriar en un baño de hielo. Se agregaron $0,1 \mathrm{ml}$ de m-hidroxibyfenil $(0,15 \%)$. Para cada una de las muestras se preparó una muestra blanco, a la cual se le agregaron $0.1 \mathrm{ml}$ de hidróxido de sodio al $0.5 \%$ en lugar de m-hidroxibifenil. Los tubos fueron agitados con un vortex y se dejaron reposar 15 minutos para después medir la absorbancia de las muestras a $520 \mathrm{~nm}$ en un espectrofotómetro UV1-visible Thermo Spectronic. Los resultados fueron expresados en $\mathrm{mg}$ AGU/100g de muestra. Las determinaciones se realizaron por triplicado.

\section{III.2.7 Fósforo}

La determinación del fósforo se llevó a cabo por colorimetría, utilizando un Espectrofotómetro UV1-visible Thermo Spectronic. La uva se homogeneizó (Ultra-turrax T25) y se centrifugó (10000 $\left.\mathrm{rpm} / 10 \mathrm{~min} / 4^{\circ} \mathrm{C}\right)$. A continuación se recogieron $2 \mathrm{~g}$ del sobrenadante $\mathrm{y}$ se llevaron a un aforado de $25 \mathrm{ml}$, enrasándose con agua destilada. 


\section{Capítulo III}

Posteriormente se tomaron $0,5 \mathrm{ml}$ de muestra y se llevaron a un aforado de $25 \mathrm{ml}$, al cual se le añadieron $5 \mathrm{ml}$ de molibdato amónico y se enrasó con agua destilada. Posteriormente se añadió $1 \mathrm{ml}$ de una disolución previamente preparada con $1 \mathrm{ml}$ de Cloruro de estaño $+66 \mathrm{ml} \mathrm{de} \mathrm{H}_{2} 0$ destilada para dar la coloración azul a las muestras, índice del contenido en fósforo de la muestra. Se agitó y se dejó reposar 10 minutos y enseguida se realizó la medida a $600 \mathrm{~nm}$. Los análisis se efectuaron por triplicado.

\section{III.2.8 Glucosa, fructosa y sacarosa}

La identificación y cuantificación de los azúcares (glucosa, fructosa, sacarosa) se realizó por amperometría. El equipo empleado fue un cromatógrafo de intercambio iónico dotado de un detector de pulsos amperométrico (HPAEC-PAD) marca Metrohm. Como fase móvil se empleó $\mathrm{NaOH} 0,1 \mathrm{~N}$ con un flujo de $1 \mathrm{ml} / \mathrm{min}$ y una columna para carbohidratos Metrosep Carb 1 (4.6 x 250mm) con un tamaño de partícula de $5 \mu \mathrm{m}$.

La identificación se realizo a partir del tiempo de retención de cada compuesto en relación a los patrones comerciales de los tres azúcares y la cuantificación mediante la integración de las áreas. La uva fue homogeneizada en un ultraturrax y centrifugada $(10000$ $\mathrm{rpm} / 10 \mathrm{~min} / 4^{\circ} \mathrm{C}$ ). Del sobrenadante se pesó una cantidad de muestra entre $0,05-0,1 \mathrm{~g}$, se diluyó hasta $25 \mathrm{ml}$ con agua bidestilada y se inyectó en el equipo. Las determinaciones ser realizaron por triplicado. 


\section{III.2.9 Calcio, magnesio y potasio}

La determinación de $\mathrm{Ca}, \mathrm{Mg}$ y $\mathrm{K}$ se llevó a cabo mediante la técnica de cromatografía de intercambio Iónico (HPAEC) por detección de conductividad directa, utilizando un cromatógrafo marca Metrohm y empleando como fase móvil ácido tartárico (4mmol/l) y ácido dipicolínico (0,75 mmol/l) y una columna Metrosep C2-150 (4.0 x $150 \mathrm{~mm}$ ) con un tamaño de partícula de $7 \mu \mathrm{m}$. Para determinar los minerales en las muestras de fruta fue necesario homogeneizarlas y centrifugarlas $\left(10000 \mathrm{rpm} / 10 \mathrm{~min} / 4^{\circ} \mathrm{C}\right)$. Posteriormente se pesó $1 \mathrm{~g}$ del sobrenadante, se enrasó a $25 \mathrm{ml}$ con agua bidestilada y se inyectó la muestra en el equipo. La identificación se realizó a partir del tiempo de retención de cada compuesto en relación a los patrones comerciales de los minerales de interés y la cuantificación mediante la integración de las áreas. Los análisis se efectuaron por triplicado.

\section{III.2.10 Fenoles totales}

La extracción para la cuantificación de los fenoles totales se llevó a cabo mediante una adaptación del método descrito por Peiró et al. (2006). Se pesaron $35 \mathrm{~g}$ de muestra y se añadieron $50 \mathrm{ml}$ de una disolución de metanol/ $\mathrm{HCl}$ 6N en proporción 8:2. A la disolución resultante se le añadió $\mathrm{NaF} 2 \mathrm{mM}$ para evitar la posible degradación de los compuestos fenólicos presentes en la uva. La mezcla resultante se homogeneizó durante 15 minutos. Posteriormente se centrifugó a 11500 rpm durante 15 minutos a $4^{\circ} \mathrm{C}$ y después se filtró a vacío. El sobrenadante se congeló a $-20^{\circ} \mathrm{C}$ hasta su utilización $(24$ h). Durante todo el proceso se trabajó con agua bidestilada y con la mínima 


\section{Capítulo III}

presencia de luz con la finalidad de evitar la degradación de los compuestos fenólicos.

La determinación de los fenoles totales se llevó a cabo mediante el método de B.B Li et al., (2006), que modifica el método de FolinCiocalteau. Se tomaron $250 \mu 1$ de extracto y se llevaron a un aforado de $25 \mathrm{ml}$. Después se agregaron $15 \mathrm{ml}$ de $\mathrm{H}_{2} \mathrm{O}$ bidestilada, se añadió 1,25 ml del reactivo Folin-Ciocalteau, se agitó la muestra y se dejó reposar durante 5-8minutos. A continuación se agregaron $3,75 \mathrm{ml}$ de carbonato de sodio al 7,5\% y finalmente se enrasó con agua bidestilada dejándose reposar durante 2 horas. Las medidas espectrofotométricas se realizaron a 765nm. Las determinaciones se realizaron por triplicado.

\section{III.2.11 Actividad antioxidante}

Para la determinación de la actividad antioxidante de la fruta se trabajó con el mismo extracto utilizado para la determinación de los fenoles totales. La actividad antioxidante se cuantificó mediante una modificación de la técnica espectofotométrica desarrollada del ABTS ${ }^{\prime+}$, empleado por Re et al. (1999). Para ello en primer lugar se diluyó el ABTS en agua hasta alcanzar una concentración de $7 \mathrm{mM}$. Posteriormente, se formó el radical $\mathrm{ABTS}^{+}$preparando una disolución de persulfato potásico $(2,45 \mathrm{mM})$. Para ello el $\mathrm{K}_{2} \mathrm{~S}_{2} \mathrm{O}_{8}$ se diluyó en el ABTS (7mM) dejándose en incubación a temperatura ambiente y en oscuridad. Una vez formado el radical ABTS se diluyó en etanol hasta obtener un valor de absorbancia de $0,700 \pm 100$ a 753nm (longitud máxima de absorción). A continuación se realizaron las lecturas de las muestras, para lo cual se tomaron $100 \mu 1$ de extracto y se le agregaron 
$900 \mu 1$ de ABTS midiéndose la absorbancia a 753nm. El antioxidante sintético Trolox se tomó como referencia en una concentración de 0 $50 \mathrm{mg} / \mathrm{L}$ (en etanol) y se midió bajo las mismas condiciones. Los resultados fueron expresados en equivalentes Trolox (TEAC) en $100 \mathrm{~g}$ de muestra. Los análisis se realizaron por triplicado.

\section{III.2.12 Análisis estadístico}

El estudio de la significación de los diferentes efectos y de sus posibles interacciones se realizó mediante análisis de la varianza (ANOVA) para un nivel de significancia $(\alpha)$ de 0,05 . Para ello se utilizó el software Statgraphics Plus 5.1. 
CARACTERIZACIÓN DE MATERIA

PRIMA 



\section{IV.- CARACTERIZACIÓN DE LA MATERIA PRIMA}

\section{IV.1 JUSTIFICACIÓN}

Las bayas o granos de uva presentan diversas características, principalmente en función de la variedad y, en menor importancia, de las condiciones de cultivo del viñedo. Su composición varía según se trate de uvas blancas o tintas.

Entre los compuestos que no son agua, los principales solutos que se acumulan en las bayas son hexosas, D (+) Glucosa y D (-) Fructosa (Coombe, 1992). Durante el crecimiento de la baya o granos de uva, predomina la glucosa, mientras que en la maduración las proporciones de glucosa $y$ fructosa son aproximadamente iguales $y$ en uvas sobremaduras la fructosa es el azúcar principal (Winkler, 1965). El aumento del contenido de azúcares de la uva a lo largo de la maduración obedece a tres procesos: la migración de azúcares producidos por fotosíntesis; la movilización eventual de reservas y la transformación de ácido málico en azúcares (Reynier, 1989). Además de azúcares, la uva contiene vitaminas (ácido fólico y vitamina A, además de pequeñas cantidades de B1, B2, B3, B6 y vitamina C), enzimas, ácidos orgánicos (tartárico y málico, que constituyen más del 90\%, cítrico, ascórbico y fosfórico), minerales como el calcio (que participa en la formación de huesos, dientes y ayuda a la coagulación de la sangre), magnesio (relacionado con el funcionamiento del intestino, nervios y músculos, forma parte de huesos y dientes), fósforo (segundo mineral después del calcio más abundante en nuestro cuerpo y en la mayoría de los alimentos y que participa en casi todos los procesos metabólicos) y potasio (muy 


\section{Capítulo IV}

importante y necesario para la transmisión del impulso nervioso y para la actividad muscular normal, que además contribuye al equilibrio de agua dentro y fuera de la célula). El potasio es el mineral más abundante, en cambio el magnesio, calcio y fósforo se encuentran en cantidades más moderadas. También en la uva encontramos compuestos aromáticos, materias pécticas, sustancias nitrogenadas y compuestos fenólicos. La proporción de todos estos compuestos en cada variedad de uva varía a lo largo del período de maduración.

Otro tipo de compuestos, como los antocianos, taninos y flavonoides, tienen en común su acción antioxidante. Estas sustancias de origen vegetal se incluyen dentro del grupo de los fitoquímicos, quimiopreventores $\mathrm{o}$ sustancias bioactivas $\mathrm{y}$ tienen importantes propiedades y efectos biológicos, aparte de sus atributos sensoriales (King et Young, 1999, Belstein, 2001).

En relación con su impacto sobre la salud, numerosos estudios aportan datos que apoyan una correlación negativa entre la ingesta de fitoquímicos y el riesgo de padecer determinadas enfermedades como las cardiovasculares, cerebrovasculares y el cáncer (Klein et Kurilich, 2000, Wargovich, 2000, Kaur et Kapoor, 2001) además de la enfermedad de Alzheimer, cataratas y algunas otras disfunciones asociadas a la edad (Rui, 2003). Los mecanismos de acción por los que estas sustancias parecen ejercer su actividad en la prevención de estas enfermedades aún no están claramente identificados, aunque entre ellos se han descrito su actividad antioxidante (Velioglu et al, 1998) (Prior et Guohua, 2000) (Ming et al, 2002) (Wolfe et al, 2003), vasodilatadora (Waladkhani et Clemens, 1998) (Venant et al, 1998) (Morton et al, 2000), neutralizadora 
de radicales libres (Rui, 2003), acción sobre algunos procesos de diferenciación y proliferación celular, aumento de la actividad de enzimas de Fase II, acción sobre el metabolismos de los estrógenos, modificación del medio colónico, etc. (Tómas, 2003). A los beneficios de las sustancias antioxidantes de las uvas, se suma la abundante fibra, beneficiosa en caso de estreñimiento, sobre todo cuando es consumida en forma de uva pasa.

Sin embargo, a pesar de conocer los beneficios que brinda esta fruta la información publicada de estudios sobre su composición es limitada y no diferencia ni separa los valores obtenidos para cada variedad. Tan solo podremos encontrar valores en función de su color. Es por esto que resulta interesante y necesario realizar la caracterización de la materia prima usada para cada una de las partes del trabajo, diferenciando entre variedades y época del año en que fue utilizada para el estudio.

\section{IV.2 OBJETIVO}

Caracterización de los macro y micronutrientes de las diferentes variedades de uva utilizadas en este estudio.

\section{IV.3 MATERIAL Y MÉTODOS}

\section{IV.3.1 Materia Prima}

Para el desarrollo de este trabajo, se utilizaron las variedades Moscatel, Thompson seedless, Imperial seedless y Festival seedless compradas en diferentes épocas de año en supermercados de la ciudad de Valencia. 


\section{Capítulo IV}

IV.3.2 Análisis realizados.

Las diferentes variedades de uva fueron caracterizadas en cuanto a la actividad del agua, acidez total, ácido ascórbico, humedad, ${ }^{\circ}$ Brix, calcio, fósforo, magnesio, potasio, glucosa, fructosa, sacarosa, pectina total, pectina hidrosoluble, pectina oxalato-soluble, fenoles totales y la actividad antioxidante.

Las determinaciones se llevaron a cabo de acuerdo a los procedimientos citados en el apartado III.2 del capítulo anterior.

\section{IV.4 RESULTADOS}

La tabla 2 muestra los valores medios de los parámetros analizados en la caracterización de la fruta fresca. En ella aparecen los valores correspondientes a los diferentes lotes de uva de cada variedad utilizados para los estudios realizados.

Cabe destacar que todos los parámetros analizados mostraron diferencias significativas en función de la variedad y también del lote. Esto pone de manifiesto que los macro y micronutrientes en la uva van a depender de muchos factores como la variedad, la zona geográfica, la temporada de lluvias, entre otros.

De acuerdo con los resultados, la $\mathrm{a}_{\mathrm{w}}$ de la uva Thompson seedless presentó el nivel más elevado (a excepción de uno de los lotes), seguido por la variedad Moscatel, la Festival seedless y la Imperial seedless. Con respecto a los sólidos solubles se observaron valores dentro del intervalo de 16,1 a $20,9^{\circ}$ Brix, siendo la variedad Festival la de menor contenido En relación con el contenido en humedad, que varió entre 0,783 a 0,846 g $\mathrm{H}_{2} \mathrm{O} / \mathrm{g}$ de muestra, éste fue mayor para la variedad Imperial. No 
obstante, teniendo en cuenta la variabilidad entre lotes comentada y los grupos homogéneos establecidos por el ANOVA, así como los resultados de la tabla, parece indicado establecer un valor promedio de los diferentes compuestos comentados para las variedades de uva estudiadas, que se establecería en una $\mathrm{a}_{\mathrm{w}}=0,975,{ }^{\circ} \mathrm{Brix}=18 \mathrm{~g}$ sólidos solubles/100g muestra) y humedad $=0,81$ ( $\mathrm{g}$ agua/g muestra).

Con respecto a la acidez total (expresada como $\mathrm{mg}$ de ácido tartárico/100 g muestra) se obtuvieron valores entre 389 y $571 \mathrm{mg} / 100 \mathrm{~g}$ de fruta fresca, para las variedades Moscatel y Thompson seedless respectivamente en el mínimo y el máximo. En promedio la acidez de las uvas estudiadas fue de $473 \mathrm{mg}$ ácido tartárico/100g. Por otra parte, con los valores de los sólidos solubles y con la acidez total se calculó el índice de madurez ( $\mathrm{IM}={ }^{\circ}$ Brix/Acidez). La madurez de la uva es un fenómeno asincrónico. Maduran a tiempos diferentes las uvas de diferentes cepas del mismo campo, los racimos de una misma cepa y los granos de un mismo racimo y también son diferentes los momentos y mecanismos que llevan a la madurez de la pulpa, la piel o las semillas (Catania et Avagnina, 2007). Esto contribuye a la alta variabilidad composicional comentada hasta el momento. Los resultados de este índice mostraron que la uva de la variedad Thompson seedless (lote 3) era la que se encontraba con un mayor grado de madurez $(\mathrm{IM}=53,8)$. Teniendo en cuenta que el índice de madurez idóneo en las uvas es 35 (Primo, 1998), podemos decir que algunas de las uvas que se analizaron se encontraban en una etapa de sobremaduración de acuerdo con este índice a pesar de que visualmente la fruta estuviera en muy buen estado. 


\section{Capítulo IV}

En concreto éste fue el caso de ese lote de Thompson y de la uva Moscatel estudiada.

Los análisis de los azúcares (glucosa, fructosa y sacarosa) mostraron que el contenido en fructosa y glucosa sumó aproximadamente el 90\% del total de los tres azúcares analizados. Cabe resaltar que, en todos los análisis, el azúcar mayoritario fue la fructosa, independientemente de la variedad de uva. El menor contenido en azúcares, con bastante diferencia lo presentó el lote de uva Moscatel adquirido en noviembre, con valores de $6,9 \mathrm{~g}$ de glucosa/100g de fruta fresca y 7,8g de fructosa/100g de fruta fresca. En los demás casos, el contenido en glucosa varió entre 6,03 y 10,5g glucosa/100g de fruta fresca, mientras que el contenido en fructosa varió entre 6,6 y $11,42 \mathrm{~g} / 100 \mathrm{~g}$ de fruta fresca.

Como sabemos, el consumo de frutas y verduras parece estar asociado al bajo riesgo de incidencias y mortalidad por cáncer y enfermedades coronarias. Es por esto que uno de los aspectos más atractivos de la uva, en los últimos años, sea la capacidad antioxidante que se le atribuye, debido a su contenido en fitoquímicos, especialmente en compuestos fenólicos, y también en vitamina C. En la tabla 2 se muestran los valores del contenido en fenoles totales, vitamina $\mathrm{C}$ y de la actividad antioxidante de las diferentes variedades de uva y de los diferentes lotes. No obstante, el contenido en ácido ascórbico de la uva fue muy bajo, entre 1,14 y $3,8 \mathrm{mg} / 100 \mathrm{~g}$ fruta, valor del mismo orden del que se ha encontrado en manzana (Mataix, 2003). Los valores de la actividad antioxidante, variaron entre 25 y $34 \mathrm{mg} / 100 \mathrm{~g}$ de fruta fresca 
siendo algunos de los lotes de la variedad Thompson seedless los que mostraron un contenido significativamente mayor al resto de variedades.

En cuanto al contenido en fenoles totales se registraron cifras entre 40 y $70 \mathrm{mg}$ de ácido gálico $/ 100 \mathrm{~g}$ de fruta fresca, valores bajos comparados con otras variedades de uva blanca (230 en la uva Niágara, 201 en la variedad Chardonnay, 256 en la variedad Riesling y 206 mg de ácido gálico /100g en la variedad Cayuga White) según describen Jun Yang et al. (2009). No se han encontrado más referencias con valores de contenido en fenoles totales de uva blanca. No se observa una correlación clara entre la actividad antioxidante y los fenoles totales de las distintas variedades de uva estudiadas, lo que quizá se deba a que en no todos los compuestos fenólicos de la uva posean la misma capacidad antioxidante (Kuskoski et al, 2005).

En cuanto a los minerales los resultados obtenidos fueron muy heterogéneos. De los cuatro minerales analizados el potasio es el más abundante con claridad, encontrándose valores dentro del intervalo 81$235 \mathrm{mg} / 100 \mathrm{~g}$ de fruta fresca. El fosforo es el segundo mineral mayoritario variando su contenido entre $6 \mathrm{mg}$ y $28 \mathrm{mg} / 100 \mathrm{~g}$ de fruta fresca. El contenido en calcio osciló entre 2,9 mg y $13 \mathrm{mg} / 100 \mathrm{~g}$ de fruta fresca y el de magnesio entre 4,9 mg y 9,4 mg/100g de fruta fresca. El contenido en minerales analizado fue similar al encontrado en diferentes fuentes bibliográficas consultadas (Primo 1998; Mataix, 2003).

En relación a las pectinas, el contenido medio en pectina total en la uva fue de $347 \mathrm{mg}$ de ácido galacturónico/100g, encontrándose por encima del contenido dado para la uva por Primo (1998) (280 mg /100g) y en menor cantidad de lo que presentan otras frutas como la fresa (530 


\section{Capítulo IV}

$\mathrm{mg} / 100 \mathrm{~g}$ de fruta fresca, Contreras et al., 2005), la manzana (844 mg / $100 \mathrm{~g}$ de fruta fresca, Contreras et al., 2005). Las pectinas designan cadenas formadas principalmente por unidades de ácido galacturónico parcialmente esterificadas por etanol. El grado de esterificación de las pectinas de la uva es del orden del 70-80\% (Blouin y Guimberteau, 2004) siendo este grado mayor al de la pulpa de la manzana o de la corteza de limón cuya esterificación es del $60 \%$ y al 10\% de la pulpa de fresa. Con respecto a las diferentes fracciones pécticas presentes en la uva fresca, los resultados indicaron que la fracción mayoritaria es la oxalato soluble (POS) con un contenido promedio de $114 \mathrm{mg}$ de acido galacturónico/100g de fruta fresca. Cabe mencionar que la pectina oxalato soluble (POS) se encuentra en mayor cantidad que la hidrosoluble (PHS), independientemente de la variedad de uva que se trate. El contenido en pectina hidrosoluble osciló en $35 \mathrm{mg} / 100 \mathrm{~g}$ de fruta fresca. 
Tabla 2.- Valores medios y desviación estándar (entre paréntesis) obtenidos en la caracterización de las diferentes variedades de uva.

\begin{tabular}{|c|c|c|c|c|c|c|c|c|c|}
\hline \multirow[t]{2}{*}{ Análisis } & \multicolumn{2}{|c|}{ Moscatel } & \multicolumn{4}{|c|}{ Thompson Seedless } & \multicolumn{2}{|c|}{ Imperial Seedless } & \multirow{2}{*}{$\begin{array}{c}\text { Festival } \\
\text { Jul-08 }\end{array}$} \\
\hline & Nov-05 & Jun-06 & Jun-06 & Ene-07 & Ene-07 & May-08 & Feb-07 & Feb-07 & \\
\hline$a_{w}$ & $\begin{array}{c}0,974(0,001) \\
b, c\end{array}$ & $\begin{array}{c}0,975(001) \\
C\end{array}$ & $\begin{array}{c}0,981(0,001) \\
\mathrm{e}\end{array}$ & $\begin{array}{c}0,977(0,001) \\
d\end{array}$ & $\begin{array}{c}0,971(0,002) \\
a\end{array}$ & $\begin{array}{c}0,977(0,003) \\
d\end{array}$ & $\begin{array}{c}0,973(0,002) \\
a, b\end{array}$ & $\begin{array}{c}0,972(0,001) \\
\text { b }\end{array}$ & $\begin{array}{c}0,973(0,001) \\
b, c\end{array}$ \\
\hline${ }^{\circ}$ Brix (g/100g) & $18,70(0,5) \mathrm{c}$ & $18,6(0,3) \mathrm{c}$ & $16,3(0,5) a$ & $18,9(1,8) \mathrm{C}$ & $20,9(0,5) d$ & $16,1(0,5) a$ & $15(2) c$ & $17,1(0,9) \mathrm{b}$ & $16,4(0,5) \mathrm{a}$ \\
\hline *Humedad (g/g) & $0,78(0.01) a$ & $\begin{array}{c}0,812(0,003) \\
c, d\end{array}$ & $\begin{array}{c}0,805(0,007) \\
b, c, d\end{array}$ & $0,80(0,023)$ a & $\begin{array}{c}0,798(0,013) \\
a, b, c\end{array}$ & $\begin{array}{c}0,792(0,014) \\
a, b\end{array}$ & $\begin{array}{c}0,84(0,002) \\
e\end{array}$ & $\begin{array}{c}0,846(0,003) \\
e\end{array}$ & $\begin{array}{c}0,82(0,01) \\
d\end{array}$ \\
\hline $\begin{array}{l}\text { Acidez total (mg ácido } \\
\text { tártarico/100g) }\end{array}$ & 408 (19) a, b & 389 (14) a & $571(12) \mathrm{e}$ & $563(10) e$ & 389 (10) a & $496(39) \mathrm{C}$ & $424(7) \mathrm{c}$ & $494(8) b$ & $519(22) d$ \\
\hline Índice de Madurez & 45,9 & 47,9 & 28,5 & 33,6 & 53,8 & 32,4 & 35,4 & 34,6 & 31,6 \\
\hline $\begin{array}{c}\text { Acido ascórbico } \\
(\mathrm{mg} / 100 \mathrm{~g})\end{array}$ & $\mathrm{Nr}$ & $\mathrm{Nr}$ & $\mathrm{Nr}$ & $2,6(0,6) \mathrm{b}$ & $3,2(0,7) b, c$ & $1,14(0,001) \mathrm{a}$ & $3.8(1.1) \mathrm{C}$ & $2.929(0.012) b, c$ & $\mathrm{Nr}$ \\
\hline Calcio (mg/100g) & $2,9(0,2) a$ & $4,93(0,4) \mathrm{b}$ & $5,3(0,2) b$ & $8,7(1,8) \mathrm{c}$ & $13(5) d$ & $2(2) a$ & \multicolumn{2}{|c|}{$\frac{d}{10,12(0,12) d}$} & $\mathrm{Nr}$ \\
\hline Fósforo $(\mathrm{mg} / 100 \mathrm{~g})$ & $28,3(1,5) \mathrm{e}$ & $13,4(0,2) b$ & $6,6(0,6)$ a & $27,7(1,2) \mathrm{e}$ & $25(3) d$ & $17,5(1,6) \mathrm{c}$ & \multicolumn{2}{|c|}{$\frac{7,2(0,6) a}{92(0,3) d}$} & $\mathrm{Nr}$ \\
\hline Magnesio (mg/100g) & $9,4(0,7) d$ & $4,9(1,0) a$ & $12,6(0,3) \mathrm{e}$ & $5,8(1,5) b$ & $9(2) c$ & $7,3(0,7) b, c$ & \multirow{2}{*}{\multicolumn{2}{|c|}{$\begin{array}{c}\frac{9,2(0,3) d}{149(3) c} \\
\end{array}$}} & $\mathrm{Nr}$ \\
\hline Potasio (mg/100g) & $166(3) d$ & $124,7(1,3) \mathrm{b}$ & $98(3) \mathrm{a}$ & $235(4) \mathrm{e}$ & $234(5) \mathrm{e}$ & $81(4) a$ & & & $\mathrm{Nr}$ \\
\hline Glucosa (g/100g) & $6,9(0,2) a$ & $8,6(0,2) \mathrm{c}$ & $6,90(0,14) b$ & $8,2(0,7) \mathrm{c}$ & $10,50(0,13) d$ & $6,03(0,11) b$ & \multicolumn{2}{|c|}{$6,70(0,07) a, b$} & $\mathrm{Nr}$ \\
\hline Fructosa $(\mathrm{g} / 100 \mathrm{~g})$ & $7,8(0,6)$ a & $10,7(0,2) \mathrm{e}$ & $7,54(0,09) b, c$ & $9,5(0,8) d$ & $11,42(0,02) \mathrm{e}$ & $6,6(0,15) b$ & \multicolumn{2}{|c|}{$8,3(0,09) \mathrm{c}, \mathrm{d}$} & $\mathrm{Nr}$ \\
\hline Sacarosa $(\mathrm{g} / 100 \mathrm{~g})$ & $0,10(0,05) \mathrm{a}$ & $0,34(0,03) \mathrm{b}$ & $\mathrm{Nd}$ & $0,36(0,07) b$ & $0,93(0,11) d$ & $\mathrm{Nd}$ & \multirow{2}{*}{\multicolumn{2}{|c|}{$\frac{0,55(0,05) \mathrm{c}}{47,3(1,6) \mathrm{a}}$}} & $\mathrm{Nr}$ \\
\hline $\begin{array}{c}\text { Fenoles Totales (mg } \\
\text { GAE/100g) }\end{array}$ & $\mathrm{Nr}$ & $\mathrm{Nr}$ & $\mathrm{Nr}$ & $70(2) b$ & $52(3) a$ & $70,3(0,5) b$ & & & $69(10) b$ \\
\hline $\begin{array}{l}\text { Actividad Antioxidante } \\
\text { (mg de Trolox/100g) }\end{array}$ & $\mathrm{Nr}$ & $\mathrm{Nr}$ & $\mathrm{Nr}$ & $27,5(1,3) a$ & $34(2) b, c$ & $32,0(1,3) \mathrm{c}$ & $30,2(1,1) a, b$ & $28,6(1,5) a, b$ & $25(3) a$ \\
\hline $\begin{array}{c}\text { Pectina Total } \\
\text { (mg de AGU/100g) }\end{array}$ & $541(49) f$ & $121(78) a$ & $446(60) \mathrm{e}$ & $355(3) c, d, e$ & $\begin{array}{c}275(20) \\
b, c \\
\end{array}$ & $\begin{array}{c}297(60) \\
b, c, d\end{array}$ & $\begin{array}{c}443(73) \\
d, e\end{array}$ & $386(9) \mathrm{e}$ & $260(31) b$ \\
\hline $\begin{array}{c}\text { P. Hidrosluble } \\
\text { (mg de AGU/100g) }\end{array}$ & $\mathrm{Nr}$ & $\mathrm{Nr}$ & $\mathrm{Nr}$ & $14(8) a$ & $55(36) \mathrm{b}$ & $20(5) a$ & $57(3) b$ & $54,9(1,6) b$ & $21(9) a$ \\
\hline $\begin{array}{l}\text { P. Oxalato Soluble } \\
\text { (mg de AGU/100g) }\end{array}$ & $\mathrm{Nr}$ & $\mathrm{Nr}$ & $\mathrm{Nr}$ & $\begin{array}{c}117(32) \\
b, c\end{array}$ & $\begin{array}{c}183(53) \\
b, c\end{array}$ & $\begin{array}{c}59,1(1,3) \\
a\end{array}$ & $\begin{array}{c}119(50) \\
c\end{array}$ & $\begin{array}{c}205(17) \\
b\end{array}$ & $\begin{array}{c}32(4) \\
a\end{array}$ \\
\hline
\end{tabular}

$\mathrm{Nd}=$ Valor no detectado, $\mathrm{Nr}=$ análisis no realizado. Las letras diferentes en la misma fila indican grupos significativamente diferentes según el ANOVA realizado. 
Capítulo IV

\section{IV.5 CONCLUSIONES}

Los diferentes lotes de las variedades de uva con las que se ha trabajado mostraron una alta variabilidad composicional, que no permitió establecer diferencias entre ellas. En promedio, la composición, expresada como valores medios \pm desviación estándar, puede resumirse en: 0,975 \pm 0,003 de actividad del agua, 18,05 $\pm 1,5$ de ${ }^{\circ}$ Brix, 0,81 \pm 0,02 de humedad, 473,5 $\pm 71 \mathrm{mg}$ de acido tartárico/100g de fruta fresca, 2,75 $\pm 1,0 \mathrm{mg}$ de acido ascórbico/100g de fruta fresca, 6,7 $\pm 3,9 \mathrm{mg}$ de calcio/100g de fruta fresca, $18 \pm 9,3 \mathrm{mg}$ de fósforo/100g de fruta fresca, $8,3 \pm 2,6 \mathrm{mg}$ de magnesio/100g de fruta fresca, $156 \pm 61 \mathrm{mg}$ de potasio/100g de fruta fresca, 7,7 $\pm 1,5 \mathrm{~g}$ de glucosa/ $100 \mathrm{~g}$ de fruta fresca, $8,8 \pm 1,8 \mathrm{~g}$ de fructosa/ $100 \mathrm{~g}$ de fruta fresca, $0,5 \pm 0,3 \mathrm{~g}$ de sacarosa $/ 100 \mathrm{~g}$ de fruta fresca, $61,8 \pm 11,7 \mathrm{mg}$ de ácido gálico/100g de fruta fresca (Fenoles totales), $29,5 \pm 3,2 \mathrm{mg}$ de Trolox/100g de fruta fresca (Actividad antioxidante), $347 \pm 125 \mathrm{mg}$ de acido galacturónico/100g de fruta fresca (pectina total), $37 \pm 20,5 \mathrm{mg}$ de acido galacturónico/100g de fruta fresca (pectina hidrosoluble) y $119 \pm 67,2 \mathrm{mg}$ de acido galacturonico/100g de fruta fresca (pectina oxalato-soluble). 


\section{UVA PARCIALMENTE DESHIDRATADA}



UVA PARCIALMENTE DESHIDRATADA

\section{V.- UVA PARCIALMENTE DESHIDRATADA}

\section{V.1 JUSTIFICACIÓN}

La facilidad que ofrece la uva para ser consumida, los beneficios que brinda a la salud y el dulzor que proporcionan sus granos, hacen de ella un postre ideal para las personas de todas las edades. Sin embargo su consumo está sujeto a la disponibilidad de la fruta, ya que como se mencionó anteriormente, es una fruta de temporada, que además no permite su almacenamiento prolongado. Por este motivo se tiene que recurrir a su procesado para poder alargar su vida útil y proporcionar seguridad. Este procesado puede variar desde un simple pelado para la posterior distribución en conserva, a tratamientos térmicos más o menos intensos y técnicas adecuadas para la elaboración de almíbares, mermeladas, postres preparados o fruta escarchada. En todos los casos, se obtienen productos más o menos elaborados que, debido a las variables implicadas en el proceso (temperatura, tiempo, presión etc.), han perdido las características de calidad sensorial y nutricional de la fruta fresca. Por otra parte, la mejor forma de consumir fruta se sabe que es en fresco ya que como se ha mencionado en la introducción, es rica en azúcares, micronutrientes (vitaminas, ácidos, minerales) y especialmente en fitoquímicos, que se caracterizan por tener un impacto positivo sobre la salud a largo plazo, previniendo enfermedades como las cerebro y cardiovasculares entre otras. En este sentido, sería interesante la obtención de productos con una calidad organoléptica y nutricional similares a la de la uva fresca pero con una vida útil más prolongada. La aplicación de tecnologías de procesado suave (bajas temperaturas, 


\section{Capítulo V}

tiempos cortos) como son la deshidratación osmótica y la utilización de microondas se ha estudiado en varias frutas como el pomelo, la fresa y piña entre otros. (Martínez-Navarrete, et al. 2007). Los productos elaborados mediante estas técnicas tienen una buena aceptación sensorial y presentan una mejor calidad en algunos aspectos como el color, la textura y el sabor, además de que nutricionalmente se observa una menor pérdida de vitamina $\mathrm{C}$ que en las obtenidas por los métodos clásicos de procesado.

Por tanto, el objetivo de este trabajo es la obtención de uva mínimamente procesada mediante la utilización de la deshidratación osmótica, las microondas y con la combinación de ambos métodos.

\section{V.2 OBJETIVOS ESPECÍFICOS}

- Estudiar la influencia del procesado térmico suave (DO, MW y método combinado (MC) en la estabilidad de los macro y micronutrientes de interés presentes en la uva.

- Conocer el efecto del tiempo de almacenamiento en refrigeración de estos compuestos. 


\section{V.3 PLAN DE TRABAJO}

1. Revisión bibliográfica

2. Estudio de la estabilidad de los macro y micronutrientes de la uva asociada a su deshidratación mediante diferentes técnicas (secado por microondas, deshidratación osmótica y método combinado).

2.1 Puesta punto de las condiciones de los diferentes métodos de secado para la obtención de uva con un $75 \%$ de humedad.

2.2 Análisis de los macro y micronutrientes en la uva antes y después de ser sometida a los diferentes tratamientos.

2.2.1 Caracterización de la fruta fresca y tratada en cuanto a humedad, ${ }^{\circ} \mathrm{Brix}, \mathrm{a}_{\mathrm{w}}$, ácido tartárico, pectinas, minerales y azúcares mediante las técnicas descritas en el capítulo III de Materiales y Métodos de Análisis.

2.2.2 Estudio comparativo (análisis de la varianza) del efecto de las diferentes técnicas de deshidratación en los componentes analizados.

3. Estudio del efecto del almacenamiento en la estabilidad de los macro y micronutrientes de la uva fresca y deshidratada por los distintos métodos. Se analizarán todo los compuestos antes mencionados a diferentes tiempos de almacenamiento de la uva en refrigeración, hasta un máximo de 10 días.

\section{V.4. MATERIAL Y MÉTODOS}

\section{V.4.1 Materia Prima}

Los experimentos fueron realizados con uva (Vitis vinífera) seleccionada de las variedades Moscatel y Thompson seedless adquiridas en supermercados de la ciudad de Valencia. Se trabajó con un 


\section{Capítulo V}

lote de Thompson, para estudiar el efecto del procesado, y dos de Moscatel, uno para el estudio del efecto del procesado (lote 2) y otro para el estudio del efecto del almacenamiento (lote 1). La uva se conservó refrigerada antes de su manipulación (máximo 12 h), se enjuagó con agua destilada, se secó con papel y se separaron los granos del racimo. Inmediatamente después recibió el tratamiento correspondiente.

\section{V.4.2 Procesado}

La uva se sometió a tres métodos de deshidratación: deshidratación osmótica (DO), deshidratación por aire caliente asistido con microondas (MW) y la combinación de ambos métodos (MC). En los tres casos se fijó un nivel de humedad para la uva deshidratada del 75\%, valor que permite una mayor estabilidad del producto pero manteniendo una gran similitud con el fresco. A continuación, se detalla el procedimiento que se siguió para cada uno de estos tres tratamientos.

El tratamiento de DO consistió en introducir uva partida por la mitad en la disolución osmótica contenida en una cubeta, a $30{ }^{\circ} \mathrm{C}$, con una agitación de 200 rpm, durante 4 horas. En estas condiciones, y según unas experiencias previas, se consigue obtener un producto con un $75 \%$ de humedad. Para evitar el daño de la materia prima, se colocó en el interior de la cubeta una malla, que impedía que las aspas del agitador tuvieran contacto con la uva. Al finalizar el tratamiento, las uvas se secaron y almacenaron a $4^{\circ} \mathrm{C}$ hasta su análisis.

Por otra parte el secado por microondas se realizó en dos equipos diferentes. Las características de ambos equipos se muestran en la Tabla 
3. Ambos equipos disponen de una balanza que permite registrar la evolución del peso de muestra durante el proceso.

Las condiciones de proceso en el equipo A fueron potencia de microondas de $1 \mathrm{~W} / \mathrm{g}$, con una velocidad del aire de $1.6 \mathrm{~m} / \mathrm{s}$ y una temperatura del aire de $50{ }^{\circ} \mathrm{C}$. En el equipo B se trabajó a $1 \mathrm{~W} / \mathrm{g}$ de potencia de microondas, la temperatura del aire de $50^{\circ} \mathrm{C}$ y velocidad del aire de $4 \mathrm{~m} / \mathrm{s}$. Para ambos casos el tiempo de proceso fue el necesario para conseguir en la muestra la humedad final prefijada.

Tabla 3. Características de los equipos de Microondas utilizados

\begin{tabular}{|c|c|c|}
\hline & $\begin{array}{c}\text { Equipo A } \\
\text { Uva Moscatel }\end{array}$ & $\begin{array}{c}\text { Equipo B } \\
\text { Uva Thompson S. }\end{array}$ \\
\hline $\begin{array}{c}\text { Velocidad } \\
\text { máxima del aire }\end{array}$ & $4 \mathrm{~m} / \mathrm{s}$ & $10 \mathrm{~m} / \mathrm{s}$ \\
\hline $\begin{array}{c}\text { Temperatura } \\
\text { máxima de } \\
\text { secado }\end{array}$ & $100^{\circ} \mathrm{C}$ & $1000 \mathrm{~W}$ \\
\hline $\begin{array}{c}\text { Potencia máxima } \\
\text { de incidencia de } \\
\text { las microondas }\end{array}$ & $2000 \mathrm{~W}$ & $1000 \mathrm{~g}$ \\
\hline $\begin{array}{c}\text { Capacidad } \\
\text { máxima de } \\
\text { muestra }\end{array}$ & $510 \mathrm{~g}$ & \\
\hline
\end{tabular}

El peso de la muestra registrado durante el proceso permite conocer la humedad de la muestra a cada tiempo (Ec. 1). Aplicando esta ecuación el proceso se detuvo cuando la muestra alcanzó el peso correspondiente a un contenido en humedad del $75 \%$, asumiendo que todo el peso perdido se corresponde con agua evaporada de la muestra.

$$
X_{w t}=M_{0}-X_{w 0}+\frac{\Delta P}{M_{t}}
$$




\section{Capítulo V}

Donde:

$\mathrm{X}_{\mathrm{wt}}=$ Humedad a cada tiempo de proceso ( $\mathrm{g}$ de agua/g de producto)

$\mathrm{M}_{0}=$ masa inicial de uva $(\mathrm{g})$

$\mathrm{X}_{\mathrm{w} 0}=$ Humedad inicial (g de agua/g de producto)

$\Delta \mathrm{P}=\mathrm{M}_{\mathrm{t}}-\mathrm{M}_{0}$

$\mathrm{M}_{\mathrm{t}}=$ masa de uva a cada tiempo de proceso $(\mathrm{g})$

De esta forma, el tiempo de proceso para conseguir el nivel de humedad prefijado fue de 11-12 minutos en el equipo A y de 14-15 minutos en el equipo B.

Por otra parte el método combinado consistió en la aplicación de los dos tratamientos anteriores. Para esto se deshidrató osmóticamente uva de las 2 variedades durante una hora a $30^{\circ} \mathrm{C}$, tiempo en el que se disminuye un $2 \%$ de humedad inicial. Al finalizar la deshidratación osmótica, se elimino el excedente de disolución osmótica y la uva se secó con papel. Se introdujo la uva en el microondas, en tandas de 100 gramos para el caso de la uva Moscatel (equipo A) y los 400g para el caso de la uva Thompson seedless (equipo B), siguiendo el mismo procedimiento de secado explicado en el punto anterior. Se realizaron los cálculos (Ec. 1) para que la deshidratación por microondas diera como resultado la humedad del $75 \%$, siempre teniendo en cuenta que la fruta ya había perdido una cierta cantidad de agua debido a la deshidratación osmótica. El tiempo de proceso en este caso fue de 8-10 $\min$. 


\section{V.4.3 Análisis realizados}

Las dos variedades de uva fresca y tratada mediante la deshidratación osmótica, microondas y el método combinado, según se describe a continuación, fueron analizadas en cuanto a su actividad del agua, acidez total, humedad, ${ }^{\circ}$ Brix, calcio, fósforo, magnesio, potasio, glucosa, fructosa, sacarosa y pectina total. Las determinaciones se llevaron a cabo de acuerdo con los procedimientos citados en el apartado III.2 del capítulo III. Por otra parte, se realizó un estudio de almacenamiento en la uva Moscatel, fresca y procesada, a una temperatura de $4{ }^{\circ} \mathrm{C}$ durante 10 días.

\section{V.5 RESULTADOS}

\section{V.5.1 Influencia del método de deshidratación en la composición de} la uva.

La tabla 4 muestra los resultados obtenidos de los análisis de $\mathrm{a}_{\mathrm{w}}$, ${ }^{\circ}$ Brix y $X_{w}$ en la uva de las dos variedades seleccionadas, tanto frescas como deshidratadas mediante los tres métodos de secado estudiados.

Como era de esperar, en todos los casos, el tratamiento provocó una disminución de la $\mathrm{a}_{\mathrm{w}}$, como consecuencia de la disminución en la humedad hasta aproximadamente el valor prefijado del 75\%, mostrándose diferencias significativas entre la uva fresca y la tratada, según el análisis multifactorial de la varianza, pero no encontrándose diferencias significativas entre los tratamientos. Lo mismo ocurrió con los ${ }^{\circ}$ Brix. En este sentido cabe mencionar que el procesado osmótico no 


\section{Capítulo $V$}

fue suficientemente intenso como para provocar un aumento importante en el contenido en azúcar de la uva.

Tabla 4. Valores medios y desviación estándar (entre paréntesis) de la actividad del agua, humedad y sólidos solubles de uva fresca (UF) y deshidratada osmóticamente (DO), mediante microondas (MW) y por el método combinado (MC).

\begin{tabular}{|c|c|c|c|c|c|c|c|c|c|}
\hline & \multicolumn{3}{|c|}{ Moscatel 1} & \multicolumn{3}{|c|}{ Moscatel 2} & \multicolumn{3}{|c|}{ Thompson S. } \\
\hline & $a_{w}$ & ${ }^{\circ}$ Brix & $X w(g / g)$ & $a_{w}$ & ${ }^{\circ}$ Brix & $X w(g / g)$ & $a_{w}$ & ${ }^{\circ}$ Brix & $X w(g / g)$ \\
\hline UF & $\begin{array}{l}0,974 \\
(0,001)\end{array}$ & $\begin{array}{l}18,7 \\
(0,5)\end{array}$ & $\begin{array}{l}0,783 \\
(0,010)\end{array}$ & $\begin{array}{l}0,975 \\
(0,001) \\
\text { (b) }\end{array}$ & $\begin{array}{l}18,6 \\
(0,5) \\
\text { (a) }\end{array}$ & $\begin{array}{l}0,812 \\
(0,003) \\
\text { (b) }\end{array}$ & $\begin{array}{l}0,981 \\
(0,001) \\
(c)\end{array}$ & $\begin{array}{c}16,3 \\
(0,5) \\
(a)\end{array}$ & $\begin{array}{c}0,805 \\
(0,003) \\
(c)\end{array}$ \\
\hline DO & $\begin{array}{l}0,972 \\
(0,002)\end{array}$ & $\begin{array}{l}21,3 \\
(1,1)\end{array}$ & $\begin{array}{l}0,754 \\
(0,009)\end{array}$ & $\begin{array}{l}0,966 \\
(0,002) \\
\text { (a) }\end{array}$ & $\begin{array}{l}23,6 \\
(0,5) \\
\text { (b) }\end{array}$ & $\begin{array}{l}0,748 \\
(0,008) \\
\text { (a) }\end{array}$ & $\begin{array}{l}0,972 \\
(0,001) \\
\text { (b) }\end{array}$ & $\begin{array}{c}21,8 \\
(0,5) \\
\text { (b) }\end{array}$ & $\begin{array}{c}0,759 \\
(0,009) \\
(a)\end{array}$ \\
\hline MW & $\begin{array}{l}0,968 \\
(0,01)\end{array}$ & $\begin{array}{l}21 \\
(2)\end{array}$ & $\begin{array}{l}0,776 \\
(0,019)\end{array}$ & $\begin{array}{l}0,963 \\
(0,002) \\
\text { (a) }\end{array}$ & $\begin{array}{l}24,7 \\
(0,5) \\
\text { (b) }\end{array}$ & $\begin{array}{l}0,746 \\
(0,004) \\
\text { (a) }\end{array}$ & $\begin{array}{l}0,969 \\
(0,002) \\
(a, b)\end{array}$ & $\begin{array}{l}22,8 \\
(1,5) \\
(b, c)\end{array}$ & $\begin{array}{c}0,785 \\
(0,016) \\
\text { (b) }\end{array}$ \\
\hline MC & $\begin{array}{l}0,967 \\
(0,01)\end{array}$ & $\begin{array}{l}24 \\
(4)\end{array}$ & $\begin{array}{l}0,770 \\
(0,009)\end{array}$ & $\begin{array}{l}0,964 \\
(0,003) \\
\text { (a) }\end{array}$ & $\begin{array}{l}23,8 \\
(1,5) \\
\text { (b) }\end{array}$ & $\begin{array}{l}0,736 \\
(0,013) \\
\text { (a) }\end{array}$ & $\begin{array}{l}0,968 \\
(0,003) \\
\text { (a) }\end{array}$ & $\begin{array}{c}23,5 \\
(0,9) \\
(c)\end{array}$ & $\begin{array}{c}0,742 \\
(0,008) \\
(a)\end{array}$ \\
\hline
\end{tabular}

Las letras diferentes en la misma columna indican grupos significativamente diferentes según el ANOVA realizado.

Con el fin de comparar el contenido en los diferentes componentes analizados en la uva antes y después de los tratamientos, y dada la pérdida de agua que suponen estos últimos, todas las cantidades de las muestras deshidratadas se han referido a la fruta fresca de partida. En cuanto a la acidez total (mg ácido tartárico / 100 g fruta fresca, Figura 2), se observó una disminución significativa en su contenido después de cada uno de los tratamientos, siendo la variedad Thompson seedless la 
que acusó mayores pérdidas, sobre todo cuando se trató con DO y MW. Con respecto a los métodos de procesado, la DO provocó siempre mayores pérdidas, lo cual, puede deberse al flujo de materia que emigró hacia la disolución durante el tratamiento osmótico. Además del efecto negativo causado en la acidez por el calentamiento, la pérdida producida por el MW puede deberse a la expulsión de liquido ocasionado por la ebullición del agua de la uva, que posiblemente arrastró consigo parte del contenido de ácidos.

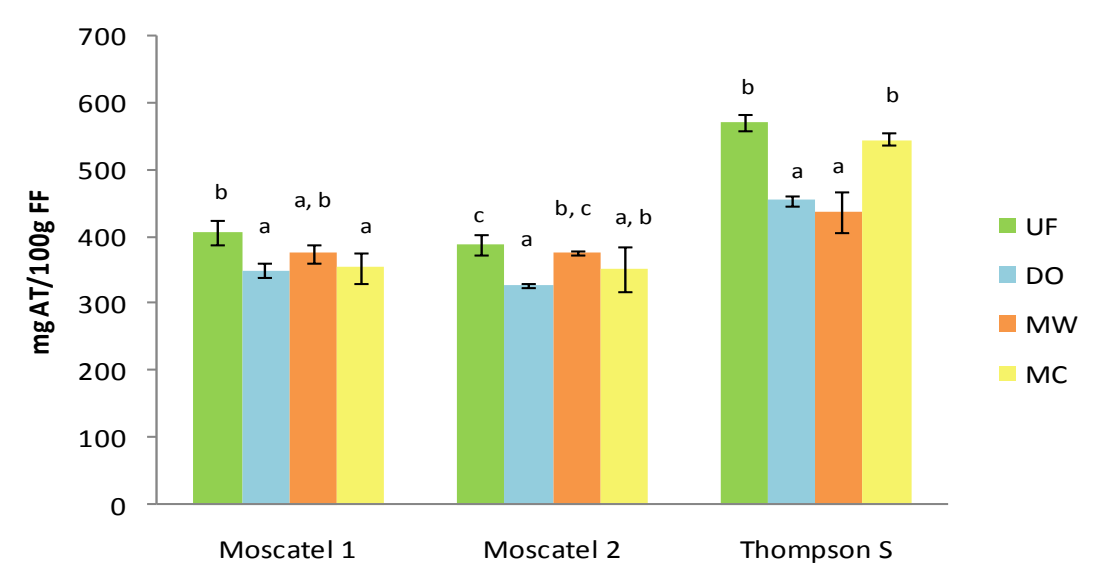

Figura 2. Acidez total (expresada como acido tartárico) de la uva fresca así como de la deshidratada osmóticamente (DO), mediante microondas (MW) y por el método combinado (MC). En todos los casos la acidez está referida al peso de uva antes de la deshidratación. Las letras diferentes en el mismo bloque indican grupos significativamente diferentes según el ANOVA realizado.

Los resultados obtenidos del análisis de los minerales, se muestran en la Tabla 5 y Figura 3. En cuanto al calcio, magnesio y potasio, como puede observarse, no parece haber ninguna tendencia clara sobre su 


\section{Capítulo $V$}

comportamiento por efecto del procesado. En el caso del fósforo si que se observó, en general, una disminución significativa por efecto del tratamiento, significativamente mayor al aplicar microondas.

Tabla 5. Valores medios y desviación estándar (entre paréntesis) del contenido en minerales en uva fresca (UF), deshidratada osmóticamente (DO), mediante microondas (MW) y por el método combinado (MC).

\begin{tabular}{|c|c|c|c|c|c|c|c|c|c|}
\hline & \multicolumn{3}{|c|}{ Moscatel 1} & \multicolumn{3}{|c|}{ Moscatel 2} & \multicolumn{3}{|c|}{ Thompson S. } \\
\hline & $\mathrm{Ca}$ & $\mathrm{Mg}$ & $\mathrm{K}$ & $\mathrm{Ca}$ & $\mathrm{Mg}$ & $\mathrm{K}$ & $\mathrm{Ca}$ & $\mathrm{Mg}$ & $\mathrm{K}$ \\
\hline \multirow[t]{3}{*}{ UF } & 2,9 & 9,4 & 166 & 4,9 & 4,9 & 125 & 5,3 & 12,6 & 97,5 \\
\hline & $(0,2)$ & $(0,7)$ & $(2,9)$ & $(0,4)$ & (1) & $(1,3)$ & $(0,2)$ & $(0,3)$ & (3) \\
\hline & (b) & (a) & (b) & (c) & (c) & (c) & & (b) & (c) \\
\hline \multirow[t]{3}{*}{$\overline{D O}$} & 3,29 & 22,6 & 187,5 & 4 & 5 & 160 & 5,5 & 12,1 & 82,3 \\
\hline & $(0,4)$ & $(0,8)$ & $(3,5)$ & $(0,2)$ & $(1,6)$ & (4) & $(0,7)$ & $(0,6)$ & $(1,6)$ \\
\hline & (b) & (d) & (c) & (b) & (d) & (d) & & $(a, b)$ & (b) \\
\hline \multirow[t]{3}{*}{ MW } & 3 & 20,8 & 181,5 & 3,6 & 4,6 & 101,5 & 5,9 & 13,9 & 75,4 \\
\hline & $(0,4)$ & $(2,8)$ & $(9,6)$ & $(0,4)$ & $(0,5)$ & $(2,7)$ & $(0,3)$ & $(0,2)$ & $(2,2)$ \\
\hline & (b) & (c) & (b) & $(a, b)$ & (b) & (b) & & (c) & (a) \\
\hline \multirow[t]{3}{*}{ MC } & 2 & 13,4 & 160 & 3,4 & 4,3 & 92,3 & 5,3 & 11,4 & 77 \\
\hline & $(0,6)$ & $(2,1)$ & $(0,5)$ & $(0,1)$ & $(0,1)$ & (2) & $(0,4)$ & $(0,4)$ & $(3,3)$ \\
\hline & (a) & (b) & (a) & (a) & (a) & (a) & & (a) & (a) \\
\hline
\end{tabular}

*Los resultados aparecen expresados en $\mathrm{mg} / 100 \mathrm{~g}$ de uva fresca. Las letras diferentes en la misma columna indican grupos significativamente diferentes según el ANOVA realizado. 


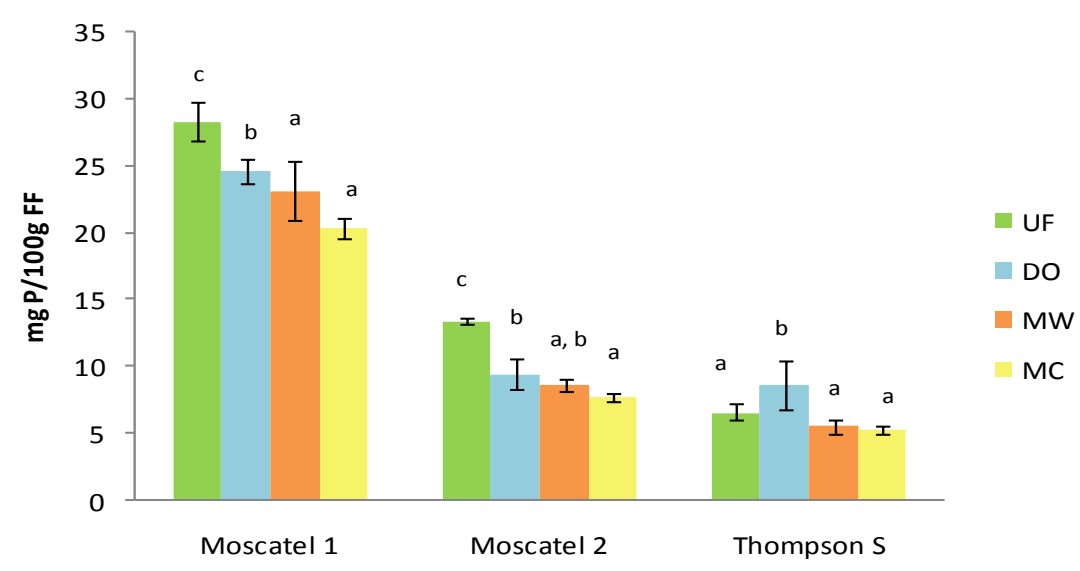

Figura 3. Contenido en fósforo de las diferentes variedades de uva antes y después de cada tratamiento de secado. En todos los casos el contenido está referido al peso de uva antes de la deshidratación. Las letras diferentes en el mismo bloque indican grupos significativamente diferentes según el ANOVA realizado.

Como se mencionó anteriormente, la uva es rica en azucares, especialmente en fructosa y glucosa, razón por la cual posee un alto contenido energético. El resultado de los ANOVAs mostró diferencias significativas entre las uvas tratadas y la fresca. No obstante, los grupos homogéneos que se establecen (Tabla 6) no permiten confirmar un efecto diferente de los tratamientos, sino que más bien parece tratarse de una variabilidad de la propia uva. De hecho, era de esperar que los tratamientos no supusieran un cambio significativo en el contenido de glucosa y fructosa cuando se expresa en base de fruta fresca. Únicamente podría esperarse un aumento en la sacarosa en los tratamientos osmóticos. Esto fue así, si bien este aumento fue muy 


\section{Capítulo $V$}

pequeño, lo que confirma la escasa entrada de azúcar en la fruta ya comentada anteriormente.

Tabla 6. Valores medios y desviación estándar (entre paréntesis) del contenido en azúcares presentes en la uva fresca y la deshidratada por los diferentes métodos de procesado.

\begin{tabular}{|c|c|c|c|c|c|c|c|c|c|}
\hline & \multicolumn{3}{|c|}{ Moscatel 1} & \multicolumn{3}{|c|}{ Moscatel 2} & \multicolumn{3}{|c|}{ Thompson S. } \\
\hline & Glu & Fru & Sac & Glu & Fru & Sac & Glu & Fru & Sac \\
\hline UF & $\begin{array}{c}6,9 \\
(0,2)\end{array}$ & $\begin{array}{c}7,8 \\
(0,6) \\
(\mathrm{a})\end{array}$ & $\begin{array}{c}0,1 \\
(0,04) \\
(a)\end{array}$ & $\begin{array}{c}6,9 \\
(0,14) \\
\text { (c) }\end{array}$ & $\begin{array}{c}7,54 \\
(0,09) \\
(b)\end{array}$ & $\begin{array}{r}0,34 \\
(0,03) \\
(a)\end{array}$ & $\begin{array}{l}8,5 \\
(0,2) \\
\text { (b) }\end{array}$ & $\begin{array}{c}10,7 \\
(0,16) \\
\text { (b) }\end{array}$ & $\begin{array}{c}0,34 \\
(0,03)\end{array}$ \\
\hline DO & $\begin{array}{c}6,4 \\
(0,3)\end{array}$ & $\begin{array}{c}7,4 \\
(0,4) \\
(a, b)\end{array}$ & $\begin{array}{c}1,15 \\
(0,1) \\
\text { (b) }\end{array}$ & $\begin{array}{l}6,9 \\
(0,9) \\
(d)\end{array}$ & $\begin{array}{c}7,31 \\
(0,04) \\
(c)\end{array}$ & $\begin{array}{c}0,83 \\
(0,04) \\
\text { (b) }\end{array}$ & $\begin{array}{c}8,99 \\
(0,12) \\
\text { (b) }\end{array}$ & $\begin{array}{c}11,1 \\
(0,03) \\
(a, b)\end{array}$ & $\begin{array}{c}0,87 \\
(0,10)\end{array}$ \\
\hline MW & $\begin{array}{c}6,5 \\
(0,4)\end{array}$ & $\begin{array}{c}7,6 \\
(0,6) \\
\text { (b) }\end{array}$ & ND & $\begin{array}{c}6,42 \\
(0,14) \\
\text { (b) }\end{array}$ & $\begin{array}{c}7,04 \\
(0,17) \\
(c)\end{array}$ & ND & $\begin{array}{c}8,15 \\
(0,13) \\
(a)\end{array}$ & $\begin{array}{c}11,3 \\
(0,18) \\
\text { (a) }\end{array}$ & ND \\
\hline MC & $\begin{array}{c}7,2 \\
(0,6)\end{array}$ & $\begin{array}{c}8,1 \\
(0,54) \\
\text { (b) }\end{array}$ & $\begin{array}{c}0,1 \\
(0,02) \\
(a)\end{array}$ & $\begin{array}{c}7,69 \\
(0,13) \\
\text { (a) }\end{array}$ & $\begin{array}{c}8,1(0,3) \\
\text { (a) }\end{array}$ & ND & $\begin{array}{c}7,6(0,3) \\
\text { (c) }\end{array}$ & $\begin{array}{c}10,1 \\
(0,01) \\
(c)\end{array}$ & ND \\
\hline
\end{tabular}

Valores expresados en $\mathrm{g} / 100 \mathrm{~g}$ de fruta fresca, entre paréntesis aparece la desviación estándar. ND: No detectado. Las letras diferentes en la misma columna indican grupos significativamente diferentes según el ANOVA realizado.

Los resultados obtenidos del análisis del contenido en pectina total se muestran en la Figura 4. En este caso, la alta variabilidad de los resultados no permitió detectar diferencias significativas por efecto del tratamiento. En este sentido, parece que ni las altas temperaturas ni la lixiviación que pueda ocurrir durante el procesado osmótico afectaron a este compuesto. 


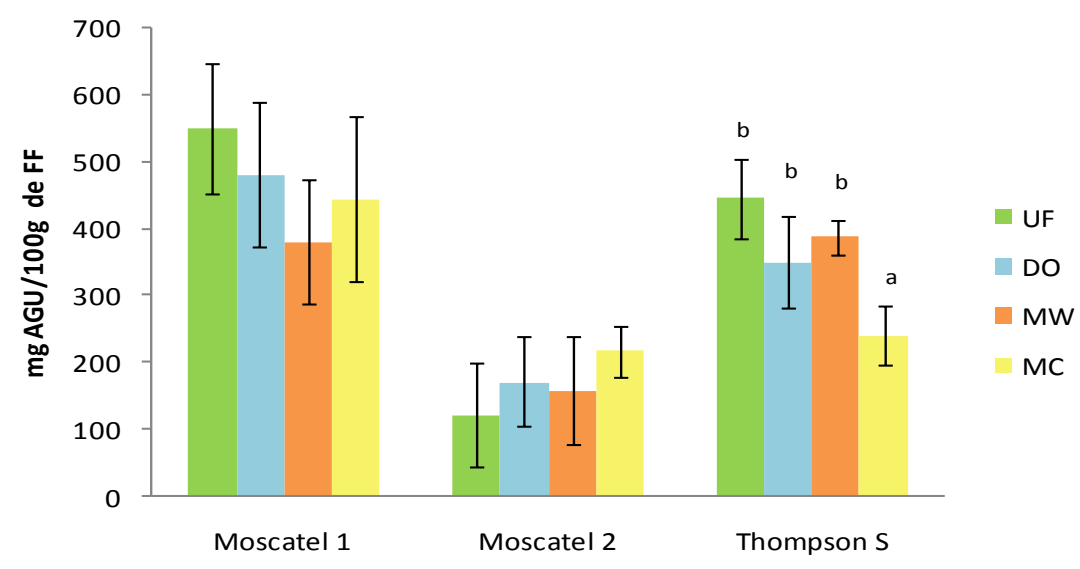

Figura 4. Contenido en pectina total en la uva fresca y deshidratada mediante los diferentes métodos. En todos los casos la pectina está referida al peso de uva antes de la deshidratación. Las letras diferentes en el mismo bloque indican grupos significativamente diferentes según el ANOVA realizado.

\section{V.5.2 Evolución de los macro y micronutrientes de la uva durante el almacenamiento.}

Para ver la influencia de almacenamiento sobre los macro y micronutrientes de la uva se trabajó con la uva moscatel fresca y procesada mediante los tres métodos de deshidratación comentados en el apartado anterior. En ambos casos se almacenó a $4{ }^{\circ} \mathrm{C}$ durante 10 días, analizándose los mismos parámetros que para la uva fresca y recién procesada.

En relación a la evolución de los ${ }^{\circ}$ Brix (Figura 5), humedad (Figura 6) y actividad del agua (Figura 7) en la uva tanto fresca como tratada, en general, no se observaron cambios significativos que puedan asociarse a una evolución de las muestras con el almacenamiento. Únicamente a los 


\section{Capítulo V}

10 días parece observarse una disminución significativa de la $\mathrm{a}_{\mathrm{w}}$ en todas las muestras que sería coherente con una cierta deshidratación. En el caso de la uva fresca se observó una disminución significativa del contenido en sólidos solubles durante el primer día de almacenamiento, coherente con el aumento de humedad y actividad del agua observados, que sin embargo no parece lógico.

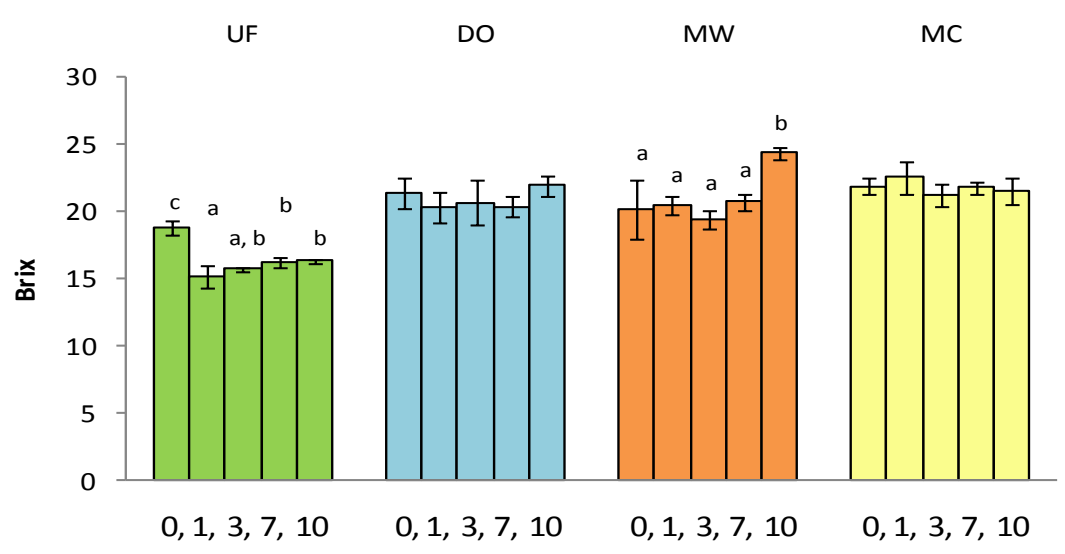

Figura 5. Evolución del contenido en sólidos solubles ( ${ }^{\circ}$ Brix) en la uva fresca y deshidratada mediante los diferentes tratamientos durante el período de almacenamiento. Las letras diferentes en el mismo bloque indican grupos significativamente diferentes según el ANOVA realizado. 
UVA PARCIALMENTE DESHIDRATADA

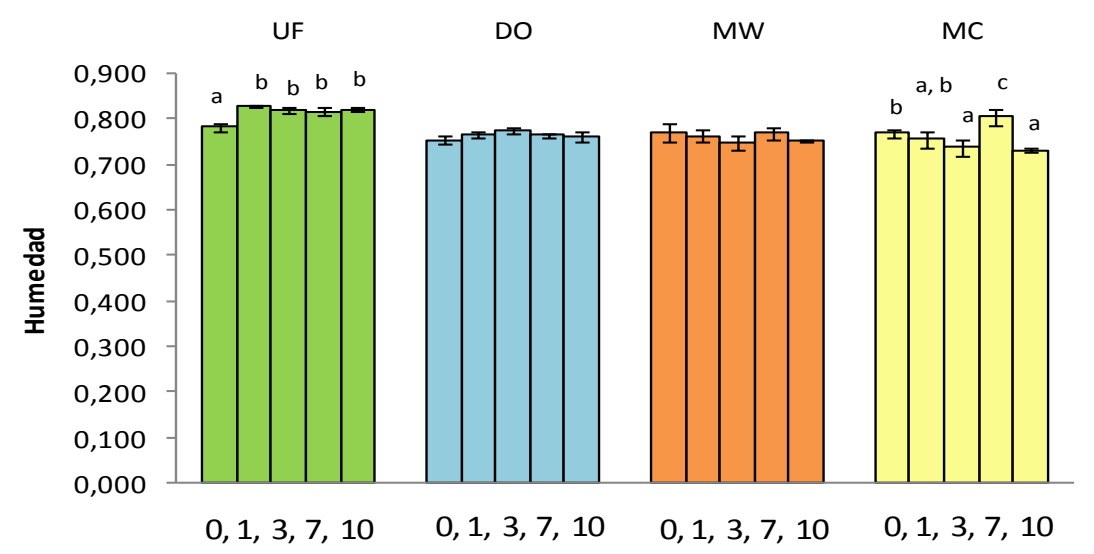

Figura 6. Evolución del contenido en humedad (Xw) en la uva moscatel fresca y deshidratada mediante los diferentes tratamientos durante el período de almacenamiento. Las letras diferentes en el mismo bloque indican grupos significativamente diferentes según el ANOVA realizado.

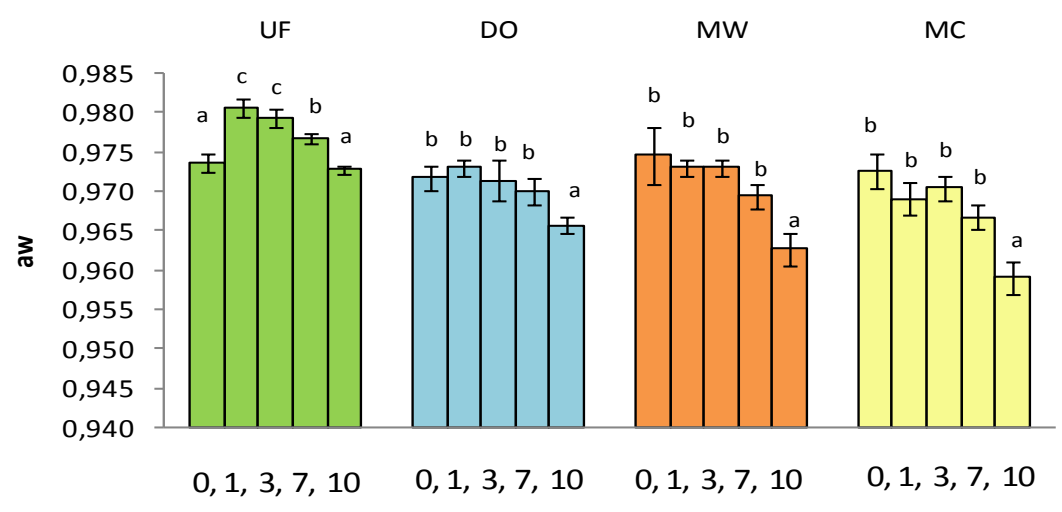

Figura 7. Evolución de la actividad del agua $\left(a_{\mathrm{w}}\right)$ en la uva moscatel fresca y deshidratada mediante los diferentes tratamientos durante el período de almacenamiento. Las letras diferentes en el mismo bloque 


\section{Capítulo V}

indican grupos significativamente diferentes según el ANOVA realizado.

En relación con la glucosa (Figura 8) y la fructosa (Figura 9), no se observó un cambio significativo excepto en el caso de las muestras deshidratadas osmóticamente y en el primer día de almacenamiento. Este incremento en la DO puede deberse a la hidrólisis parcial de la sacarosa incorporada durante el tratamiento de deshidratación.

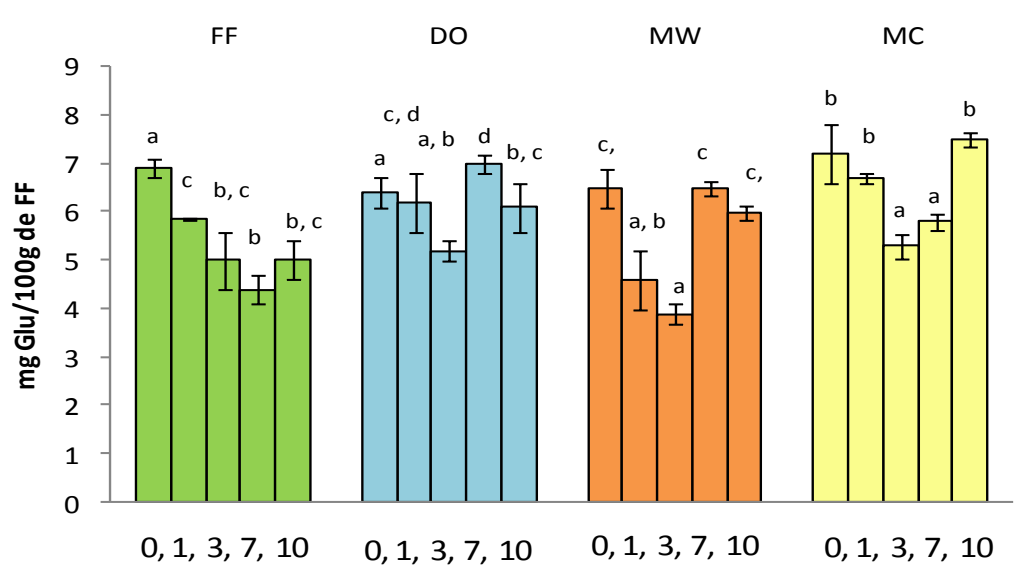

Figura 8. Evolución del contenido en glucosa (Glu) en la uva fresca y deshidratada mediante los diferentes tratamientos durante el período de almacenamiento. En todos los casos la glucosa está referida al peso de uva antes de la deshidratación. Las letras diferentes en el mismo bloque indican grupos significativamente diferentes según el ANOVA realizado. 
UVA PARCIALMENTE DESHIDRATADA

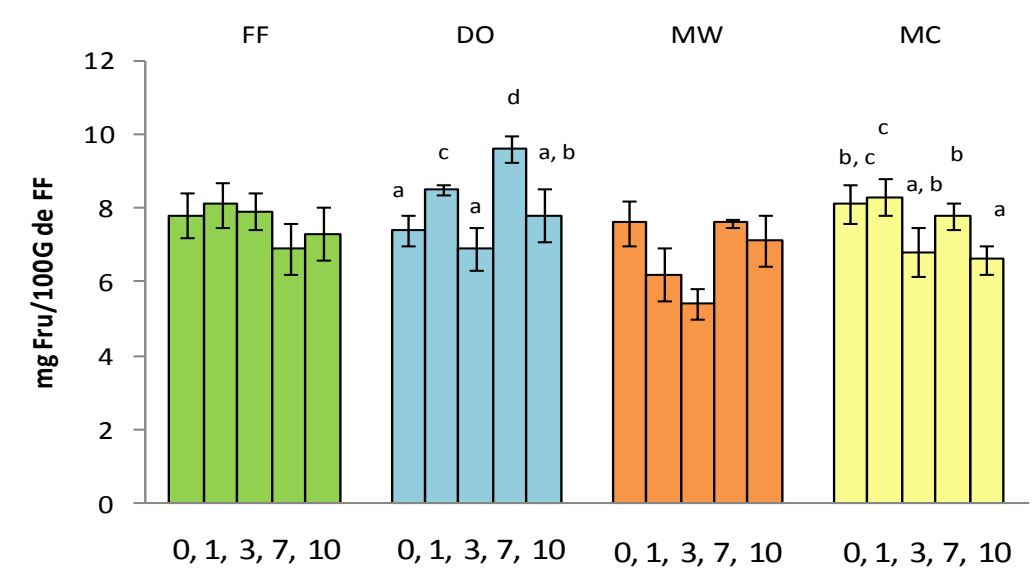

Figura 9. Evolución del contenido en fructosa (Fru) en la uva fresca y deshidratada mediante los diferentes tratamientos durante el período de almacenamiento. En todos los casos la fructosa está referida al peso de uva antes de la deshidratación. Las letras diferentes en el mismo bloque indican grupos significativamente diferentes según el ANOVA realizado.

En cuanto a la sacarosa (Fig. 10), su bajo contenido en la uva fresca no permite evidenciar ningún cambio con el almacenamiento. Con respecto a la muestra $\mathrm{DO}$, se observa una disminución significativa durante el transcurso del almacenamiento, que confirmaría una progresiva hidrólisis de la misma, como ya se ha comentado. 


\section{Capítulo V}

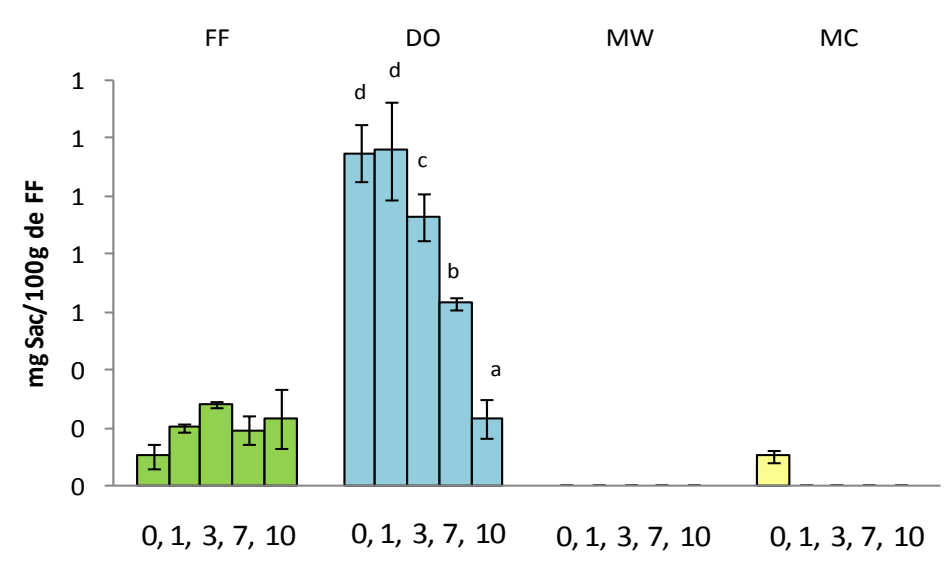

Figura 10. Evolución del contenido en sacarosa (Sac) en la uva fresca y deshidratada mediante los diferentes tratamientos durante el período de almacenamiento. En todos los casos el contenido está referido al peso de uva antes de la deshidratación. Las letras diferentes en el mismo bloque indican grupos significativamente diferentes según el ANOVA realizado.

La figuras 11 a 14 muestran el comportamiento del Ca, P, Mg y K, respectivamente, durante el almacenamiento. Las diferencias observadas y reflejadas por los ANOVAs tampoco permiten, en este caso, concluir que haya una evolución del contenido en minerales estudiados durante el almacenamiento, sino que más bien parecen ser consecuencia de la alta variabilidad que presenta la propia fruta. 


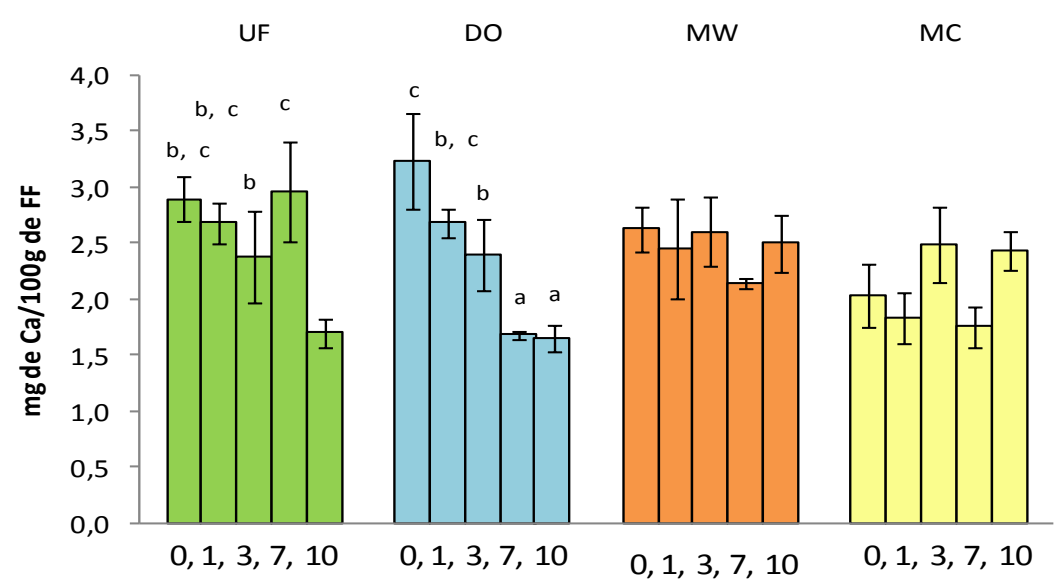

Figura 11. Evolución del contenido en calcio (Ca) en la uva fresca y deshidratada mediante los diferentes tratamientos durante el período de almacenamiento. En todos los casos el contenido está referido al peso de uva antes de la deshidratación. Las letras diferentes en el mismo bloque indican grupos significativamente diferentes según el ANOVA realizado.

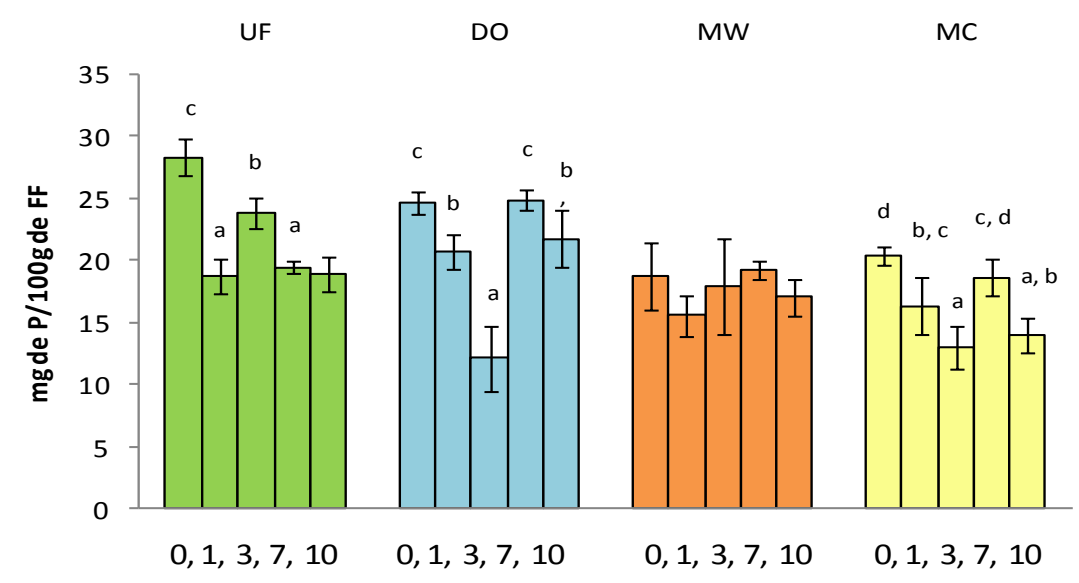

Figura 12. Evolución del contenido en fósforo (P) en la uva fresca y deshidratada mediante los diferentes tratamientos durante el período de almacenamiento. En todos los casos el contenido está referido al peso de 


\section{Capítulo V}

uva antes de la deshidratación. Las letras diferentes en el mismo bloque indican grupos significativamente diferentes según el ANOVA realizado.

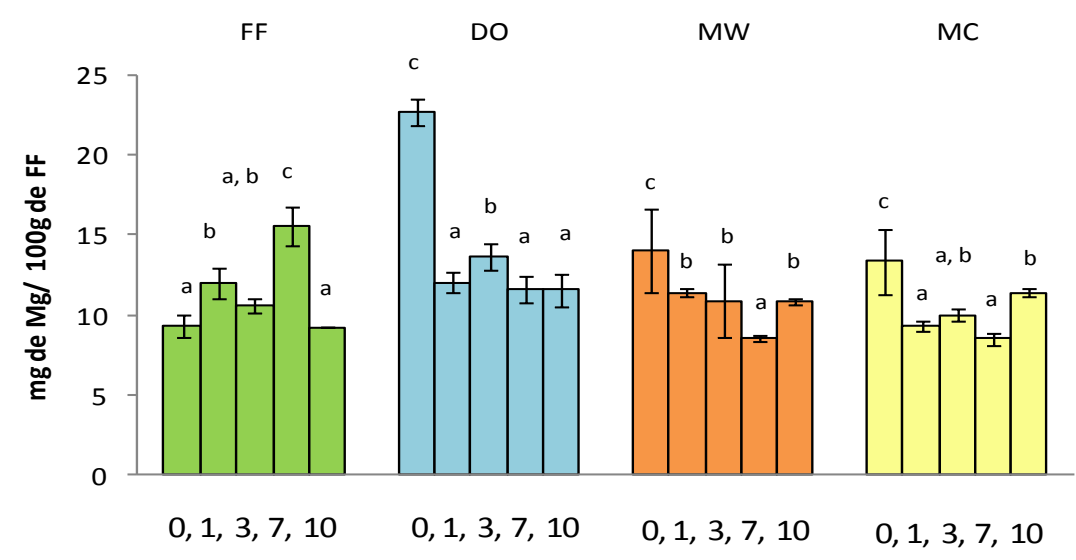

Figura 13. Evolución del contenido en magnesio $(\mathrm{Mg})$ en la uva fresca y deshidratada mediante los diferentes tratamientos durante el período de almacenamiento. En todos los casos el contenido está referido al peso de uva antes de la deshidratación. Las letras diferentes en el mismo bloque indican grupos significativamente diferentes según el ANOVA realizado. 


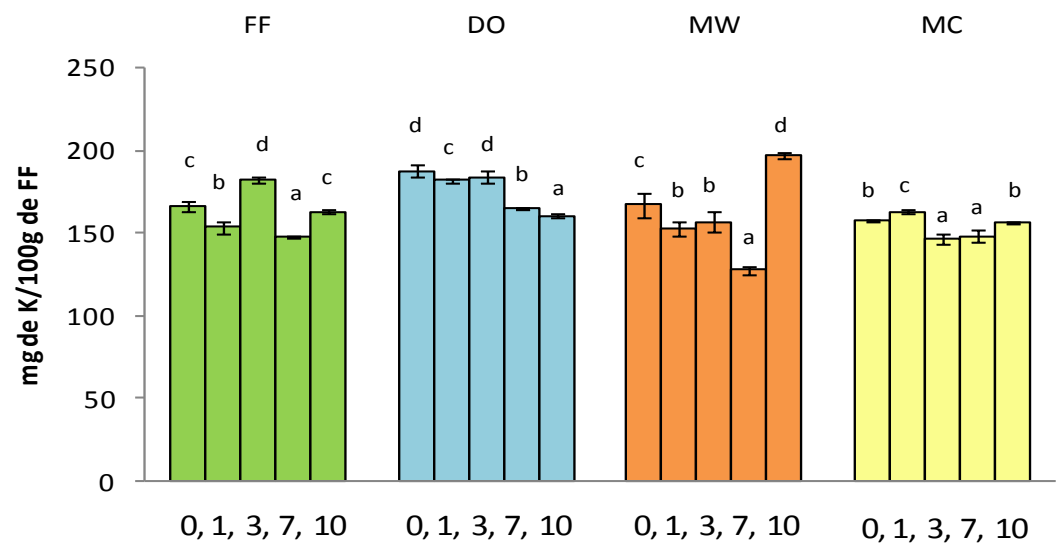

Figura 14. Evolución del contenido en potasio (K) en la uva fresca y deshidratada mediante los diferentes tratamientos durante el período de almacenamiento. En todos los casos el contenido está referido al peso de uva antes de la deshidratación. Las letras diferentes en el mismo bloque indican grupos significativamente diferentes según el ANOVA realizado.

Lo mismo ocurre con la acidez (Fig. 15) y con la pectina (Fig. 16), que tampoco parece verse afectada por el almacenamiento en ninguna de las muestras tratadas. 


\section{Capítulo V}

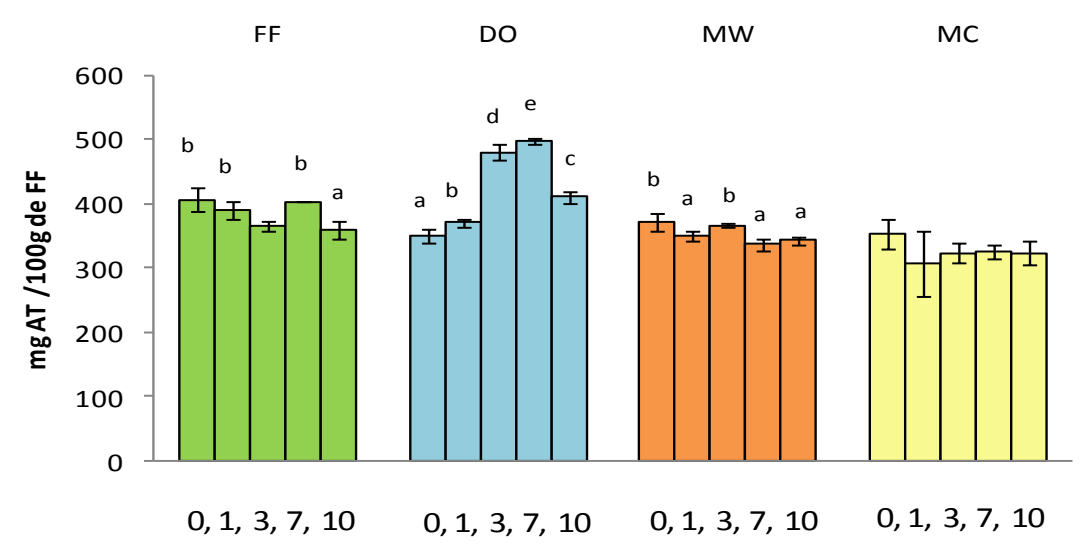

Figura 15. Evolución del contenido en ácido tartárico (AT) en la uva fresca y deshidratada mediante los diferentes tratamientos durante el período de almacenamiento. En todos los casos la acidez está referida al peso de uva antes de la deshidratación. Las letras diferentes en el mismo bloque indican grupos significativamente diferentes según el ANOVA realizado.

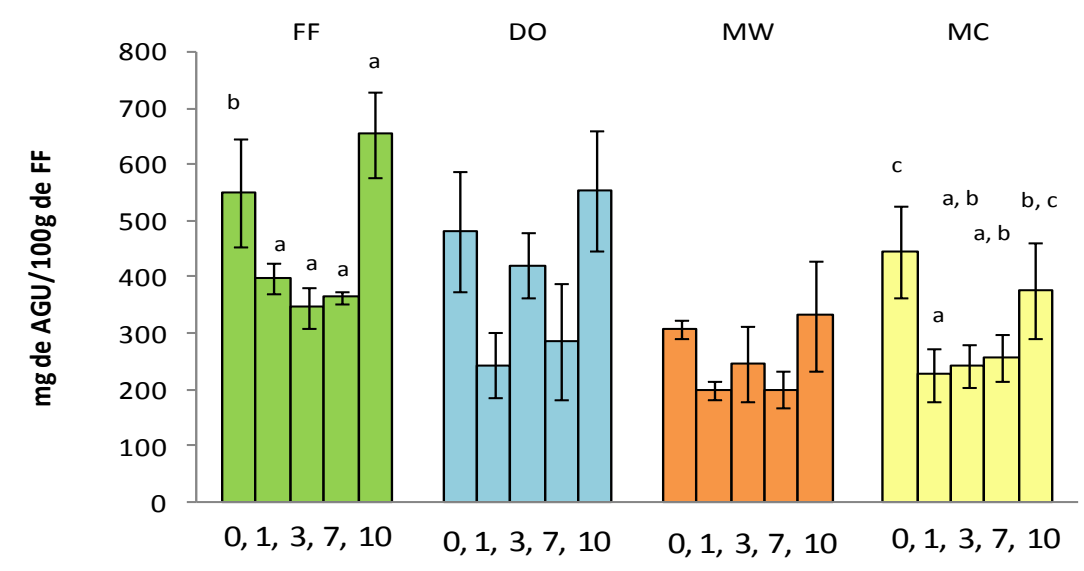

Figura 16. Evolución del contenido en pectina total (PT) en la uva fresca y deshidratada mediante los diferentes tratamientos durante el período de almacenamiento. En todos los casos la pectina total está 
referida al peso de uva antes de la deshidratación. Las letras diferentes en el mismo bloque indican grupos significativamente diferentes según el ANOVA realizado

\section{V.6. CONCLUSIONES}

- La deshidratación de las muestras hasta la humedad prefijada no supuso un cambio significativo en el contenido en azucares, pectina, calcio, potasio y magnesio. La suavidad de los tratamientos aplicados podría explicar que no ocurriera una degradación de estos compuestos por efecto de la temperatura en el caso de los tratamientos con microondas ni una lixiviación significativa debida al procesado osmótico. Si que fueron sensibles a estos tratamientos tanto el ácido tartárico como el fósforo.

- Todos los compuestos analizados se mantienen estables durante el almacenamiento en refrigeración de la uva, tanto fresca como tratada, independientemente del método de deshidratación aplicado. 
UVA EN ALMÍBAR 

UVAS EN ALMÍBAR

\section{UVAS EN ALMÍBAR}

\section{VI.1 JUSTIFICACIÓN}

Las características organolépticas de los alimentos (textura, sabor, aroma, forma y color) son las que determinan las preferencias del consumidor por determinados productos, ya que pequeñas diferencias entre las características organolépticas de productos semejantes de marcas distintas son a veces determinantes de su grado de aceptabilidad. Así pues, el mejorar la tecnología de elaboración para mantener o mejorar las características organolépticas de los productos tratando de reducir las modificaciones que en ellos produce el proceso de elaboración es el objetivo primordial de la industria alimentaria (Aleixandre, 1997).

A partir de la frutas se obtienen muy diversos productos, tales como conservas, jaleas, zumos, néctares y alimentos deshidratados. La industrialización permite disponer de ellas en forma de derivados cuando no es posible el consumo en fresco así como el aprovechamiento de las cosechas que no pueden ser absorbidas por el mercado en consumo directo. Sin embargo en muchos procesos de elaboración de alimentos se producen reacciones, que modifican los componentes afectando sensiblemente a las propiedades organolépticas (Primo, 1997). Dentro de estos procesos encontramos al tratamiento térmico, que es uno de los más utilizados en la conservación de alimentos, el cual nos permite eliminar numerosas categorías de microorganismos e inactivar las enzimas que pudiesen alterar el producto. 


\section{Capítulo VI}

En particular, enzimas como la peroxidasa y polifenoloxidasa son consideradas como indicadores de la eficacia del tratamiento térmico. Estas enzimas son capaces de catalizar un gran número y variedad de reacciones de oxidación (McLellan y Robinson 1984). Entre ellas la peroxidasa es la más significativa gracias a su resistencia al calor y a la capacidad de regeneración (Viña et al., 2006). Su total destrucción asegura la inactivación de otras enzimas existentes. No obstante, algunos estudios demuestran que generalmente esta enzima no es la responsable de la principal reacción de degradación. Por tanto, conseguir la inactivación total de la peroxidasa implica un procesado con consecuencias innecesarias en la calidad del alimento, principalmente en la textura (Viña et al., 2006). El pardeamiento enzimático en frutas es causado principalmente por la polifenoloxidasa (PPO) (Walker, 1995, Cash y col., 1976, Valero y col., 1988, Yokotsuka y col., 1991). Esta enzima puede provocar el pardeamiento enzimático catalizando la oxidación de mono- y difenoles a o-quinonas. Estas quinonas se polimerizan produciendo pardeamiento enzimático (melaninas) (McEvily et al., 1992). La PPO muestra su actividad óptima a un $\mathrm{pH}$ entre 5 y 7. Sin embargo, esta actividad puede ser inactivada al ser sometida a un tratamiento térmico o eliminando alguno de sus componentes necesarios: $\mathrm{O}_{2}, \mathrm{Cu}^{+2}$ o el substrato (Lambretch, 1995; Richardson y Hyslop, 1985). Esta enzima está presente en todas las plantas (Whitaker, 1972) pero su actividad es particularmente alta en aquellas frutas o vegetales que contienen un alto nivel de compuestos fenólicos, como sucede en la uva (Cantos et al., 2002; Maxcheix et al., 1990). La actividad polifenoloxidasa está considerablemente 
influenciada por algunos factores como la variedad, la etapa de desarrollo y las condiciones medioambientales (Mayer y Harel, 1979; Sapis et al., 1983).

Las operaciones térmicas utilizadas en alimentos frecuentemente tienen como resultado una significante pérdida de la textura ( $\mathrm{Li}$ et al., 2005). En estos procesos, las pectinas son degradadas y solubilizadas de la pared celular ( $\mathrm{Li}$ et al., 2005), lo que produce una pérdida en la firmeza de los tejidos (Greve et al., 1994; Stolle-Smiths et al., 1997). Por otra parte, la acción de enzimas como la pectinmetilesterasa (PME) tendrá un efecto muy marcado en la calidad de los productos frescos o procesados, en relación también con su textura. La enzima PME puede encontrarse en muchas frutas $\mathrm{y}$ vegetales (Rexova-Benkova y Markovich., 1976). Su acción comprende la demetilación de los grupos carboximetílicos de las cadenas de polisacáridos pécticos. La disminución del grado de metilación desencadenará procesos relacionados con la pérdida de textura y firmeza, por lo que la PME tiene un gran historial de informes sobre sus efectos en la firmeza. No obstante, la relación entre la actividad PME medida y la firmeza observada es intrínsecamente compleja. Uno tiene que considerar que el organismo vivo, durante su vida, es capaz de adaptar o cambiar los niveles de enzimas activas y la accesibilidad del sustrato. Consecuentemente, el efecto total ejercido por la PME nunca puede basarse en una sola medida de la actividad en función del tiempo. La actividad de cualquier enzima es probable que sea el resultado de un complejo esquema de reacciones biológicas. La dependencia de la actividad en diferentes condiciones de escaldado, para diferentes lotes de 


\section{Capítulo VI}

producto con diferente grado de madurez es probable que resulte complejo también. Por consiguiente, es posible que no exista relación entre la actividad de la PME y el ablandamiento (Tijskens et al., 1999). En cualquier caso, la inactivación enzimática de la PME debe ser alcanzada sin el compromiso de otros aspectos como la seguridad y calidad (Hendrix \& Redd, 1995).

La técnica más usual para inactivar enzimas es el escaldado, el cual es considerado como un pretratamiento. Este puede llevarse a cabo mediante la exposición del producto en agua caliente o hirviendo (el método más común es a $85-100^{\circ} \mathrm{C}$ ), en disoluciones ácidas o básicas calientes o hirviendo, mediante vapor (Kidmose y Martens, 1999) o por microondas mediante la inmersión del producto en agua o disoluciones durante algunos segundos o minutos (Chen et al., 1971; Ramaswany y Van de Voort, 1990; Ponne et al., 1991; Severini et al., 2001). Esta manipulación no constituye en sí misma un método de conservación, sino tan solo un pretratamiento normalmente aplicado en el acondicionamiento de la materia prima o bien antes de otras operaciones de conservación, en especial la esterilización, la deshidratación y la congelación.

Los tiempos cortos de exposición son efectivos para reducir la incidencia de las reacciones de degradación durante el almacenamiento, sin embargo el escaldado también produce modificaciones en la estructura celular y en la composición del alimento (Philippon, 1984). El calor recibido por los alimentos durante el escaldado origina inevitablemente algunos cambios en las características sensoriales y nutritivas. Muchas veces es necesario encontrar la tecnología y el tiempo 
adecuado para cada producto en particular, en favor de inactivar las enzimas responsables del daño, tratando de establecer un equilibrio para obtener una adecuada inactivación y minimizando al mismo tiempo pérdidas en la calidad y en los atributos del producto.

Para mejorar la calidad del producto se han estudiado diferentes métodos de escaldado, siendo el tratamiento por microondas una alternativa interesante al procesado convencional. La penetración de las microondas provoca un rápido calentamiento pero además, éstas parecen tener un efecto no térmico en la inactivación de la enzima, el cual reduce el impacto de la temperatura y mejora la retención de los componentes termolábiles y las características sensoriales (Heedleson and Doores, 1994). Por el contrario, como se mencionó anteriormente, el uso del microondas, tiene el inconveniente de que es muy difícil conocer la distribución del campo energético, pues resulta modificado por la introducción de una carga en el sistema (Zhang et al., 2006), además de la poca repetitividad y del elevado coste. Sin embargo Lin y Brewer (2005) mencionan que el escaldado por microondas permite una transferencia de calor eficiente con poca cantidad o sin la utilización de agua, lo cual reduce la pérdida de nutrientes en comparación con el método tradicional. En este trabajo se pretende estudiar en qué medida la aplicación de un escaldado alternativo al tradicional, mediante microondas, afecta a las propiedades de la uva en almíbar.

El Real Decreto 2420/1978 define las frutas en almíbar como los productos obtenidos a partir de frutas enteras, mitades, segmentos, tiras o cubos, rodajas o gajos a los que se les ha adicionado un jarabe de cobertura cuya graduación final será como mínimo $14^{\circ}$ Brix. Los 


\section{Capítulo VI}

almíbares se denominan, según la concentración en ${ }^{\circ}$ Brix del producto

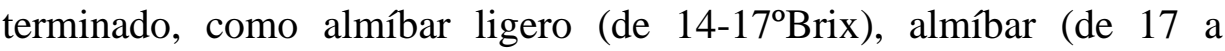
$20^{\circ}$ Brix), almíbar denso (más de $20^{\circ}$ Brix). Por su parte la legislación comunitaria en el reglamento (CE)1535/2003 define almíbar como el líquido resultante de combinar agua y azúcar.

La conservación de frutas en almíbar tiene como principio la reducción del agua disponible por la adición de azúcar. La inmersión de la fruta en el jarabe da lugar a fenómenos de transferencia de masa debido al equilibrio espontaneo generado entre los dos materiales. Las sustancias se transfieren del medio menos concentrado en soluto al más concentrado (ósmosis). Esto hace que el producto final adquiera unas características organolépticas particulares y que sean apreciadas por el consumidor pero que, sin embargo, podría mejorar si el proceso de escaldado habitual en este producto perjudicara lo menos posible a la calidad del producto. Es por esto por lo que se plantea este trabajo.

\section{VI.2 OBJETIVOS ESPECÍFICOS}

- Puesta a punto de los métodos de análisis de actividad enzimática.

- Selección de las condiciones del escaldado tradicional de uva, utilizando como indicadores las actividades enzimáticas residuales de la pectinmetilesterasa, peroxidasa y polifenoloxidasa. 
- Puesta a punto y selección del proceso de escaldado con microondas para uva, utilizando como indicadores las actividades enzimáticas residuales de la PME, la POD y la PPO.

- Caracterización de la variedad de uva fresca utilizada para el estudio.

- Obtención y caracterización de uvas en almíbar previamente escaldadas por los dos métodos propuestos.

- Evaluación de los cambios composicionales después del procesado así como durante el almacenamiento a temperatura ambiente.

- Comparación de producto obtenido experimentalmente con los disponibles en el mercado.

\section{VI.3 PLAN DE TRABAJO}

1. Revisión bibliográfica.

2. Aplicación de diferentes métodos para la medida de la actividad peroxidasa, polifenoloxidasa y pectinmetilesterasa en uva y selección del más adecuado.

3. Aplicación de tratamientos de escaldado de uva por el método tradicional (variando el tiempo) y por microondas (variando la potencia y el tiempo) para seleccionar el más adecuado en base a la inactivación enzimática conseguida.

4. Elaboración de uva en almíbar por los diferentes procedimientos seleccionados. 


\section{Capítulo VI}

5. Estudio del efecto del procesado para la obtención de uva en almíbar y de su almacenamiento a temperatura ambiente en la composición y actividad enzimática.

\section{VI.4. MATERIAL Y MÉTODOS}

\section{VI.4.1 Materia Prima}

Para la puesta a punto de los métodos de análisis de la actividad enzimática y para la selección de los tratamientos de escaldado a aplicar se utilizaron distintas variedades de uva blanca (Vitis vinifera L.) según la disponibilidad en el mercado a la hora de hacer los ensayos: Festival, Victoria, Moscatel, Aledo y Thompson seedless. Ésta se adquirió en supermercados de la ciudad de Valencia. Se seleccionaron granos de uva con características externas e internas típicas de la uva blanca y similares en cuanto a firmeza y tamaño. Previamente a su utilización, la uva fue enjuagada con agua destilada y seguidamente secada con papel absorbente para su posterior tratamiento y análisis.

El almíbar elaborado fue de $16^{\circ}$ Brix, para lo cual se utilizó agua destilada $(84 \%$ p/p) y azúcar común de grado alimentario $(16 \%$ p/p) disolviéndose mediante agitación continua a $30^{\circ} \mathrm{C}$. Para el estudio del efecto del tratamiento y del almacenamiento se utilizó uva de la variedad Festival. Para poder comparar nuestro producto experimental, se adquirió producto comercial de uvas en almíbar procedentes de dos marcas diferentes. 
UVAS EN ALMÍBAR

\section{VI.4.2 Procesado}

Las condiciones de escaldado, tanto tradicional como mediante microondas, fueron seleccionadas tal y como se muestra a continuación.

\section{a).- Escaldado tradicional}

Para la selección del tratamiento de escaldado tradicional (inmersión en agua caliente) se utilizó un baño (Selecta Precisterm) a $100^{\circ} \mathrm{C}$, en función del tratamiento aplicado, en el que se introdujo siempre la misma cantidad de uva blanca (100g). El tiempo de permanencia de la uva en el baño varió entre 1 y 3 minutos, tal como se explica en la tabla 7. Transcurrido este tiempo, la uva se enfrió rápidamente en un baño con hielo y se secó para posteriormente ser analizada en cuanto a la actividad enzimática de la polifenoloxidasa, peroxidasa y pectinmetilesterasa.

Tabla 7. Condiciones (temperatura y tiempo) de los diferentes escaldados tradicionales ensayados para la uva.

\begin{tabular}{|c|c|}
\hline Temperatura $\left({ }^{\circ} \mathrm{C}\right)$ & Tiempo \\
\hline 100 & $1 \mathrm{~min} 30 \mathrm{~s}$ \\
\hline 100 & $2 \mathrm{~min}$ \\
\hline 100 & $2 \mathrm{~min} 30 \mathrm{~s}$ \\
\hline 100 & $3 \mathrm{~min}$ \\
\hline
\end{tabular}

\section{b).- Escaldado con microondas}

Para la selección del tratamiento de escaldado con microondas, se utilizó un microondas (Moulinex, 5141) en el que se introdujo la uva (100g) utilizando dos procedimientos diferentes: el calentamiento directo de la uva y el calentamiento de la uva inmersa en agua. 


\section{Capítulo VI}

\section{Calentamiento directo}

Se introdujeron en el microondas $100 \mathrm{~g}$ de uva colocados sobre una malla de forma circular, con el objetivo de conseguir un calentamiento más homogéneo en la fruta. La geometría de la malla se seleccionó después de probar diferentes formas: cuadrada, rectangular y circular, siendo esta última la escogida por ser la más indicada por la uniformidad que presentaba la temperatura de los granos de uva al acabar el proceso térmico por radiación de microondas. La potencia utilizada para el escaldado varió entre 300 y $900 \mathrm{~W}$, mientras que el tiempo que se mantuvo el producto en el microondas fue de 30 y 45 segundos, según el tratamiento (Tabla 8).

Tabla 8. Condiciones (potencia y tiempo) de los diferentes escaldados por microondas para la uva.

\begin{tabular}{|c|c|}
\hline Potencia (W) & Tiempo (s) \\
\hline 300 & 45 \\
\hline \multirow{2}{*}{500} & 30 \\
\cline { 2 - 2 } & 45 \\
\hline \multirow{2}{*}{700} & 30 \\
\hline \multirow{2}{*}{900} & 45 \\
\hline
\end{tabular}

Al finalizar el proceso, la uva se enfrió rápidamente en un baño con hielo, se secó y a continuación se realizo el análisis de la actividad enzimática residual de la PME, PPO y POD. 


\section{Calentamiento con agua}

En este caso, los $100 \mathrm{~g}$ de uva se introdujeron en un vaso de precipitados de 500ml con agua destilada (relación 1:3) $(\mathrm{m} / \mathrm{v})$ a una potencia de 900w variando las condiciones de tiempo según indica la tabla 9.

Tabla 9. Condiciones (potencia y tiempo) de los diferentes escaldados por microondas con inmersión en agua de la uva.

\begin{tabular}{|c|c|}
\hline Potencia (W) & Tiempo \\
\hline \multirow{2}{*}{900} & $2 \mathrm{~min}$ \\
\cline { 2 - 2 } & $2 \mathrm{~min} 50 \mathrm{~s}$ \\
\cline { 2 - 2 } & $3 \mathrm{~min}$ \\
\hline
\end{tabular}

Una vez finalizado el tratamiento, el producto se enfrió en un baño con hielo y se secó para su posterior análisis en cuanto a la actividad de la PPO, POD y PME (apartado III.2.12).

\section{c).- Selección de los tratamientos de escaldado}

A partir de los resultados de inactivación enzimática obtenidos, se seleccionó un tratamiento convencional y otro por microondas, tal y como se expone en el apartado VII.5.1 de resultados.

\section{VI.4.3 Análisis realizados}

A la uva fresca y procesada se le midió el porcentaje de inactivación de las enzimas peroxidasa, polifenoloxidasa, pectinmetilesterasa. Además, a la fruta tanto fresca como después de procesada por los tratamientos seleccionados se le evaluó el contenido en humedad, los 


\section{Capítulo VI}

sólidos solubles, la actividad del agua, la acidez total, el contenido en pectina total, en pectina hidrosoluble y pectina oxalato soluble, los fenoles totales y la actividad antioxidante, tal y como se describe en el capítulo III de este trabajo. Así mismo, se le determinó el color y las propiedades mecánicas tal y como se describe a continuación.

Con el fin de disponer de valores de referencia, se analizó también uva comercial en almíbar de dos marcas diferentes. En este caso se determinó la $\mathrm{a}_{\mathrm{w}}$, los sólidos solubles, la acidez total, los fenoles totales y la actividad antioxidante, el color y las propiedades mecánicas utilizando los mismos métodos anteriormente mencionados. Finalmente, en el almíbar de nuestro producto así como en el del producto comercial, se analizaron los ${ }^{\circ}$ Brix, la $\mathrm{a}_{\mathrm{w}}$, la acidez total, los fenoles totales y la actividad antioxidante.

\section{VI.4.3.1 Medida de la actividad enzimática}

Para la selección y puesta a punto de los métodos de medida de la actividad enzimática se trabajó con uva fresca y escaldada por inmersión en agua a $100{ }^{\circ} \mathrm{C}$ durante $3 \mathrm{~min}$.

\section{VI.4.3.1.1 Polifenoloxidasa (PPO)}

En este trabajo, para el análisis enzimático de la PPO, se probaron dos procedimientos: el descrito por Rapeanu et al. (2006) y el descrito por De Pieri et al. (2003). 
a).- Determinación de la PPO mediante el método propuesto por Rapeanu et al. (2006)

Para la determinación de la PPO mediante este método, la extracción de la enzima se llevó a cabo por dos procedimientos diferentes: uno en el que se purifica parcialmente la enzima y otro con una extracción directa del zumo de uva. En todas las extracciones se usó hielo para atenuar las reacciones de oxidación y enzimáticas naturales de la uva. El análisis se realizó por triplicado.

\section{Extracción y purificación parcial de la enzima PPO}

La extracción de la enzima PPO se llevó a cabo utilizando una modificación del método de Valero et al. (1998). Las uvas (250g) se suspendieron en $125 \mathrm{ml}$ de tampón McIlvaine ( $\mathrm{pH} \mathrm{5)} \mathrm{y} \mathrm{se} \mathrm{mezclaron}$ durante 15 segundos en una batidora convencional. La mezcla homogeneizada fue filtrada a través de un filtro de algodón y el filtrado obtenido centrifugado durante $15 \mathrm{~min}\left(4000 \mathrm{~g}, 4^{\circ} \mathrm{C}\right)$. El precipitado resultante fue extraído durante $1 \mathrm{~h} \mathrm{a} 4^{\circ} \mathrm{C}$ y 15000 g con Triton X-100 al 1,5\% y PVP insoluble al $2.0 \%$ en el tampón McIlvaine ( $\mathrm{pH} 5)$. El sobrenadante resultante fue sometido a precipitación con sulfato de amonio. La fracción precipitada entre el 30\% y el $90 \%$ de saturación fue redisuelta en el mismo tampón y dializada durante $24 \mathrm{~h}$ con una membrana de celulosa (Medicell International, L.t.d.) para quitar el exceso de sulfato de iones amonio. Las muestras dializadas se mantuvieron en tubos a $-80^{\circ} \mathrm{C}$ y se utilizaron como fuente de enzima PPO en posteriores experimentos. La extracción se realizó por triplicado. 


\section{Capítulo VI}

Extracción directa (Rapeanu et al. 2006)

$100 \mathrm{~g}$ de uva fueron homogeneizados y filtrados por una tela de algodón. El filtrado fue clarificado a $4^{\circ} \mathrm{C}$ durante 24 horas y utilizado como fuente enzimática para la determinación correspondiente. La extracción se realizó por triplicado

\section{Análisis}

El ensayo de actividad PPO se llevó a cabo mediante un método espectrofotométrico (UV-visible Thermo Spectronic). El incremento de la absorbancia a 400nm fue registrado cada 60 segundos durante 20 minutos. La muestra contenía $1 \mathrm{ml}$ de substrato (catecol $10 \mathrm{mM}$ en tampón McIlvaine $\mathrm{pH}=5$ cuando la muestra fue extraída y purificada, y catecol 0,1M en tampón McIlvaine $\mathrm{pH}=5$ para la muestra de extracción directa) y $100 \mu 1$ de extracto. El blanco solo contenía $1 \mathrm{ml}$ de tampón McIlvaine $\mathrm{pH}=5$. La actividad enzimática fue calculada a partir de la pendiente obtenida de la parte lineal de la curva de la absorbancia a 400 nm v.s. tiempo de incubación. El análisis se realizó por triplicado.

En todos los casos la actividad enzimática residual (AR) se calculó a partir de la ecuación 2:

$$
A R=100 * \frac{A_{t}}{A_{0}}
$$

Donde $\mathrm{A}_{\mathrm{t}}$ y $\mathrm{A}_{0}$ fueron las actividades enzimáticas de la fruta procesada y fresca respectivamente. 
b).- Determinación de la PPO mediante el método propuesto por De Pieri et al. (2003).

Siguiendo el método de McLellan y Robinson (1984) para coles de Bruselas y zumo de naranja, respectivamente, modificados por De Pieri et al. (2003) para la extracción de la PPO en uva, se pesaron 300g de uva y se homogeneizaron durante un minuto en $100 \mathrm{ml}$ de tampón fosfato (100mM, pH 6.0), usando una batidora convencional. La suspensión resultante fue centrifugada a $17000 \mathrm{~g}$ durante $20 \mathrm{~min}$ a $4^{\circ} \mathrm{C}$. El sobrenadante, designado como un extracto soluble enzimático, fue recogido. Para obtener el extracto de las enzimas iónicamente ligadas, el residuo remanente tras la extracción de la fracción soluble fue resuspendida en una disolución de $100 \mathrm{ml}$ de $\mathrm{NaCl}$ (4g) en el tampón fosfato $(100 \mathrm{mM}, \mathrm{pH} 6.0)$ y centrifugado a $17000 \mathrm{~g}$ durante $20 \mathrm{~min}$ a $4^{\circ}$ C. El fluido sobrenadante fue recogido. El sobrenadante que contenía la fracción soluble y la fracción iónica ligada fue mezclado y almacenado a $-18^{\circ} \mathrm{C}$ para su posterior análisis.

De Pieri et al. (2003) proponen determinar la actividad polifenoloxidásica mediante una modificación del método descrito por Siddiq et al. (1992) en el que se determina el aumento de la absorbancia a $420 \mathrm{~nm}$ durante 5 minutos a intervalos de 30 segundos en un espectrofotómetro (UV1 Thermo Spectronic). La mezcla reactiva estándar consistió en 3,4 ml de tampón fosfato $100 \mathrm{mM}$ (pH 6) 0,4 ml de catecol y $0,2 \mathrm{ml}$ del extracto enzimático.

La actividad enzimática fue definida como el cambio de absorbancia a $420 \mathrm{~nm}$ del extracto enzimático de la uva. En todos los casos la 


\section{Capítulo VI}

actividad enzimática residual (AR) se calculó a partir de la ecuación 2 antes mencionada. Las determinaciones re realizaron por triplicado.

\section{VI.4.3.1.2 Peroxidasa}

Para el análisis enzimático de la POD se probaron dos procedimientos diferentes: uno propuesto por De Pieri et al. (2003) y otro propuesto por Elez-Martínez et al. (2006).

a).- Determinación de la POD mediante el método propuesto por De Pieri et al. (2003)

La extracción de la enzima se realizó tal y como se ha descrito en el inciso b del punto VI.4.3.1.1, la cual es válida para el análisis de ambas enzimas. Para la determinación de la actividad enzimática se midió la oxidación de la $o$-dianisidina (Fluka) a 460nm (UV1 Thermo Spectronic) de acuerdo con el método descrito por Clemente (1998). Las medidas de absorbancia se determinaron durante 5 minutos a intervalos de 30 segundos. La mezcla reactiva estándar se componía de $2,7 \mathrm{ml}$ de $\mathrm{H}_{2} \mathrm{O}_{2}$ al 0,03\% en tampón fosfato $0,1 \mathrm{M}(\mathrm{pH}=6), 0,1 \mathrm{ml}$ de $o$-dianisidina al $1 \%$ (w/v) en $\mathrm{H}_{2} \mathrm{O}$ y $0,2 \mathrm{ml}$ del extracto enzimático obtenido según De Pieri et al. (2003). La actividad de la peroxidasa se determinó midiendo la velocidad inicial de la reacción, es decir, midiendo la pendiente de la parte lineal de la curva obtenida en la representación de la absorbancia frente al tiempo.

La unidad de actividad de la POD se definió como el cambio de absorbancia a $460 \mathrm{~nm}$ del extracto enzimático de la uva. El porcentaje de 
actividad residual de la POD (AR) se definió como indica la ecuación 2. Los análisis se efectuaron por triplicado.

b).- Determinación de la POD mediante el método propuesto por ElezMartínez et al. (2006).

La extracción de la enzima peroxidasa se realizó mediante una ligera modificación del método descrito por Elez-Martínez et al (2006). Se mezclaron $10 \mathrm{~g}$ de zumo de uva con $20 \mathrm{ml}$ de tampón fosfato 0,2M $(\mathrm{pH}=6,5)$. A continuación se centrifugó la muestra a 20000g durante 15 minutos a $4^{\circ} \mathrm{C}$, se filtro a través de papel Whatman $\mathrm{N}^{\circ} 1$ y se almacenó a $-20^{\circ} \mathrm{C}$ hasta su utilización (máximo 24 horas). Durante todo el proceso de extracción la muestra se mantuvo a una temperatura menor de $4^{\circ} \mathrm{C}$. La actividad POD se llevo a cabo con un espectrofotómetro UV-visible Thermo Spectronic a $485 \mathrm{~nm}$. Se agregaron $2,7 \mathrm{ml}$ de tampón fosfato $0,05 \mathrm{M}, 0,2 \mathrm{ml}$ de reactivo $p$-fenilendiamina $\left(10 \mathrm{gkg}^{-1}\right)$ como donador de hidrogeno, $0,1 \mathrm{ml}$ de peróxido de hidrogeno $\left(15 \mathrm{gkg}^{-1}\right)$ como oxidante y $0,1 \mathrm{ml}$ de extracto en una cubeta de $1 \mathrm{~cm}$. La oxidación de la $p$ fenilendiamina se midió a $485 \mathrm{~nm}$ y $25^{\circ} \mathrm{C}$. La actividad POD se determinó midiendo la velocidad inicial de reacción la cual fue calculada de la parte lineal de la curva obtenida al representar la absorbancia vs. tiempo. Una unidad de actividad POD se definió como el cambio en la absorbancia a $485 \mathrm{~nm}$ de extracto enzimático. El porcentaje de actividad POD residual fue definido como indica la ecuación 2. Todos los análisis se realizaron por triplicado. 


\section{Capítulo VI}

\section{VI.4.3.1.3 Pectinmetilesterasa}

Para la puesta a punto y selección del método de análisis de la actividad de la pectinmetilesterasa se utilizaron dos métodos: el propuesto por Kimball (1999) y el que propone Carbonell et al. (2006).

a).- Determinación de la PME mediante el Método Kimball (1999)

La actividad PME se determinó con una ligera modificación del método descrito por Kimball (1999). El método se basa en la medida de los grupos carboxílicos de la pectina liberados por efecto de la actividad enzimática del zumo. La determinación de la muestra se realizó en un baño a $30^{\circ} \mathrm{C}$. Se mezclaron $10 \mathrm{~g}$ de zumo de uva y $40 \mathrm{ml}$ de pectina previamente atemperados a $30^{\circ} \mathrm{C}$ (en nuestro caso de cáscara de Fluka al $0,5 \%)$. Se neutraliza la mezcla con $\mathrm{NaOH} 1 \mathrm{~N}$ y $\mathrm{NaOH} 0,05$ hasta llegar a un $\mathrm{pH}$ próximo a 7,5. Inmediatamente después se adicionaron $100 \mu 1 \mathrm{de}$ $\mathrm{NaOH} 0,05 \mathrm{~N}$ y se cronometró el tiempo que tarda en alcanzar el pH anterior a la adición de los $100 \mu 1(7,5)$.

Las determinaciones se realizaron por triplicado. Para la obtención de las unidades de PME (PEU) se utilizó la ecuación 3.

$$
P E U=\frac{m l \mathrm{NaOH} \times \mathrm{N} \text { de la } \mathrm{NaOH}}{g \text { de muestra }(\mathrm{ml}) \times \text { Tiempo }(\min )}
$$

b).- Determinación de la PME mediante el método propuesto por Carbonell et al. (2006)

Tanto para las muestras frescas como para las tratadas, la actividad PME fue determinada siguiendo el método propuesto por Carbonell et 
al., (2006). Las muestras de zumo $(10 \mathrm{ml})$ fueron ajustadas a pH 7.8 con $\mathrm{NaOH}(1 \mathrm{~N}$ y $0,05 \mathrm{~N})$ y se mezclaron con $20 \mathrm{ml}$ de $\mathrm{NaCl} 0,2 \mathrm{M}$ y pectina al $0,5 \%$ previamente preparada y ajustada con anterioridad al mismo $\mathrm{pH}$. El descenso del $\mathrm{pH}$ causado por los grupos carboxílicos generado por la PME durante la desesterificación de la disolución péctica a $\mathrm{pH}$ 7.8 y temperatura ambiente $\left(22^{\circ} \mathrm{C}\right)$ fue anotada cada 30 segundos durante 30 minutos.

La pendiente inicial de la curva de evolución del $\mathrm{pH}$ frente al tiempo de incubación se consideró la actividad PME. En todos los casos la actividad enzimática residual (AR) se calculó a partir de la ecuación 2. Todas las determinaciones se realizaron por triplicado.

\section{VI.4.3.2 Color}

El color se determinó a partir de las coordenadas CIEL*a*b* obtenidas con un fotocolorímetro Minolta CM-1000R (Minolta Co. Ltd., Osaka, Japón), con observador $10^{\circ}$ e iluminante D65. En el momento de la medición, la muestra fue cubierta con un vidrio óptico de baja reflectancia CR-A51/1829-752 (Minolta Co. Ltd.) para evitar el deterioro de la esfera integradora. Estas mediciones se realizaron en la capa externa de la fruta y en su zona ecuatorial. El valor de $L^{*}$ indica la luminosidad de la muestra que puede tomar valores entre 0 y $100, a^{*}$ indica la cantidad de color rojo/verde, mientras que $b^{*}$ indica el color amarillo/azul. Con los valores $L^{*}, a^{*}, b^{*}$, se calculó el Croma $\left(C^{*} a b\right)$ y el tono $(h * a b)$, mediante las ecuaciones 4 y 5 , respectivamente.

$$
C * a b=\sqrt{a^{* 2}+b^{* 2}}
$$


Capítulo VI

$$
h^{*} a b=\operatorname{arctg} \frac{b^{*}}{a^{*}}
$$

\section{VI.4.3.3 Propiedades mecánicas}

Para el análisis de las propiedades mecánicas se utilizó el Texturometro de Stable Micro Systems modelo TEXTURE ANALYZER-TA-XT2 (Surrey, Inglaterra). Se realizó sobre la fruta un ensayo con un punzón de $6 \mathrm{~mm}$ de diámetro. La deformación impuesta fue del $95 \%$ a una velocidad de $2 \mathrm{~mm} / \mathrm{s}$. De la curva obtenida se analizaron los parámetros de fuerza máxima, fuerza de fractura y la pendiente de la parte recta inicial de la curva. La figura 17 muestra un ejemplo que indica la forma de obtener los parámetros evaluados a partir de la curva fuerza-deformación obtenida del ensayo.

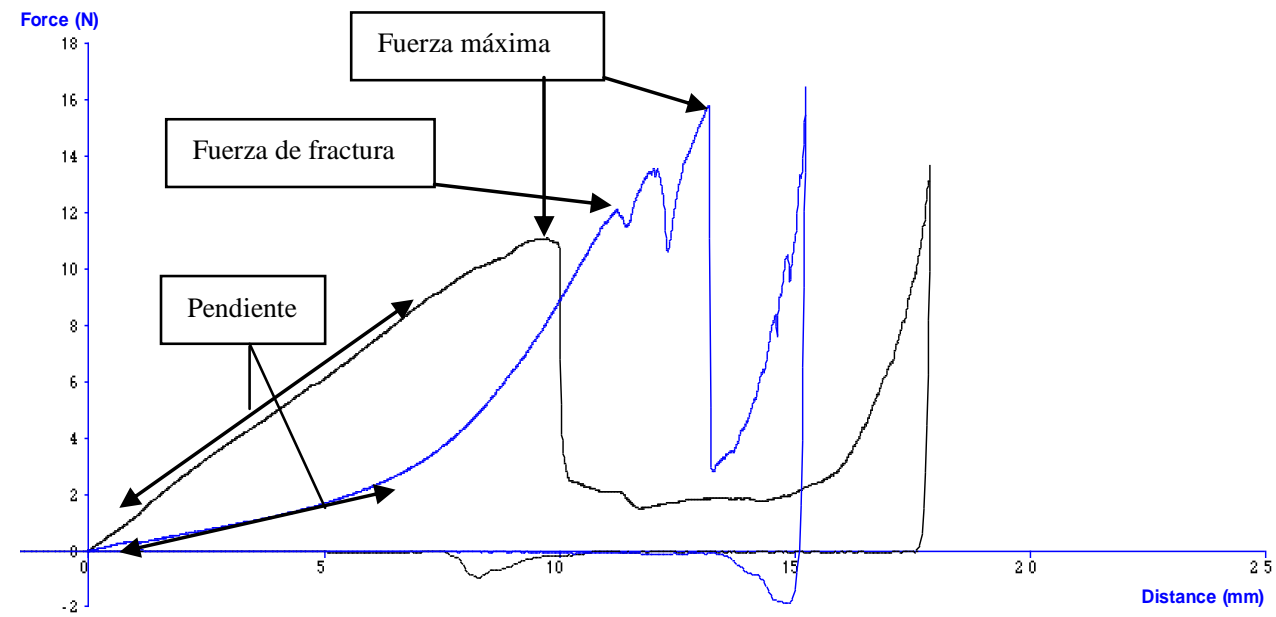

Figura 17. Parámetros evaluados en los análisis de textura a partir de las curvas fuerza-deformación obtenidos del ensayo de punción en las uvas. 
UVAS EN ALMÍBAR

\section{VI.5 RESULTADOS}

\section{VI.5.1 Selección de los métodos de análisis enzimático.}

Puesto que uno de los objetivos del trabajo es poner a punto el método de análisis de la actividad enzimática y debido a que la bibliografía es bastante amplia en este sentido, se probaron distintos procedimientos para la determinación de PPO, POD y PME para muestras frescas y para muestras escaldadas a $100^{\circ} \mathrm{C}$ durante 3 minutos. Se escogió el tratamiento de escaldado más fuerte de los que se probaron para que la inactivación fuese detectada sin problemas.

\section{VI.5.1.1. Polifenoloxidasa}

La actividad enzimática PPO se analizó por su importancia a la hora de estudiar reacciones implicadas en la oxidación de compuestos fenólicos que, como sabemos, se encuentran abundantemente en la uva. Se utilizaron dos métodos diferentes: el método descrito por Rapeanu et al. (2006) y el descrito por De Pieri et al. (2003). La actividad enzimática PPO se obtuvo de la pendiente de las curvas absorbancia/tiempo obtenidas de las medidas espectrofotométricas a 400 nm (Rapeanu et al., 2006) y a $420 \mathrm{~nm}$ (De Pieri et al., 2003), tanto para muestras frescas como para la escaldada, a $100^{\circ} \mathrm{C}$, durante 3 minutos. En la figura 18 se muestra un ejemplo de una de las gráficas absorbancia/tiempo obtenidas para el análisis de actividad PPO en uva fresca (UF) y escaldada tradicionalmente ( $\left.\mathrm{UE}_{3 \mathrm{~min}}\right)$. 


\section{Capítulo VI}

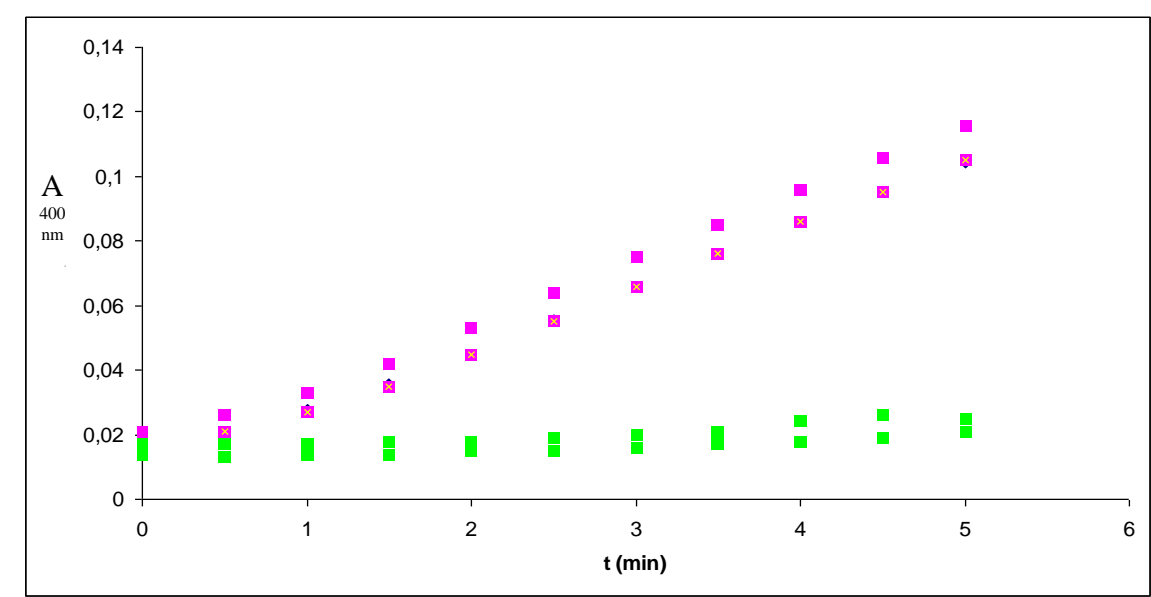

Figura 18. Valor de absorbancia frente a tiempo de la PPO analizada mediante el método propuesto por Rapeanu et al. (2006), con fruta fresca (") y fruta escaldada tradicionalmente durante 3 min ("). Las diferentes rectas del mismo color se corresponden con repeticiones.

Como se puede observar, la pendiente de la recta obtenida de las muestras frescas es mayor que en las muestras escaldadas, es decir, se produce una disminución importante de ésta, lo cual significa una disminución importante de la actividad enzimática.

En la tabla 10 se muestran las unidades de actividad enzimática (UA) de la polifenoloxidasa tanto en la fruta fresca como en la fruta escaldada tradicionalmente durante 3 minutos a $100^{\circ} \mathrm{C}$ obtenidas a partir de los dos métodos utilizados, además del porcentaje de inactivación obtenido después del escaldado a partir de la UA de la uva fresca. 
Tabla 10. Unidades de actividad enzimática (UA) de la polifenoloxidasa en uva fresca (UF) y escaldada a $100^{\circ} \mathrm{C}$ durante 3 minutos $\left(\mathrm{UE}_{3 \min }\right)$ en función del método de análisis aplicado. Porcentaje de inactivación de la enzima por efecto del tratamiento.

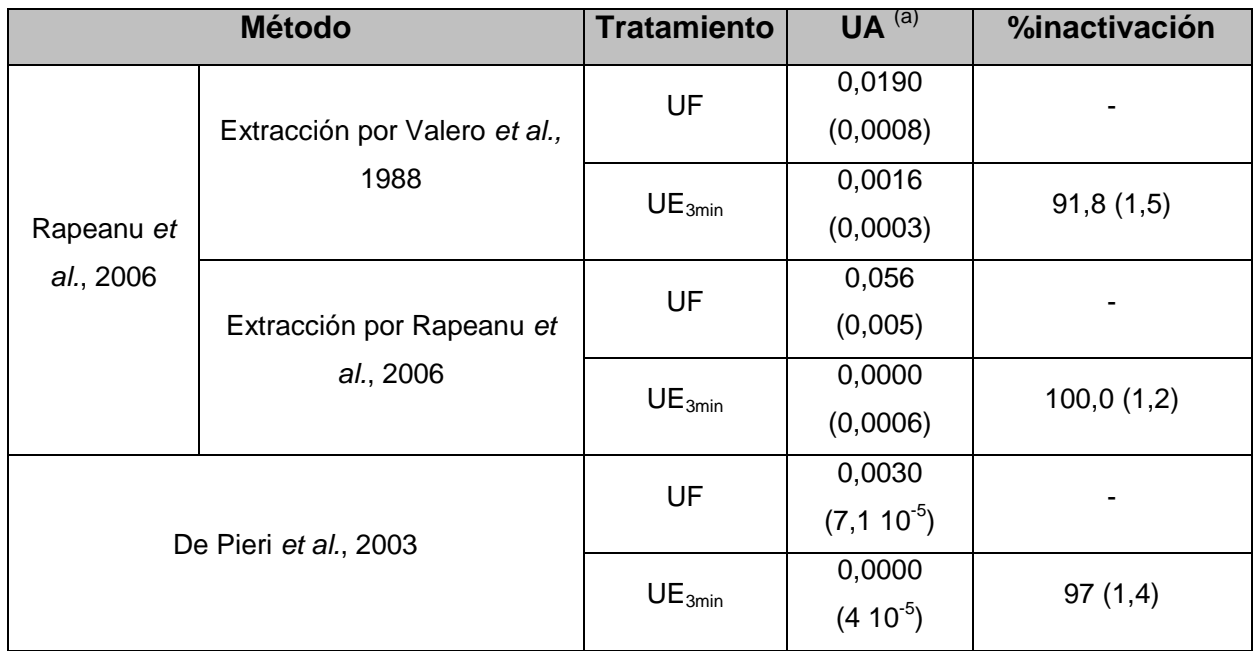

(a)Desviación estándar menor de 0,0005

Los resultados obtenidos para los dos métodos se pueden considerar aceptables al compararlos con la bibliografía. La variabilidad de la fruta fresca en cuanto a la actividad enzimática ha sido descrita por diversos autores (Elez-Martínez et al., 2006; Rapeanu et al., 2006; Snir et al., 1996) y los datos obtenidos son del mismo orden. Sin embargo, el método de Rapeanu et al. (2006), tanto para la extracción como para la determinación es el más simple en cuanto a su ejecución. La modificación que aplican estos autores basada en lo propuesto por Valero et al. (1988) para la extracción supone el empleo de una gran cantidad de tiempo (de 4 a 5 horas para la obtención de un volumen de extracto mínimo) y además obtenemos la enzima totalmente purificada, hecho que no es importante cuando lo que queremos es calcular la 


\section{Capítulo VI}

actividad residual enzimática. El método de De Pieri et al. (2003) es más costoso también en cuanto a ejecución y los resultados no son tan regulares como con el de Rapeanu et al. (2006). Por estos motivos se seleccionó el método propuesto por Rapeanu et al. (2006) para las siguientes determinaciones de la PPO.

\section{VI.5.1.2. Peroxidasa}

La actividad enzimática de la POD también se determinó mediante diferentes procedimientos en uva fresca y escaldada en las mismas condiciones descritas para la PPO ( $100^{\circ} \mathrm{C}, 3$ minutos $)$. Se aplicaron también dos métodos diferentes: el método descrito por De Pieri et al. (2003) y el descrito por Elez-Martínez et al., (2006). La actividad enzimática POD se obtuvo de la pendiente de las curvas absorbancia/tiempo obtenidas a $460 \mathrm{~nm}$ (De Pieri et al., 2003) y a 485 nm (Elez-Martínez et al., 2006), tanto para muestras frescas como para las escaldadas (Tabla 11). La figura 19 muestra un ejemplo de la relación absorbancia/tiempo para el análisis de actividad POD en fruta fresca (UF) y en fruta escaldada tradicionalmente 3 minutos ( $\left.\mathrm{UE}_{3 \mathrm{~min}}\right)$. 


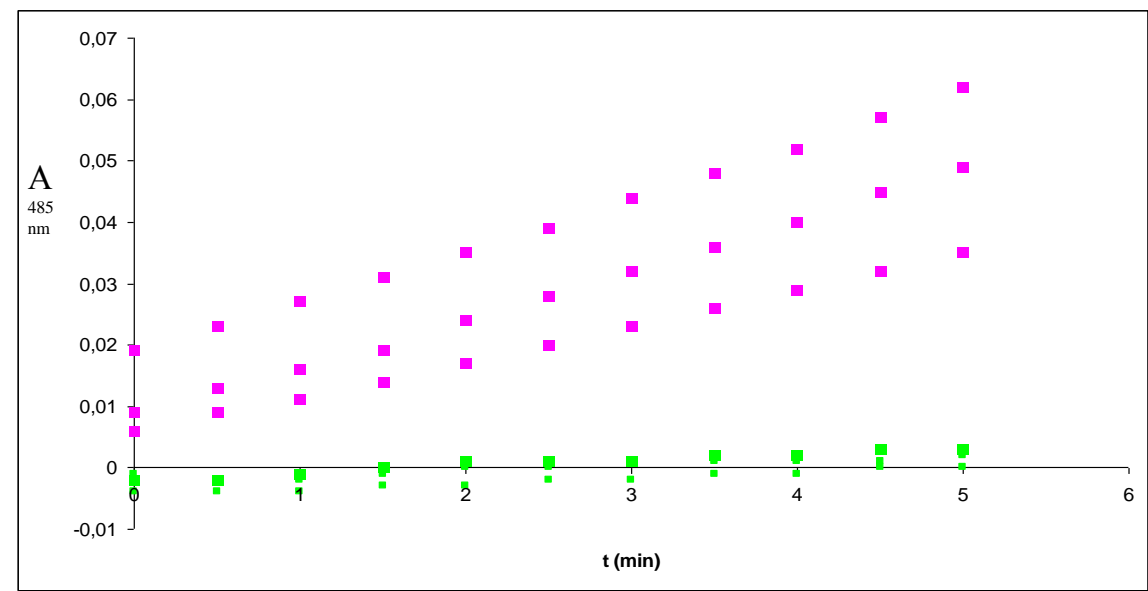

Figura 19. Valores de absorbancia frente a tiempo de la POD analizada mediante el método propuesto por Elez-Martínez (2006) con fruta fresca (") y fruta escaldada tradicionalmente durante 3 minutos (").Las diferentes rectas del mismo color se corresponden con repeticiones.

De la misma forma que pasaba con los resultados obtenidos en el análisis de la PPO, la pendiente correspondiente a las muestras escaldadas disminuye considerablemente si las comparamos con las correspondientes a las muestras frescas. Es decir, que el escaldado produce la inactivación esperada. 


\section{Capítulo VI}

Tabla 11. Unidades de actividad enzimática (UA) de la peroxidasa en uva fresca (UF) y escaldado a $100^{\circ} \mathrm{C}$ durante 3 minutos $\left(\mathrm{UE}_{3 \min }\right)$ en función del método de análisis aplicado. Porcentaje de inactivación de la enzima por efecto del tratamiento.

\begin{tabular}{|c|c|c|c|}
\hline Método & Tratamiento & UA $^{(a)}$ & \%inactivación \\
\hline \multirow{2}{*}{$\begin{array}{c}\text { De Pieri et al., } \\
2003\end{array}$} & UF & $0,009(0,008)$ & - \\
\cline { 2 - 4 } & $\mathrm{UE}_{3 \min }$ & $0,003(0,002)$ & $65(26)$ \\
\hline \multirow{2}{*}{$\begin{array}{c}\text { Elez-Martínez } \\
\text { et al., } 2006\end{array}$} & UF & $0,0150(0,005)$ & - \\
\cline { 2 - 4 } & $\mathrm{UE}_{3 \min }$ & $0,0018\left(7,110^{-5}\right)$ & $88.6(0,5)$ \\
\hline
\end{tabular}

Los resultados obtenidos al utilizar el método de De Pieri et al. (2003) mostraron una variabilidad muy alta. Esto probablemente esté relacionado con que en el procedimiento de análisis se utiliza un reactivo (o-dianisidine) difícil de manejar por su insolubilidad que, a su vez, está considerado una sustancia carcinogénica y mutógena de $2^{\mathrm{a}}$ categoría, es decir, que su exposición puede provocar cáncer. Además, el \% de inactivación detectado con este método es bajo si se compara con los resultados de la bibliografía. Por todo esto, para las siguientes determinaciones de la actividad POD se seleccionó el método descrito por Elez-Martínez et al. (2006).

\section{VI.5.1.3. Pectinmetilesterasa}

Para la determinación de la actividad enzimática de la PME también se ensayaron dos métodos diferentes en la uva fresca (UF) y en la uva escaldada a $100^{\circ} \mathrm{C}$ durante $3 \mathrm{~min}$. En este caso, los análisis se realizaron sobre uvas de diferentes variedades (Festival, Moscatel, Aledo) para 
estudiar la influencia de ésta sobre la actividad e inactivación de esta enzima.

La tabla 12 muestra los resultados obtenidos de los análisis de PME para las diferentes variedades de uvas antes y después del tratamiento de escaldado mediante los dos métodos de análisis estudiados (Kimball, 1999 y Carbonell et al., 2006). No se observaron diferencias significativas en la actividad de esta enzima en las diferentes variedades de uva analizadas.

Tabla 12. Unidades de actividad enzimática (UA) de la pectinmetilesterasa en uva fresca (UF) de las variedades Aledo, Festival y Moscatel y escaldado a $100^{\circ} \mathrm{C}$ durante 3 minutos $\left(\mathrm{UE}_{3 \min }\right)$ en función del método de análisis aplicado. Porcentaje de inactivación de la enzima por efecto del tratamiento.

\begin{tabular}{|c|c|c|c|c|}
\hline Método & Variedad & Tratamiento & UA (a) $^{(a)}$ & \%inactivación \\
\hline \multirow{6}{*}{ Kimball, 1999} & \multirow{2}{*}{ Festival } & UF (PEU) & $8,710^{-7}\left(1,710^{-7}\right)$ & - \\
\hline & & $\mathrm{UE}_{3 \min }(\mathrm{PEU})$ & $1,610^{-7}\left(6,510^{-8}\right)$ & $81(7)$ \\
\hline & \multirow[b]{2}{*}{ Moscatel } & UF (PEU) & $9,410^{-7}\left(5,210^{-8}\right)$ & - \\
\hline & & $\mathrm{UE}_{3 \min }(\mathrm{PEU})$ & $\begin{array}{c}2,910^{-7} \\
\left(3,610^{-8}\right) \\
\end{array}$ & $79(4)$ \\
\hline & \multirow{2}{*}{ Aledo } & UF (PEU) & $\begin{array}{c}7,310^{-7} \\
\left(1,310^{-7}\right)\end{array}$ & - \\
\hline & & $\mathrm{UE}_{3 \min }(\mathrm{PEU})$ & $\begin{array}{c}1,910^{-7} \\
\left(7,910^{-8}\right) \\
\end{array}$ & $78(11)$ \\
\hline \multirow{2}{*}{ Carbonell et al., 2006} & \multirow{2}{*}{ Festival } & UF (nanokatales) & $\begin{array}{c}1,510^{-10} \\
\left(2,810^{-11}\right) \\
\end{array}$ & - \\
\hline & & $\mathrm{UE}_{3 \min }$ (nanokatales) & $\begin{array}{c}5,010^{-11} \\
\left(1,210^{-11}\right)\end{array}$ & $69(8)$ \\
\hline
\end{tabular}

No podemos comparar los datos obtenidos mediante los dos métodos ensayados con la bibliografía, ya que no se han encontrado datos para uva. Sin embargo, el método de Carbonell et al. (2006) es algo más costoso en su ejecución, ya que requiere el atemperado y el ajuste del $\mathrm{pH}$ por separado, siendo más difícil la determinación enzimática. Además, 


\section{Capítulo VI}

proporciona porcentajes de inactivación menores. Por esta razón, para las determinaciones posteriores se escogió el método de Kimball (1999).

\section{VI.5.2. Selección de los métodos de escaldado}

Los tratamientos utilizados para escaldar la uva fueron el escaldado tradicional a $100{ }^{\circ} \mathrm{C}$ durante diferentes tiempos y el escaldado con microondas, en diferentes condiciones de tiempo y potencia, en seco y en agua. Los análisis de PPO, POD y PME, se realizaron mediante los métodos seleccionados de Rapeanu et al. (2006), Elez-Martínez et al., 2006 y Kimball (1999), respectivamente. El análisis de la actividad enzimática se utilizó como indicador para la selección del tratamiento de escaldado.

\section{VI.5.2.1. Escaldado tradicional}

La tabla 13 muestra los valores de \% de inactivación de las 3 enzimas para el escaldado tradicional en diferentes condiciones de tiempo y temperatura.

Tabla 13. Porcentaje de inactivación de las enzimas PPO, POD y PME en uva después de un tratamiento de escaldado tradicional en diferentes condiciones de tiempo y temperatura.

\begin{tabular}{|c|c|c|c|c|}
\hline \multirow{2}{*}{$\mathbf{T}_{\text {escaldado }}$} & tescaldado & $\begin{array}{c}\text { \%inactivación } \\
\text { PPO }\end{array}$ & $\begin{array}{c}\text { \%inactivación } \\
\text { POD }\end{array}$ & $\begin{array}{c}\text { \%inactivación } \\
\text { PME }\end{array}$ \\
\hline $100^{\circ} \mathrm{C}$ & $1 \mathrm{~min} 30 \mathrm{~s}$ & - & $52(17)$ & $29(4)$ \\
\hline $100^{\circ} \mathrm{C}$ & $2 \min$ & $58(20)$ & $47(17)$ & $44(3)$ \\
\hline \multirow{2}{*}{$100^{\circ} \mathrm{C}$} & $2 \min 30 \mathrm{~s}$ & $98,4(1,4)$ & $70(9)$ & $79(8)$ \\
\cline { 2 - 5 } & $3 \min$ & $100(1,2)$ & $78(6)$ & $92(3)$ \\
\hline
\end{tabular}


En general, el tratamiento inactiva un porcentaje mayor de las tres enzimas cuanto mayor es la temperatura y el tiempo de permanencia de la uva en éste. En la mayor parte de los tratamientos se observa que la POD es la más resistente a la temperatura, sin que llegue a sobrepasar el $78 \%$ de inactivación. Burnette, en 1977, describe esta resistencia térmica de la enzima y Carbonero, en 1975, describe su utilización como indicadora en la efectividad microbiológica del escaldado.

Por otro lado, la inactivación más alta fue la de la PPO, que llega hasta un $100 \%$ en el caso del escaldado más drástico $\left(100^{\circ} \mathrm{C}, 3 \mathrm{~min}\right)$. Esto es importante ya que la PPO es la enzima que está más implicada en la reacción de oxidación y la máxima causante del pardeamiento enzimático. Por tanto, es la enzima que más interés tendríamos que tener en inactivar.

La PME mostró un comportamiento intermedio. La inactivación después del tratamiento a $100^{\circ} \mathrm{C}$ y $2 \mathrm{~min} 30$ s ó 3 min está entre un 7992\%. Esta enzima, aunque es más importante en el sector de los zumos de frutas, porque produce enturbiamiento, gelación y pérdidas de la "nube" coloidal, provoca en la uva el ablandamiento de la fruta, disminuyendo su elasticidad, sobre todo en el almacenamiento.

En base a lo anterior, el tratamiento a $100{ }^{\circ} \mathrm{C}$ durante dos minutos y medio parece suficiente para el producto considerado.

\section{VI.5.2.2. Escaldado con microondas mediante calentamiento directo.}

En la tabla 14 se muestran los datos de inactivación enzimática de la PPO, POD y PME de las muestras tratadas con microondas a diferentes 


\section{Capítulo VI}

potencias y tiempos. Estas muestras fueron tratadas en seco con malla, tal y como se describe en el punto VI.4.2.

En la mayoría de los casos se observa que, al aumentar las condiciones de tiempo y potencia en el microondas, la actividad enzimática disminuye, aunque no es suficiente, ya que sólo se llega a porcentajes de inactivación de 67, 67 y 40 para la PPO, POD y PME, respectivamente, en las condiciones estudiadas más agresivas $(900 \mathrm{~W}$, $30 \mathrm{~s})$.

Tabla 14. Porcentaje de inactivación de las enzimas PPO, POD y PME de la uva después de un tratamiento de escaldado con microondas en diferentes condiciones de tiempo y potencia.

\begin{tabular}{|c|c|c|c|c|}
\hline $\mathbf{P}_{\text {escaldado }}$ & $\mathbf{t}_{\text {escaldado }}$ & $\begin{array}{c}\text { \% inactivación } \\
\text { PPO }\end{array}$ & $\begin{array}{c}\text { \% inactivación } \\
\text { POD }\end{array}$ & $\begin{array}{c}\text { \% inactivación } \\
\text { PME }\end{array}$ \\
\hline \multirow{2}{*}{ 300W } & $45 \mathrm{~s}$ & $34.0(1,6)$ & $40(10)$ & $34(3)$ \\
\hline \multirow{2}{*}{$500 \mathrm{~W}$} & $30 \mathrm{~s}$ & $21.0(1,2)$ & $49(15)$ & $18(4)$ \\
\cline { 2 - 5 } & $45 \mathrm{~s}$ & $30.0(0,4)$ & $47(15)$ & $33(12)$ \\
\hline \multirow{2}{*}{$700 \mathrm{~W}$} & $30 \mathrm{~s}$ & $80.0(0,2)$ & $51(9)$ & $41(7)$ \\
\cline { 2 - 5 } & $45 \mathrm{~s}$ & $74.0(0,6)$ & $59(7)$ & $24(6)$ \\
\hline 900W & $30 \mathrm{~s}$ & $67.0(0,4)$ & $67(9)$ & $40(2)$ \\
\hline
\end{tabular}

En las muestras tratadas de esta manera se desgarró la piel por completo y muchas de las uvas perdieron el zumo (entre algunos de los efectos indeseables de este escaldado). Por otra parte se observaron diferencias de temperatura en las bayas de la misma variedad y en la misma tanda de escaldado, de hasta $20^{\circ} \mathrm{C}$. Esto puede ser debido a la variabilidad del impacto de las microondas que actúan sin la barrera del agua (mediante calentamiento directo). Estas diferencias de temperatura 
justificarían la alta variabilidad observada en el porcentaje de inactivación enzimática conseguida con los tratamientos. Por todo lo anterior, se desestimó este procedimiento de calentamiento directo de la uva en el microondas para su escaldado.

\section{VI.5.2.3 Escaldado en agua con microondas}

En base a los experimentos anteriores realizados en seco, y teniendo en cuenta la insuficiente inactivación térmica y la degradación del producto después del tratamiento, se buscó la posibilidad de utilizar un conductor de las microondas que mejorara el proceso, tal como lo es el agua. En la tabla 15 se muestran los resultados obtenidos para las muestras tratadas a $900 \mathrm{~W}$ durante 2 minutos 50 segundos y 3 minutos.

Tabla 15. Porcentaje de inactivación de las enzimas PPO, POD y PME en uva después de un tratamiento de escaldado con microondas a 900W e inmersión en agua en diferentes condiciones de tiempo.

\begin{tabular}{|c|c|c|c|c|}
\hline \multirow{2}{*}{$\mathbf{P}_{\text {escaldado }}$} & $\mathbf{t}_{\text {escaldado }}$ & $\begin{array}{c}\text { \% inactivación } \\
\text { PPO }\end{array}$ & $\begin{array}{c}\text { \% inactivación } \\
\text { POD }\end{array}$ & $\begin{array}{c}\text { \% inactivación } \\
\text { PME }\end{array}$ \\
\hline \multirow{2}{*}{$900 \mathrm{~W}$} & $2 \min 50 \mathrm{~s}$ & $98,4(0,6)$ & $70(3)$ & $83,1(0,9)$ \\
\cline { 2 - 5 } & $3 \min$ & $91,8(1,5)$ & $93(3)$ & $80(2)$ \\
\hline
\end{tabular}

Como puede observarse, prácticamente no hay diferencias en función del tiempo, llegando la inactivación alcanzada en los dos tratamientos por las 3 enzimas a valores por encima del $80 \%$. La mayor resistencia térmica fue la POD, que además es la actividad enzimática crítica para la uva. Por ello se seleccionó el tratamiento más suave como 


\section{Capítulo VI}

más adecuado a fin de provocar el menor daño posible en otros componentes termolábiles de la uva.

\section{VI.5.3 Comparación de los métodos de escaldado.}

La tabla 16 presenta un resumen de los resultados de inactivación de la PPO, la POD y la PME de las muestras escaldadas a $100^{\circ} \mathrm{C}$ y a 900 W.

Tabla 16. Resumen de los porcentajes de inactivación en cada una de las tres enzimas (PPO, POD y PME) alcanzados con los métodos de escaldado tradicional $\left(\mathrm{E}_{\mathrm{T}}\right)$ y por microondas con la muestra sumergida en agua $\left(\mathrm{E}_{\mathrm{MW}}\right)$.

\begin{tabular}{|c|c|c|c|c|}
\hline & Tratamiento & $\begin{array}{c}\text { \%inactivación } \\
\text { PPO }\end{array}$ & $\begin{array}{c}\text { \%inactivación } \\
\text { POD }\end{array}$ & $\begin{array}{c}\text { \%inactivación } \\
\text { PME }\end{array}$ \\
\hline \multirow{2}{*}{$E_{T}$} & $100^{\circ} \mathrm{C}, 2 \min 30 \mathrm{~s}$ & $98,4(1,4)$ & $70(9)$ & $79(8)$ \\
\cline { 2 - 5 } & $100^{\circ} \mathrm{C}, 3 \min$ & $100,0(1,2)$ & $78(6)$ & $92(3)$ \\
\hline \multirow{2}{*}{$\mathrm{E}_{\mathrm{MW}}$} & $900 \mathrm{~W}, 2 \min 50 \mathrm{~s}$ & $98,4(0,6)$ & $70(3)$ & $83,1(0,9)$ \\
\cline { 2 - 5 } & $900 \mathrm{~W}, 3 \min$ & $91,8(1,5)$ & $93(3)$ & $80(2)$ \\
\hline
\end{tabular}

Los resultados obtenidos muestran que el método tradicional $\left(100^{\circ} \mathrm{C}\right.$, $3 \mathrm{~min}$ ) tiene un mayor efecto que el de microondas, según los resultados de los análisis de la varianza realizados (ANOVA) en las tres enzimas. Sin embargo, el método de escaldado con microondas parece ser una buena alternativa, ya que los porcentajes de inactivación son cercanos a los obtenidos con el método tradicional, sobre todo en el caso de la PPO, que como se mencionó anteriormente, es la principal enzima de degradación en las frutas (Mathew y Parpia, 1971) y específicamente en el caso de la uva (Nuñez et al., 2007) debido a su contenido en 
UVAS EN ALMÍBAR

compuestos fenólicos, siendo la actividad residual conseguida prácticamente nula en todos los tratamientos. Por otra parte, el tratar de alcanzar el mismo nivel de activación para la POD y la PME supondría un deterioro importante de la fruta. Por todo lo anteriormente descrito, podemos concluir que el tratamiento con microondas a $900 \mathrm{~W}$ durante 2 minutos y 50 segundos es adecuado y permitiría obtener resultados similares al escaldado tradicional a $100^{\circ} \mathrm{C}$ durante 2 minutos y 30 segundos.

En la figura 20 se muestran las imágenes de la variedad de uva Thompson seedless en fresco, tras un escaldado tradicional de 2 min $30 \mathrm{~s}$ y tras un escaldado con microondas e inmersión en agua de 2 min $50 \mathrm{~s}$. 


\section{Capítulo VI}

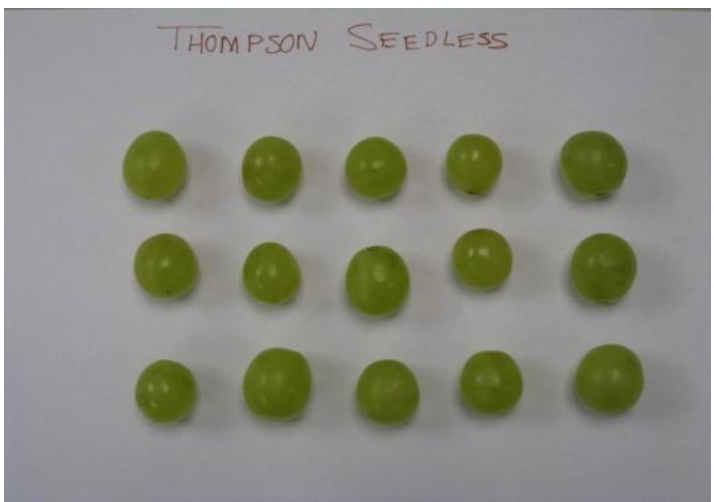

$\mathrm{E}_{\mathrm{T}}$

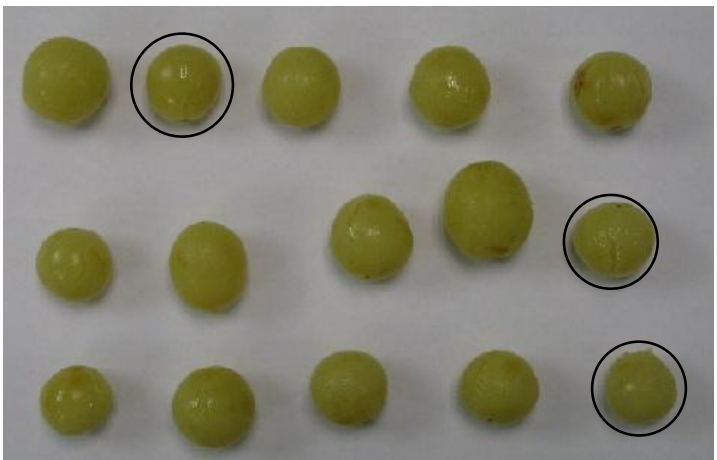

$\mathrm{E}_{\mathrm{MW}}$

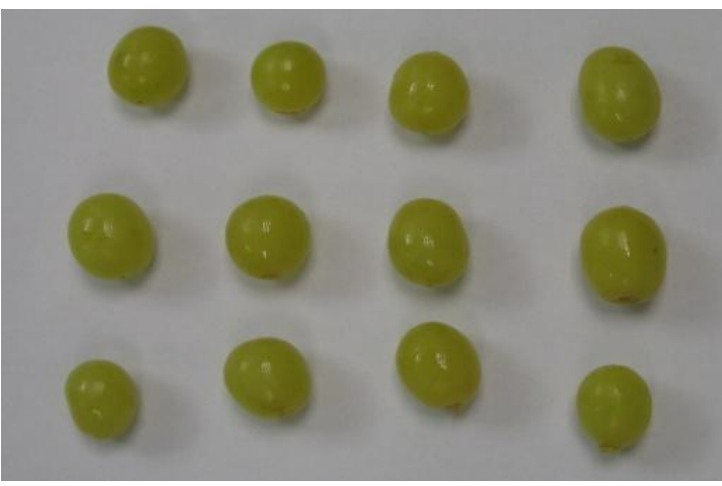

Figura 20. Uva Thompson seedless fresca (UF) y procesada mediante los tratamientos seleccionados $\mathrm{E}_{\mathrm{T}}$ y $\mathrm{E}_{\mathrm{MW}}$ 


\section{VI.5.4 Efecto del tratamiento de escaldado sobre los parámetros de} calidad de la uva

La tabla 17 muestra los resultados obtenidos de la inactivación enzimática, después de los dos tratamientos de escaldado seleccionados. En relación con la actividad enzimática, dichos resultados confirmaron que aunque el método tradicional tiene un mayor efecto que el de microondas, los porcentajes de inactivación son muy similares para ambos métodos, sobre todo en la enzima PPO.

Tabla 17. Porcentajes de inactivación obtenidos de las enzimas PPO, PME y POD mediante los tratamientos $\mathrm{E}_{\mathrm{T}}$ y $\mathrm{E}_{\mathrm{MW}}$.

\begin{tabular}{ccc}
\hline ENZIMA & \multicolumn{2}{c}{ Tratamiento } \\
\hline & $\mathrm{E}_{\mathrm{MW}}$ & $\mathrm{E}_{\mathrm{T}}$ \\
PPO & $99,9(0,05)$ & $99,8(0,01)$ \\
PME & $63,2(4,6)$ & $70,8(1,6)$ \\
POD & $81,7(1,4)$ & $86,7(0,9)$ \\
\hline
\end{tabular}

La tabla 18 muestra los valores medios de los compuestos y parámetros analizados en la uva fresca y escaldada de forma tradicional y con microondas.

Los ANOVAs realizados mostraron diferencias significativas tanto para el contenido en sólidos solubles como para la humedad. Se observa que las uvas escaldadas por el método tradicional poseen un menor contenido en sólidos solubles y una mayor humedad que la uva fresca. Por el contrario la uva escaldada por el método de microondas presentó un contenido más alto en ambos parámetros. No obstante, las diferencias 


\section{Capítulo VI}

son pequeñas, asumiendo que este hecho puede deberse más a la variabilidad de la uva que al efecto de los tratamientos. De hecho, la actividad del agua no mostró diferencias significativas.

Tabla 18. Valores medios y desviación estándar (entre paréntesis) obtenidos de los análisis de la fruta fresca y de la uva escaldada por los métodos seleccionados.

\begin{tabular}{|c|c|c|c|}
\hline \multirow{2}{*}{ Análisis } & \multicolumn{3}{|c|}{ Tratamiento de escaldado } \\
\hline & Uva fresca & $\mathrm{E}_{\mathrm{MW}}$ & $\mathrm{E}_{\mathrm{T}}$ \\
\hline Humedad (g/g) & $0,820(0,001) c$ & $0,825(0,002) b$ & $0,836(0,002) \mathrm{a}$ \\
\hline${ }^{\circ}$ Brix & $16,4(0,05) b$ & $16,7(0,05) a$ & $15,4(0,05) c$ \\
\hline Actividad del agua & $0,973(0,001) a$ & $0,971(0,001) a$ & $0,974(0,001) \mathrm{a}$ \\
\hline $\begin{array}{l}\text { Acidez total (mg de acido } \\
\text { tartárico/100g) }\end{array}$ & $519(22) \mathrm{c}$ & $409(12) a$ & $459(4) b$ \\
\hline $\begin{array}{l}\text { Actividad antioxidante } \\
\text { (mg de Trolox/100g) }\end{array}$ & $30(3) a$ & $25(5) a$ & $35(5)$ a \\
\hline $\begin{array}{l}\text { Fenoles totales (mg de } \\
\text { acido gálico/100g) }\end{array}$ & $69(10) a$ & $60(23) a$ & $71(12) a$ \\
\hline $\begin{array}{l}\text { Pectina total (mg de } \\
\text { AGU/100g) }\end{array}$ & $260(31) a$ & $261(50)$ a & $211(44) \mathrm{a}$ \\
\hline $\begin{array}{c}\text { Pectina hidrosoluble (mg } \\
\text { de AGU/100g) }\end{array}$ & $21(9) \mathrm{a}$ & $21(7) \mathrm{a}$ & $20,5(1,6)$ a \\
\hline $\begin{array}{l}\text { Pectina oxalato-soluble } \\
\text { (mg de AGU/100g) }\end{array}$ & $32(4) a$ & $39(5) \mathrm{a}$ & $36(5)$ a \\
\hline
\end{tabular}

Las letras diferentes en la misma fila indican grupos significativamente diferentes según el ANOVA realizado.

La acidez disminuye $(\mathrm{p}<0.05)$ después de ambos tratamientos, pudiéndose deber al efecto de la temperatura, que aunque el tratamiento es corto puede afectar a los compuestos más sensibles a la temperatura, 
pero también a un fenómeno de lixiviación. La pérdida de este ácido es mayor $(\mathrm{p}<0.05)$ en el tratamiento por microondas.

En cuanto al resto de compuestos analizados y a la actividad antioxidante, en ningún caso se observaron diferencias significativas de las muestras escaldadas con respecto a las frescas. Esto no es de extrañar dado que se trata de tratamientos muy suaves.

La figura 21 muestra los valores de $a^{*} \mathrm{y} \mathrm{b}^{*}$ para la uva fresca y escaldada por el método tradicional y con microondas. Como puede observarse $a^{*}$ disminuyó significativamente en la uva escaldada con microondas, mientras que $b^{*}$ aumentó también significativamente de un valor inicial de 15 a una cifra de 21 tras ambos tratamientos. La luminosidad se vio afectada por el tratamiento observándose un aumento significativo de su valor tanto en la uva tratada con el método tradicional como en la que se utilizó microondas.

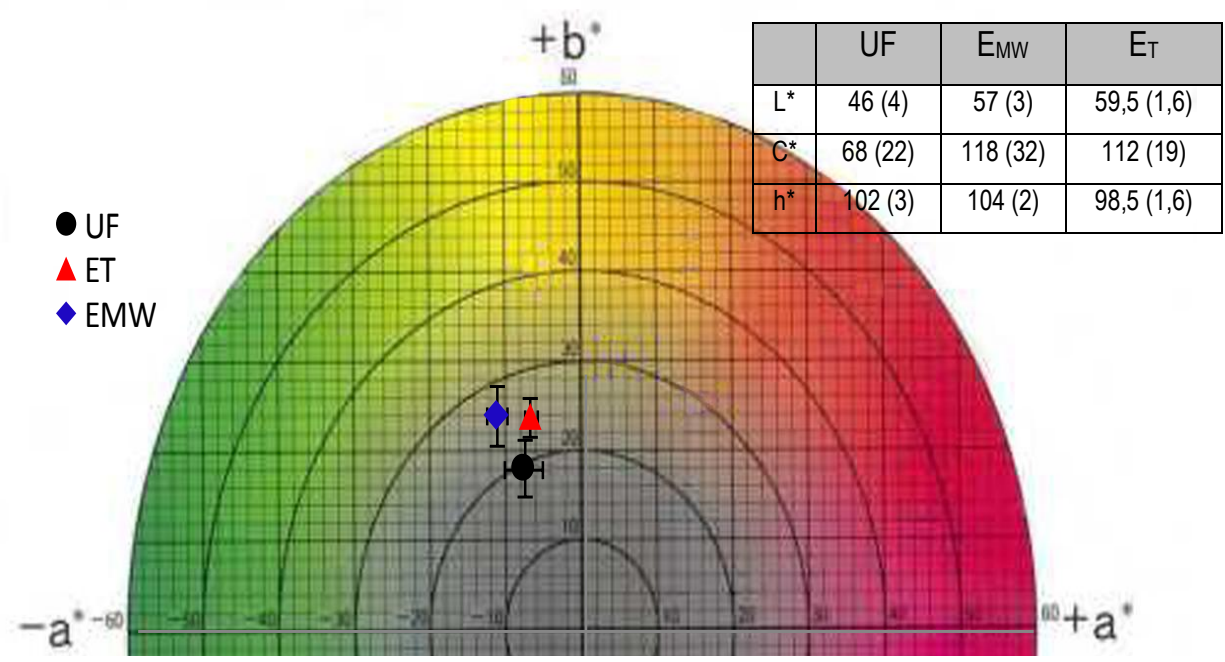

Figura 21. Valores medios y desviación estándar de $a^{*}, b^{*}$, luminosidad $\left(\mathrm{L}^{*}\right)$, croma $\left(\mathrm{C}^{*}\right)$ y tono $\left(\mathrm{h}^{*}\right)$ en la uva fresca y en la 


\section{Capítulo VI}

procesada en la uva frescas así como en las uvas escaldadas por ambos tratamientos.

Con respecto al croma $\left(\mathrm{C}^{*}\right)$, se observó un incremento significativo por ambos tratamientos y el ángulo de tono $\left(\mathrm{h}^{*}\right)$ disminuyó ligeramente cuando se realizó el escaldado tradicional. La diferencia de color $(\Delta \mathrm{E})$ fue de 12 unidades para el $\mathrm{E}_{\mathrm{MW}} \mathrm{y}$ de 15 unidades para el $\mathrm{E}_{\mathrm{T}}$.

En cuanto a la textura, ésta cambia a menudo durante el procesado de los productos debido a causas muy diversas. En los vegetales, la alteración de las células conlleva la pérdida de la presión de turgencia así como el ablandamiento de los tejidos, mientras que la gelatinización del almidón, la hidrólisis de las pectinas y la disolución de las hemicelulosas causan el ablandamiento de los tejidos.

La figura 22 muestra un ejemplo de las curvas fuerza-deformación obtenidas de los ensayos de punción que se realizaron a la uva fresca y a la uva tratada $\mathrm{E}_{\mathrm{T}}$ y $\mathrm{E}_{\mathrm{MW}}$. Como puede observarse, la forma de las curvas es muy distinta. La fruta fresca presenta una pendiente inicial mucho más acusada y con un pico de fuerza máxima que se alcanza a una menor distancia de penetración. Mientras que para la uva fresca se obtuvo una fuerza de fractura de $9.1 \pm 1.9 \mathrm{~N}$ y una pendiente de $1.5 \pm 0.4$ $\mathrm{N} / \mathrm{mm}$, para las uvas escaldadas de manera tradicional y con microondas se obtuvieron valores de $5.7 \pm 1.5 \mathrm{~N}$ y $0.6 \pm 0.1 \mathrm{~N} / \mathrm{mm}$ y $8 \pm 2 \mathrm{~N}$ y $0.8 \pm 0.2$ $\mathrm{N} / \mathrm{mm}$, respectivamente.

El tratamiento con microondas no llegó a afectar de forma significativa al valor del pico de fuerza máxima, mientras que el tradicional sí, reflejando la menor resistencia a la rotura de estas 
muestras por efecto del ensayo mecánico. De hecho, las uvas escaldadas por inmersión en agua caliente mostraron un daño en la piel de la mayoría de los granos.

Por otra parte, las muestras tratadas fueron significativamente más fácilmente deformables (menor pendiente) que la uva fresca, sin diferencias por efecto del tratamiento.

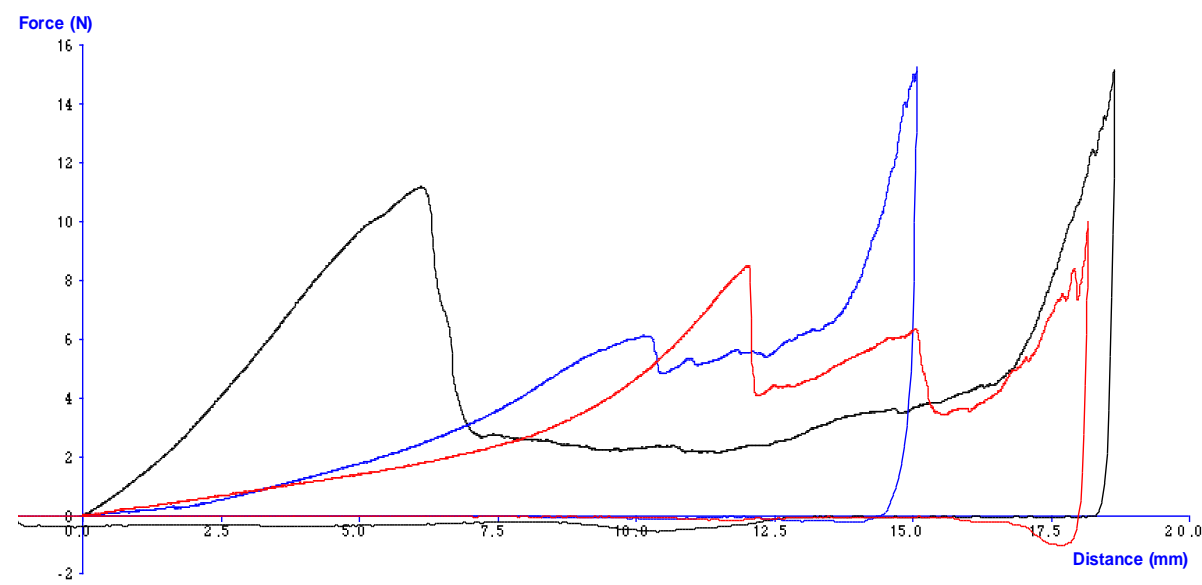

Figura 22. Ejemplo de curvas fuerza-deformación para la uva fresca (---), escaldada por $\mathrm{E}_{\mathrm{T}}(----)$ y con el $\mathrm{E}_{\mathrm{MW}}(----)$.

VI.5.5 Evolución de los parámetros de calidad de la uva durante el almacenamiento así como del almíbar utilizado para su conservación.

Como se mencionó anteriormente, para el estudio de almacenamiento, las uvas se introdujeron en almíbar de $16^{\circ}$ Brix en unos recipientes de plástico. Las conservas se dejaron bien tapadas a 


\section{Capítulo VI}

temperatura ambiente durante los días establecidos (0, 1, 4, 7, 15 y 21). A cada tiempo, a la uva se le analizaron los mismos parámetros que después del procesado. El almíbar utilizado para el almacenamiento de las uvas fue analizado en cuanto a la actividad del agua, los sólidos solubles, la acidez total, la actividad antioxidante y los fenoles totales.

De acuerdo con los resultados obtenidos se observó que los ${ }^{\circ}$ Brix de la fruta (Figura 23) aumentan significativamente durante el almacenamiento, tendiendo a estabilizarse con los sólidos solubles del almíbar. Este leve aumento concuerda con los resultados obtenidos en la humedad (Figura 24), en la que se observa una disminución significativa a lo largo del almacenamiento, especialmente en los primeros días. Estos cambios pueden atribuirse a una pequeña deshidratación e incorporación de azúcar que ocurre en la uva por encontrarse en el almíbar inicialmente con menor actividad del agua.

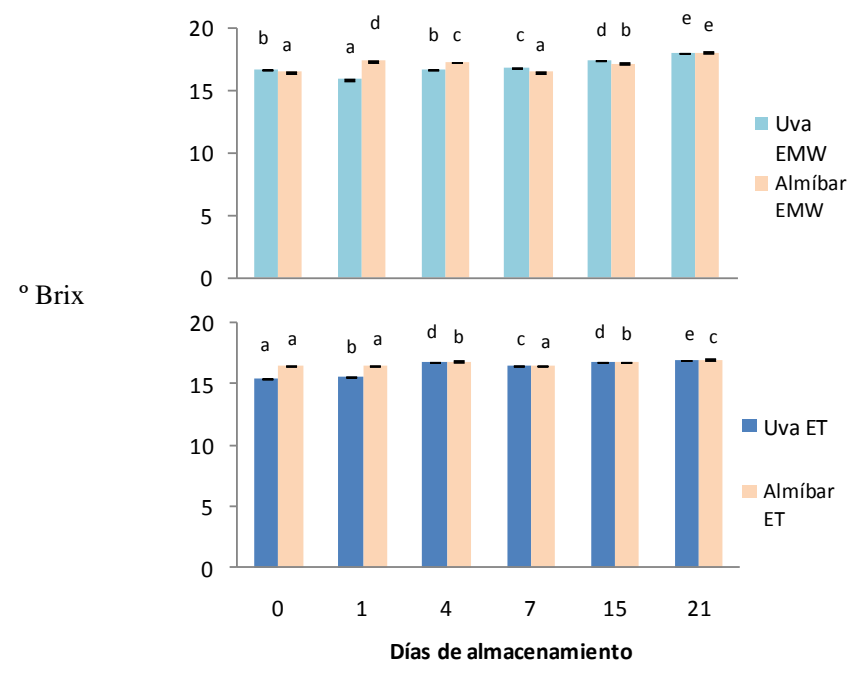

Figura 23. Evolución de los sólidos solubles del almíbar y de la uva en almíbar escaldada tradicionalmente $\left(\mathrm{E}_{\mathrm{T}}\right)$ y con microondas $\left(\mathrm{E}_{\mathrm{MW}}\right)$ 
durante el periodo de almacenamiento. Letras diferentes indican diferencias significativas entre muestras $(p<0,05)$.

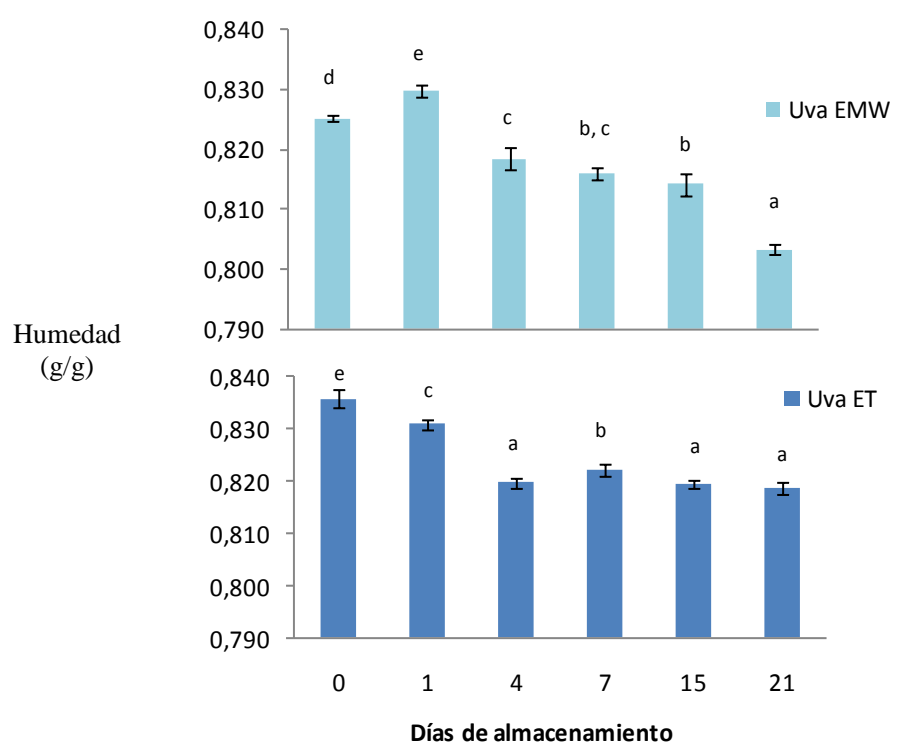

Figura 24. Evolución del contenido de humedad de la uva en almíbar escaldada por el método tradicional $\left(\mathrm{E}_{\mathrm{T}}\right)$ y con microondas $\left(\mathrm{E}_{\mathrm{MW}}\right)$ durante el período de almacenamiento. Letras diferentes indican diferencias significativas entre muestras $(p<0,05)$.

En cuanto al contenido de ácido tartárico, las uvas mostraron cambios significativos durante el almacenamiento (Fig. 25). El ácido tartárico sufrió un descenso pronunciado en el día 1 de almacenamiento, un $63 \%$ para las uvas escaldadas por el método tradicional y un 53\% para el método del microondas, estabilizándose a partir del día 7 en ambos métodos de procesado. Como puede observarse, parte de este ácido se incorpora en el almíbar, aunque la disminución que se observa 


\section{Capítulo VI}

posteriormente a partir de los 4 días estaría indicando una degradación del ácido en ese momento.

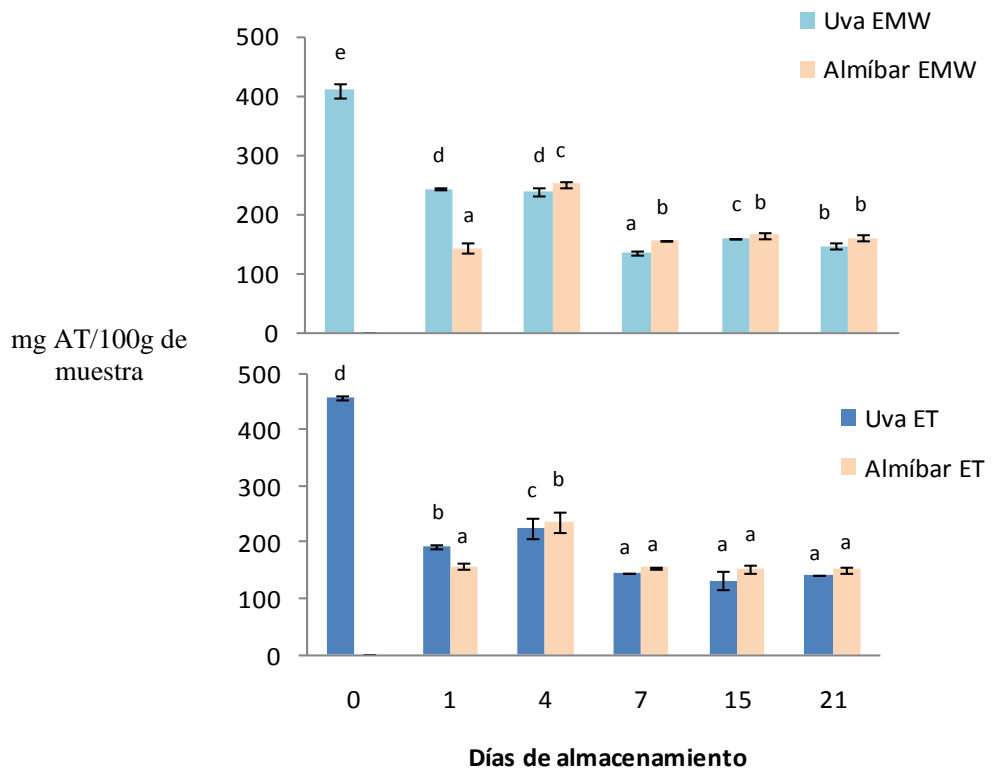

Figura 25. Evolución del contenido en ácido tartárico (AT) en la uva en almíbar escaldada por el método tradicional $\left(\mathrm{E}_{\mathrm{T}}\right)$ y por microondas ( $\left.\mathrm{E}_{\mathrm{MW}}\right)$, así como de los almíbares utilizados, durante el período de almacenamiento. Letras diferentes indican diferencias significativas entre muestras $(\mathrm{p}<0,05)$.

La figura 26 muestra los valores del contenido en FT para la uva en almíbar escaldada por ambos métodos, así como de los almíbares utilizados para su conservación. En el caso de la uva escaldada por microondas la disminución observada durante el almacenamiento fue estadísticamente significativa a partir del día 7 de almacenamiento, llegando a ser de un $30 \%$ al final del periodo estudiado. En la uva 
procesada el método tradicional la disminución fue estadísticamente significativa desde el inicio del almacenamiento y al final del periodo estudiado se registró un $45 \%$ de disminución. De la misma manera que con el ácido tartárico, el contenido en fenoles totales aumentó en el almíbar a lo largo del almacenamiento, lo que confirma el intercambio de componentes entre la fruta y la disolución. De hecho, se observó un aumento hasta el día 7, para posteriormente empezar a disminuir.

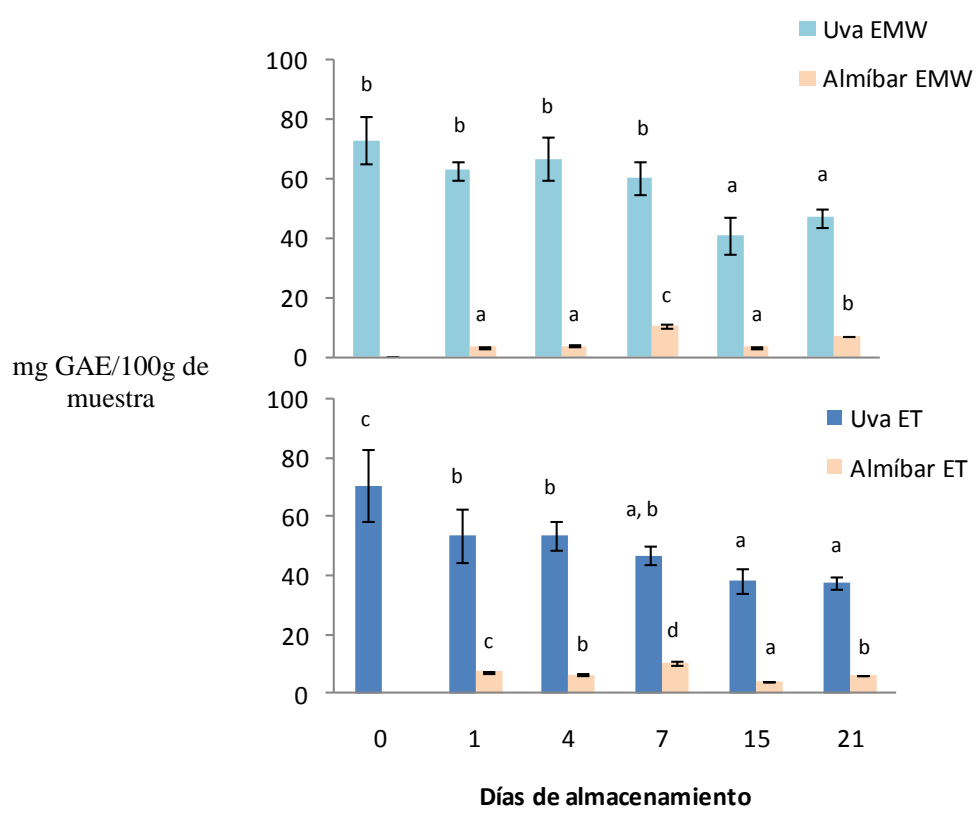

Figura 26. Evolución del contenido en fenoles totales (FT) en la uva fresca y la uva en almíbar escaldada por el método tradicional $\left(\mathrm{E}_{\mathrm{T}}\right)$ y microondas $\left(\mathrm{E}_{\mathrm{MW}}\right)$ durante el período de almacenamiento. Letras diferentes indican diferencias significativas entre muestras $(p<0,05)$. 


\section{Capítulo VI}

Los valores de la actividad antioxidante se muestran en la figura 27. Se observó una disminución significativa de esta capacidad para las uvas escaldadas por el método tradicional en las primeras $24 \mathrm{~h}$ de almacenamiento, que fue de un $23 \%$. Por el contrario las uvas escaldadas con microondas no mostraron cambios significativos. La actividad antioxidante también aumentó en el almíbar, mostrando el valor más elevado en el día 7, al igual que en los fenoles totales.

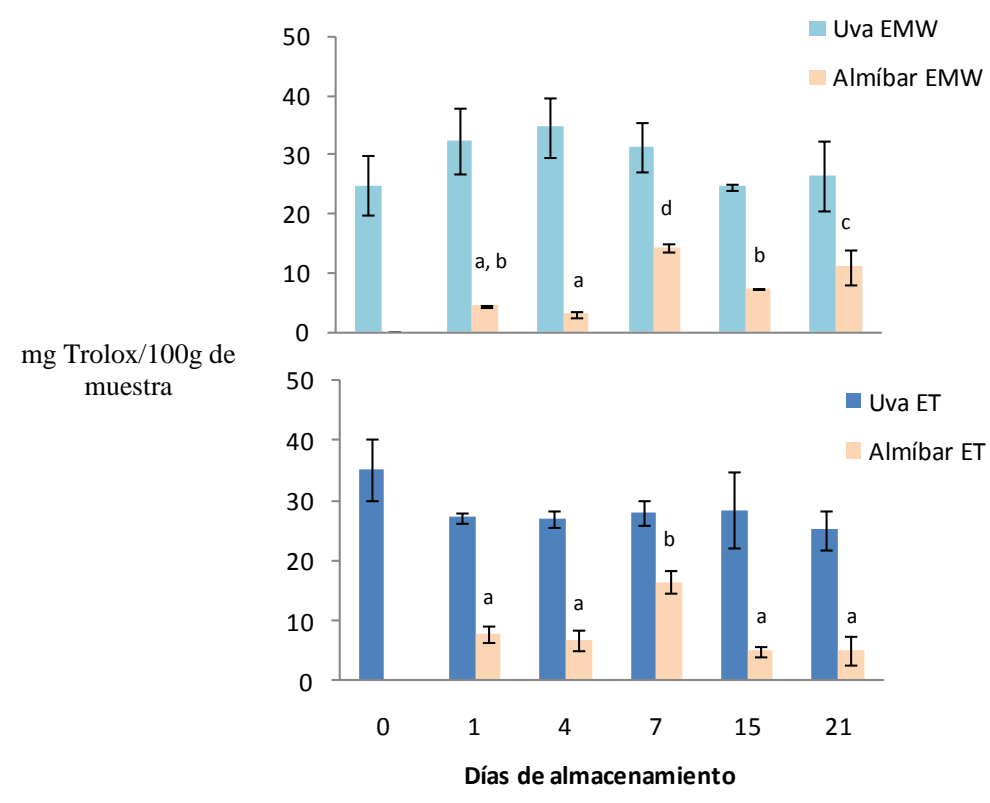

Figura 27. Evolución durante el período de almacenamiento de la actividad antioxidante (AAT) de la uva en almíbar escaldada por el método tradicional $\left(\mathrm{E}_{\mathrm{T}}\right)$ y microondas $\left(\mathrm{E}_{\mathrm{MW}}\right)$, así como de los almíbares utilizados en ambos tratamientos. Letras diferentes indican diferencias significativas entre muestras $(\mathrm{p}<0,05)$. 
Las pectinas total y oxalato soluble no sufrieron cambios significativos con el almacenamiento (Fig. 28 y 29), mientras que la hidrosoluble (Fig. 30) aumentó al final del periodo estudiado.

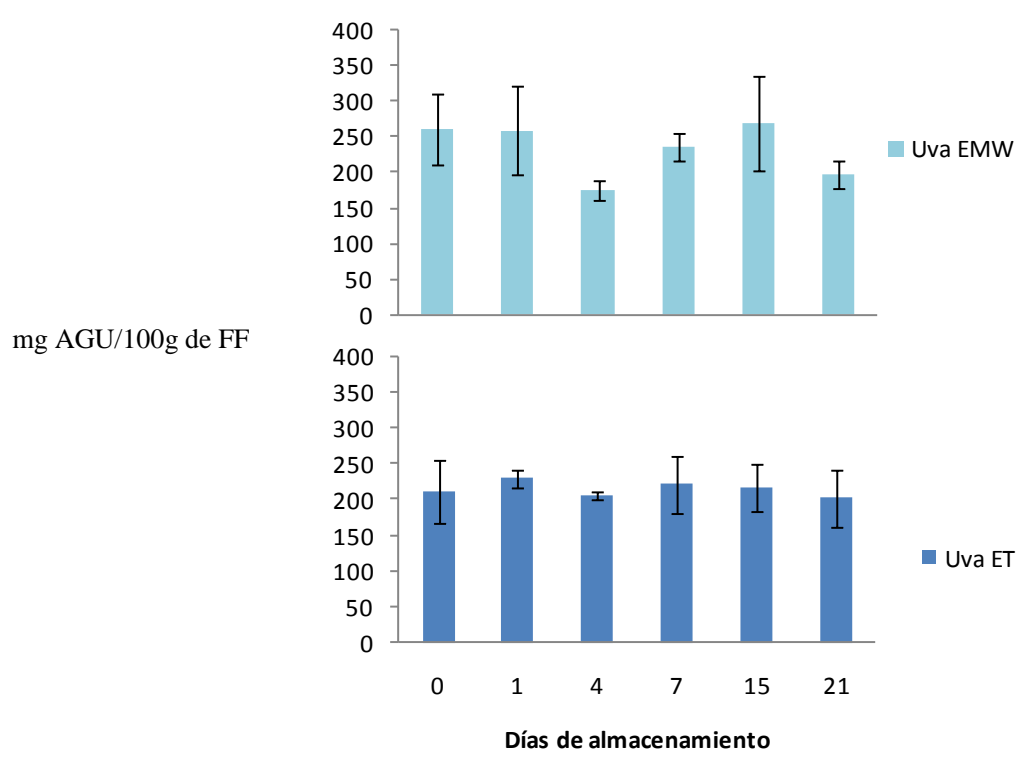

Figura 28. Evolución de la pectina total (PT) de la uva en almíbar escaldada por el método tradicional $\left(\mathrm{E}_{\mathrm{T}}\right)$ y microondas $\left(\mathrm{E}_{\mathrm{MW}}\right)$ durante el período de almacenamiento. 
Capítulo VI

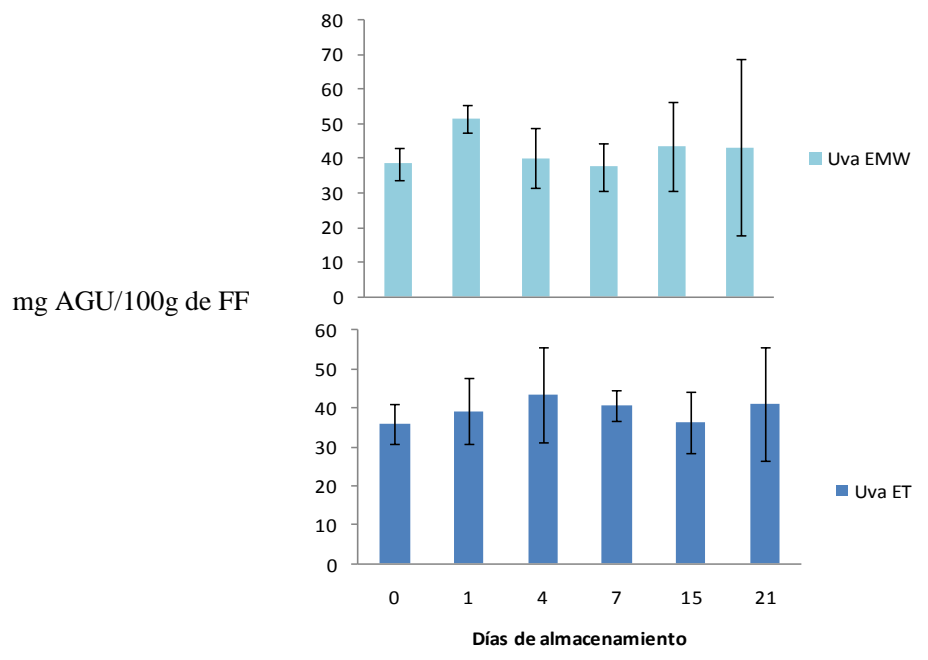

Figura 29. Evolución de la pectina oxalato soluble (POS) de la uva en almíbar escaldada por el método tradicional $\left(\mathrm{E}_{\mathrm{T}}\right)$ y microondas $\left(\mathrm{E}_{\mathrm{MW}}\right)$ durante el período de almacenamiento.

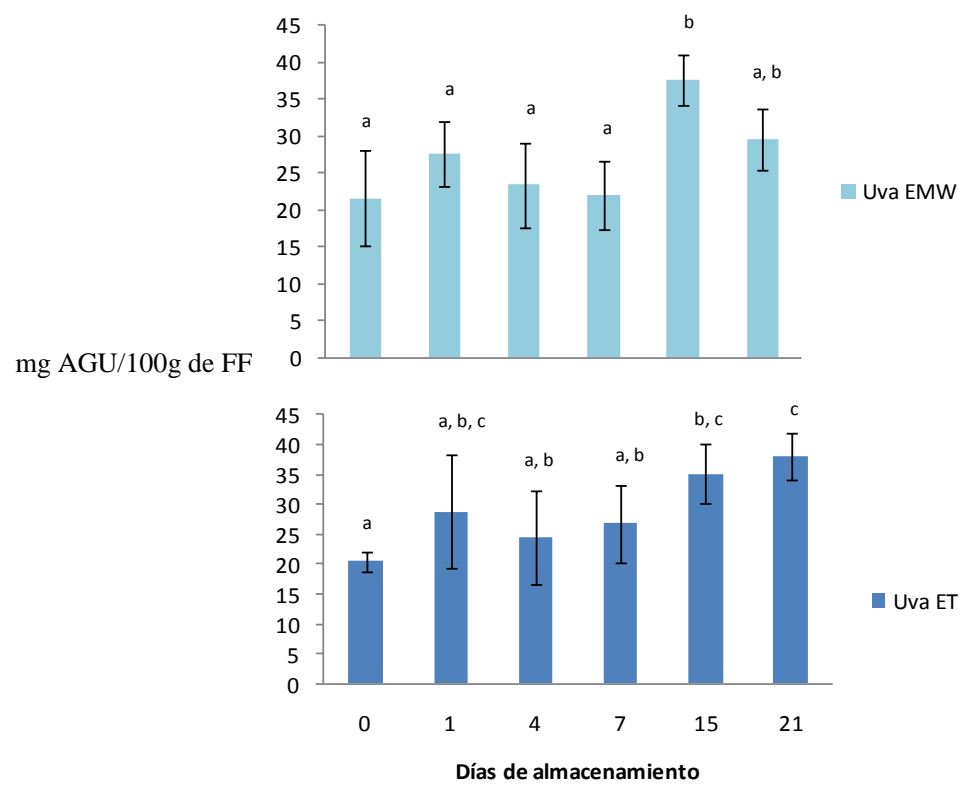

Figura 30. Evolución de la pectina hidrosoluble (PHS) de la uva en almíbar escaldada por el método tradicional $\left(\mathrm{E}_{\mathrm{T}}\right)$ y microondas $\left(\mathrm{E}_{\mathrm{MW}}\right)$ 
durante el período de almacenamiento. Letras diferentes indican diferencias significativas entre muestras $(p<0,05)$.

Las figuras 31 a 33 muestran la evolución de la actividad de la PME, POD y PPO con el almacenamiento. Con respecto a la enzima pectinmetilesterasa los porcentajes de inactivación conseguidos con el tratamiento fueron de un $70 \%$ en el escaldado tradicional y un $63 \%$ en el escaldado por microondas. Probablemente, debido a la inactivación parcial de esta enzima, durante el almacenamiento ésta recuperó parte de su actividad, mostrando valores de inactivación hasta de un $33 \%$ en el día 7 de almacenamiento en las uvas escaldadas por microondas. Posteriormente pierde de nuevo actividad. Los ANOVAs realizados confirmaron diferencias significativas en ambos métodos de escaldado durante el período de almacenamiento.

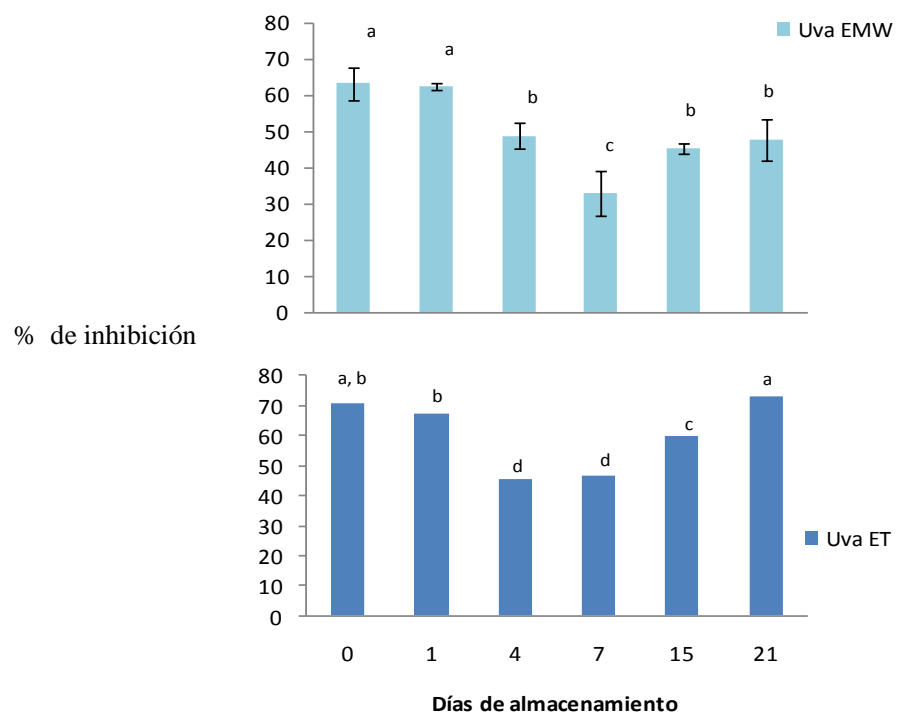

Figura 31. Evolución de la pectinmetilesterasa (PME) de la uva en almíbar escaldada por el método tradicional $\left(\mathrm{E}_{\mathrm{T}}\right)$ y microondas $\left(\mathrm{E}_{\mathrm{MW}}\right)$ 


\section{Capítulo VI}

durante el período de almacenamiento. Letras diferentes indican diferencias significativas entre muestras $(p<0,05)$.

Por otra parte la actividad de la enzima polifenoloxidasa (Figura 50) fue inhibida prácticamente en su totalidad en ambos métodos de escaldado y no mostró recuperación de su actividad durante el período de almacenamiento, lo cual es muy importante puesto que es la enzima más influye en la calidad de la uva.

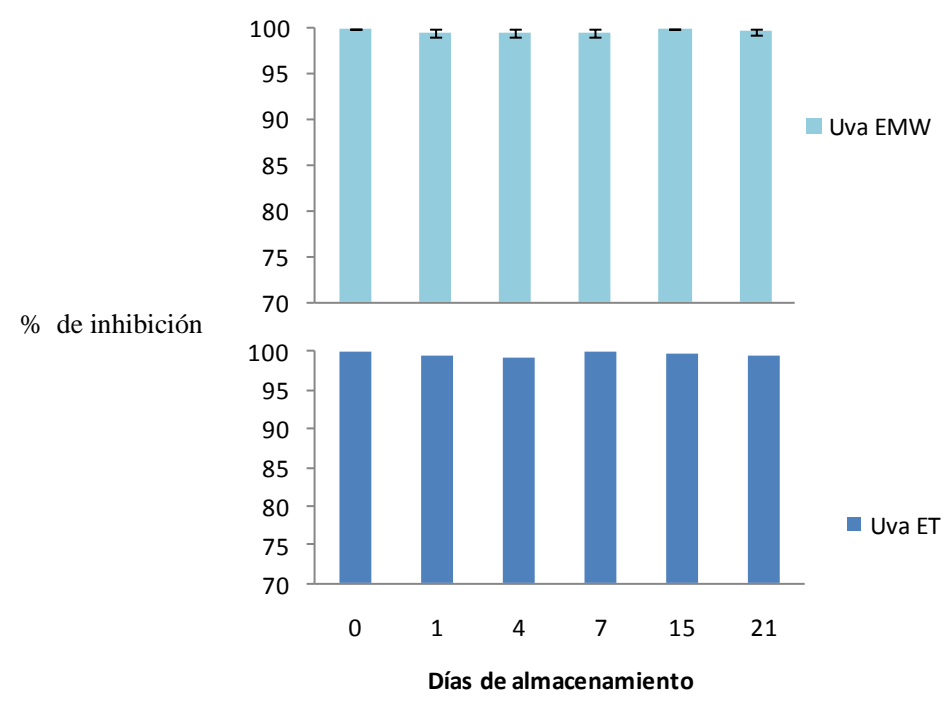

Figura 32. Evolución de la polifenoloxidasa (PPO) de la uva en almíbar escaldada por el método tradicional $\left(\mathrm{E}_{\mathrm{T}}\right)$ y microondas $\left(\mathrm{E}_{\mathrm{MW}}\right)$ durante el período de almacenamiento.

Con respecto a la enzima peroxidasa (POD) se provocó una disminución en su actividad del $80 \%$ con el tratamiento. Con el almacenamiento las muestras recuperaron parte de la actividad inicial de 
esta enzima, observándose diferencias significativas para ambos métodos de escaldado.

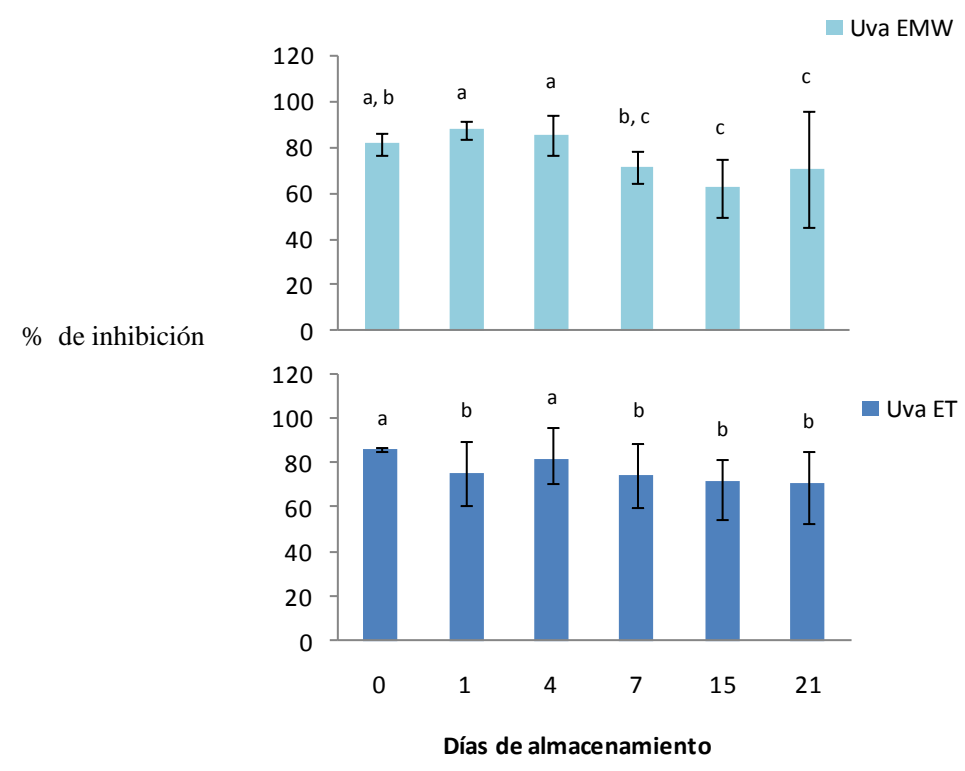

Figura 33. Evolución de la POD en la uva en almíbar escaldada por el método tradicional $\left(\mathrm{E}_{\mathrm{T}}\right)$ y microondas $\left(\mathrm{E}_{\mathrm{MW}}\right)$ durante el período de almacenamiento. Letras diferentes indican diferencias significativas entre muestras $(\mathrm{p}<0,05)$.

En cuanto a la evolución del color, la figura 34 muestra los valores de luminosidad de las uvas escaldadas de forma tradicional y con microondas. En ambos casos se observó una disminución significativa en la luminosidad a partir de los días 7-15. Esto puede indicar que en ese momento se podría estar produciendo el pardeamiento de las uvas. Teniendo en cuenta que el pardeamiento enzimático debería ser causado por la PPO, dado que esta enzima se encuentra totalmente inactivada 


\section{Capítulo VI}

durante todo el almacenamiento, cabe pensar que probablemente estén ocurriendo reacciones de Maillard responsables de un pardeamiento no enzimático, las cuales pueden ocurrir incluso a temperatura ambiente aunque más lentamente.

Luminosidad
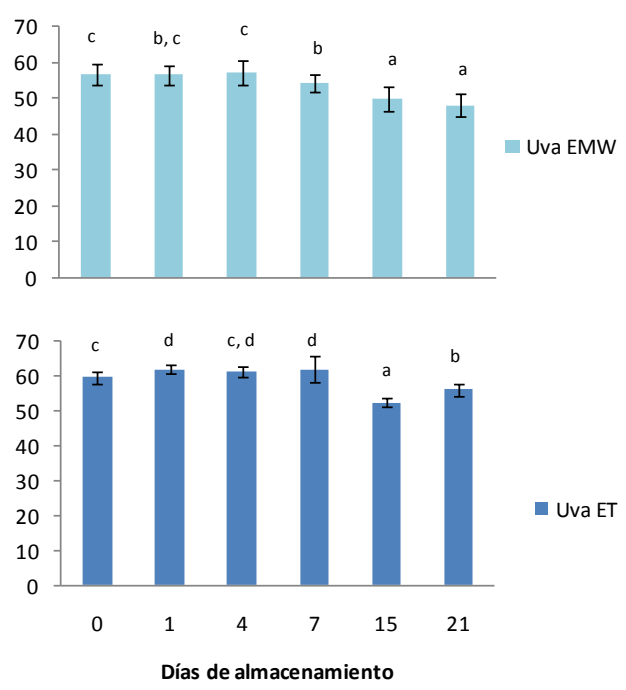

Figura 34. Evolución del valor de luminosidad en las uvas escaldadas durante el período de almacenamiento. Letras diferentes indican diferencias significativas entre muestras $(\mathrm{p}<0,05)$.

Por otra parte en los resultados de $\mathrm{a}^{*} \mathrm{y} \mathrm{b}^{*}$ (Figura 35) se observó un incremento significativo en los valores de $a^{*}$ en el caso de las uvas escaldadas por el método del microondas, que pasó de $-4,95$ a valores positivos a partir del día 1 de almacenamiento finalizando en el día 21 con una cifra de 5. La coordenada $\mathrm{b}^{*}$, aunque mostró diferencias significativas, estas no fueron coherentes con una evolución asociada al tiempo de almacenamiento, sino que más bien parecen deberse a la variabilidad natural de la uva. Además los cambios fueron de mucha 
UVAS EN ALMÍBAR

menor magnitud que en el caso de la coordenada $a^{*}$. Esto supone una evolución del color de la muestra desde tonos más verdes-amarillos hacia tonos más amarillos-rojos (Tabla 19).

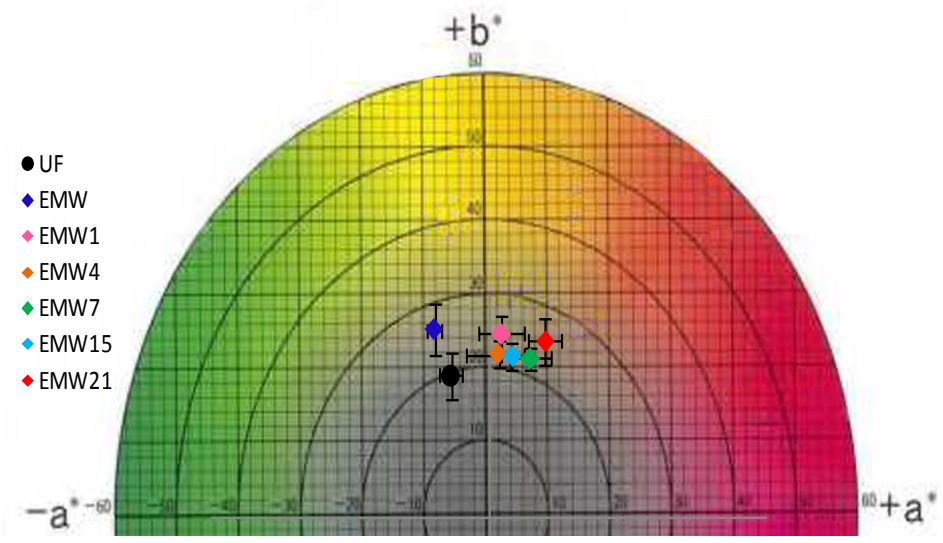

Figura 35. Evolución de las coordenadas $a^{*}$ y b* en la uva en almíbar escaldadas por el microondas $\left(\mathrm{E}_{\mathrm{MW}}\right)$ durante el período de almacenamiento.

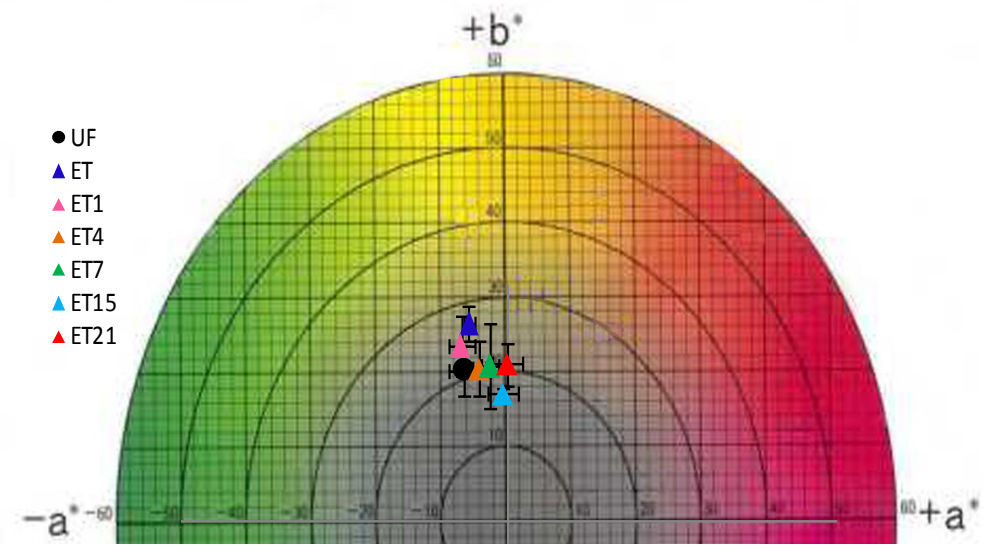

Figura 36. Evolución de las coordenadas $a^{*}$ y b* en la uva en almíbar escaldadas por el método tradicional $\left(\mathrm{E}_{\mathrm{T}}\right)$ durante el período de almacenamiento 


\section{Capítulo VI}

Las uvas escaldadas por el método tradicional (Figura 36) tuvieron la misma tendencia de aumento significativo de $\mathrm{a}^{*}$, aunque los cambios fueron menos acusados. De nuevo los cambios en $b^{*}$ parecen ser consecuencia de la variabilidad de la muestra.

Por otra parte los valores de cromaticidad y tono disminuyeron durante el almacenamiento, evolucionando también hacia tonos más pardos (Tabla 19).

Tabla 19. Valores medios y desviación estándar (entre paréntesis) del croma $\left(\mathrm{C}^{*}{ }_{\mathrm{ab}}\right)$ y el tono $\left(\mathrm{h}_{\mathrm{ab}}\right)$ obtenidos de la uvas almacenadas en almíbar previamente escaldadas con ambos métodos.

\begin{tabular}{|c|c|c|c|c|}
\hline \multirow{2}{*}{$\begin{array}{c}\text { Días de } \\
\text { almacenamiento }\end{array}$} & C*ab & E & \multicolumn{2}{c|}{ E $_{\text {MW }}$} \\
\hline $\mathbf{0}$ & $111(19) d$ & $99(2) c$ & $117(31) b$ & $103(1,6) c$ \\
\hline $\mathbf{1}$ & $90(28) c$ & $102(3) d$ & $108(22) b$ & $88(5) b$ \\
\hline $\mathbf{4}$ & $66(13) a, b$ & $98,2(1,9) b, c$ & $86(16) a$ & $88(9) b$ \\
\hline $\mathbf{7}$ & $72(39) b, c$ & $96(3) b$ & $83(10) a$ & $78(6) a$ \\
\hline 15 & $45(4) a$ & $92(5) a$ & $84(14) a$ & $83(5) b$ \\
\hline $\mathbf{2 1}$ & $70(19) b$ & $90(4) a$ & $105(27) b$ & $75(4) a$ \\
\hline
\end{tabular}

Las letras diferentes en la misma columna indican grupos significativamente diferentes según el ANOVA realizado.

Con respecto a la textura de las uvas, los análisis de fuerzadeformación revelaron que el almacenamiento de las uvas escaldadas produce un ablandamiento de las mismas. 


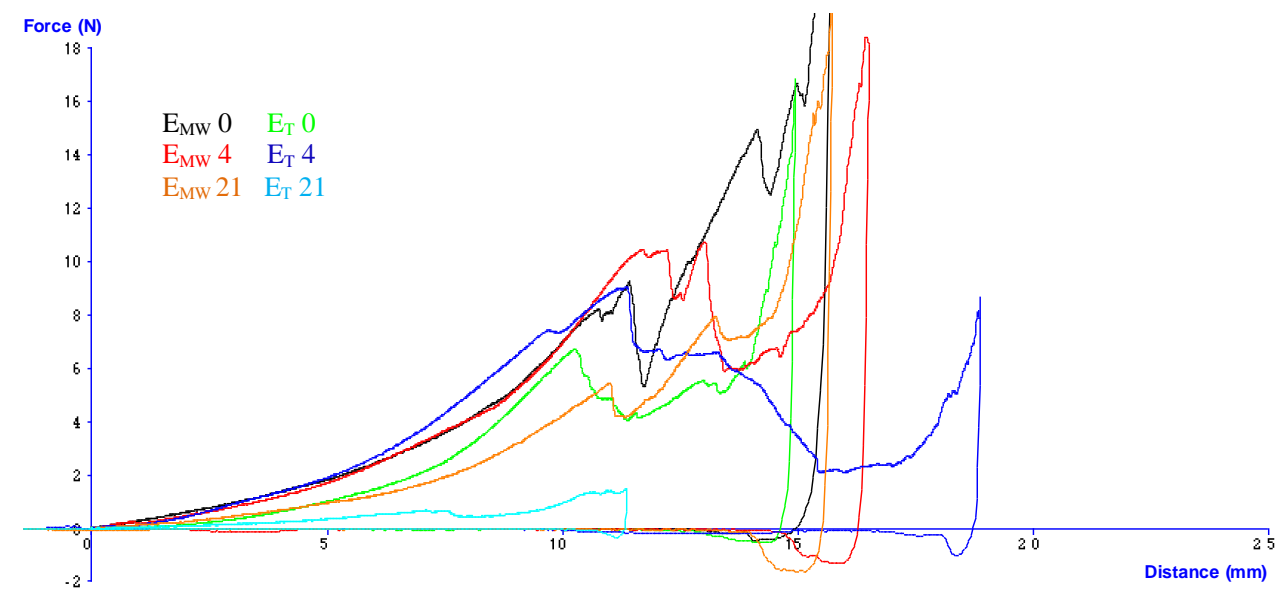

Figura 37. Ejemplo de curvas de fuerza-deformación de la uva escaldada por microondas $\left(\mathrm{E}_{\mathrm{MW}}\right)$ y escaldada por el método tradicional $\left(\mathrm{E}_{\mathrm{T}}\right)$ al día 0, 4 y 21 de almacenamiento.

En la tabla 20 se muestran los valores obtenidos en los ensayos de las propiedades mecánicas en la uva escaldada mediante los diferentes métodos durante el almacenamiento. Los ANOVAs realizados mostraron diferencias estadísticamente significativas durante el periodo de almacenamiento para la fuerza máxima, distancia y para la pendiente. Según se observa, la fuerza máxima y la distancia a la que se alcanza esta fuerza máxima aumentan al principio del almacenamiento, hasta el día 7, en las muestras sometidas a ambos tratamientos, lo que podría justificarse por la deshidratación inicial que sufren las muestras. No obstante, los cambios más significativos se dan a partir del día 15 de almacenamiento, cuando se observa una disminución importante del cociente de ambos parámetros relacionada con un ablandamiento y aumento disminución de la deformabilidad del tejido. 


\section{Capítulo VI}

Tabla 20. Valores medios y desviación estándar (entre paréntesis) de los análisis de las propiedades mecánicas de las uvas escaldadas por los diferentes métodos.

\begin{tabular}{|c|c|c|c|c|c|c|}
\hline \multirow{2}{*}{ Día } & \multicolumn{4}{|c|}{$\mathrm{E}_{\text {MW }}$} & \multicolumn{3}{|c|}{$\mathrm{E}_{\mathrm{T}}$} \\
\cline { 2 - 7 } & $\begin{array}{c}\text { Fuerza } \\
\text { Máxima (N) }\end{array}$ & $\begin{array}{c}\text { Distancia } \\
(\mathbf{m m})\end{array}$ & Cociente & $\begin{array}{c}\text { Fuerza } \\
\text { Máxima (N) }\end{array}$ & $\begin{array}{c}\text { Distancia } \\
(\mathbf{m m})\end{array}$ & Cociente \\
\hline $\mathbf{0}$ & $8(2) \mathrm{b}$ & $10(2) \mathrm{a}$ & $\begin{array}{c}0,7(0,2) \\
\mathrm{b}, \mathrm{c}\end{array}$ & $5,7(1,5) \mathrm{b}$ & $9,8(0,8) \mathrm{b}$ & $0,6(0,1) \mathrm{c}$ \\
\hline $\mathbf{1}$ & $12(3) \mathrm{c}$ & $13(1,6) \mathrm{c}$ & $0,9(0,1) \mathrm{d}$ & $7,1(1,3) \mathrm{b}, \mathrm{c}$ & $10,7(1,5) \mathrm{b}$ & $0,65(0,12) \mathrm{c}$ \\
\hline $\mathbf{4}$ & $11(3) \mathrm{c}$ & $12,4(1,2) \mathrm{b}, \mathrm{c}$ & $\begin{array}{c}0,9(0,2) \mathrm{c} \\
\mathrm{d}\end{array}$ & $6,8(1,6) \mathrm{b}, \mathrm{c}$ & $10,1(0,8) \mathrm{b}$ & $0,7(0,1) \mathrm{c}$ \\
\hline $\mathbf{7}$ & $10(3) \mathrm{c}$ & $12,9(1,4) \mathrm{c}$ & $\begin{array}{c}0,8(0,1) \\
\mathrm{b}, \mathrm{c}\end{array}$ & $7,6(3,5) \mathrm{c}$ & $11,2(1,9) \mathrm{b}$ & $0,6(0,2) \mathrm{c}$ \\
\hline $\mathbf{1 5}$ & $7,6(2) \mathrm{b}$ & $10,9(0,7) \mathrm{a}, \mathrm{b}$ & $0,6(0,1) \mathrm{b}$ & $1,9(1,3) \mathrm{a}$ & $6,9(1,9) \mathrm{a}$ & $0,23(0,15) \mathrm{b}$ \\
\hline $\mathbf{2 1}$ & $4,9(1,4) \mathrm{a}$ & $11,6(2) \mathrm{b}, \mathrm{c}$ & $0,4(0,7) \mathrm{a}$ & $0,6(0,3) \mathrm{a}$ & $7,4(4) \mathrm{a}$ & $0,08(0,03) \mathrm{a}$ \\
\hline
\end{tabular}

Las letras diferentes en la misma columna indican grupos significativamente diferentes según el ANOVA realizado.

\section{VI.5.6 Comparativa con un producto comercial de uvas en almíbar}

Los productos elaborados mediante $\mathrm{E}_{\mathrm{MW}} \mathrm{y} \mathrm{E}_{\mathrm{T}}$ se compararon con producto comercial de dos marcas de uva en almíbar disponible en el mercado. Para efectuar esta comparación, se consideraron los valores de las muestras procesadas en el laboratorio correspondientes al día 21 de almacenamiento, por suponer que el producto comercial llevaría al menos ese tiempo en el mercado. A continuación se muestra, en la tabla 21, los resultados obtenidos de dichos análisis. 
Tabla 21. Comparación de los valores medios obtenidos en las uvas en almíbar de un producto comercial con las uvas obtenidas experimentalmente mediante los diferentes métodos de escaldado y almacenadas durante 21 días a temperatura ambiente.

\begin{tabular}{|c|c|c|c|}
\hline Análisis & $\begin{array}{c}\text { Uvas en almíbar } \\
\text { (Producto comercial) }\end{array}$ & $\mathrm{E}_{\text {Mw }}$ & $\mathrm{E}_{\mathrm{T}}$ \\
\hline Humedad $(\mathrm{g} / \mathrm{g})$ & $0,798(0,014) \mathrm{a}$ & $0,803(0,001) \mathrm{a}$ & $0,82(0,001) a$ \\
\hline Actividad del agua & $0,976(0,003) \mathrm{c}$ & $0,970(0,003) \mathrm{a}$ & $0,973(0,003) b$ \\
\hline${ }^{\circ}$ Brix (g/100g) & $17,5(0,05) a$ & $18,1(0,05) b$ & $17,0(0,6) \mathrm{a}$ \\
\hline $\begin{array}{l}\text { Acidez total (mg de acido } \\
\text { tartárico } / 100 \mathrm{~g})\end{array}$ & $339(8) b$ & $147(5)$ a & $141(0,5) \mathrm{a}$ \\
\hline $\begin{array}{l}\text { Fenoles totales (mg de } \\
\text { acido gálico/100g) }\end{array}$ & $36,2(1,4) a$ & $47(3) b$ & $38(2) a$ \\
\hline $\begin{array}{l}\text { Actividad antioxidante } \\
\text { (mg de Trolox/100g) }\end{array}$ & $20(4) a$ & $30(1) b$ & $25(3) a, b$ \\
\hline $\begin{array}{l}\text { Pectina Total (mg de } \\
\text { AGU/100g) }\end{array}$ & $252(26)$ a & $197(19) \mathrm{a}$ & $202(40) \mathrm{a}$ \\
\hline $\begin{array}{l}\text { Pectina oxalato soluble } \\
\text { (mg de AGU/100g) }\end{array}$ & $28(5) \mathrm{a}$ & $56(15)$ a & $41(14) \mathrm{a}$ \\
\hline $\begin{array}{c}\text { Pectina hidrosoluble (mg } \\
\text { de AGU/100g) }\end{array}$ & $21(4) a$ & $30(4) a, b$ & $38(4) b$ \\
\hline Luminosidad & $52(4) b$ & $48(1,8) a$ & $56(3) b$ \\
\hline$a^{*}$ & $-1,1(1,1) a$ & $5,1(1,5) b$ & $-0,1(1,2) a$ \\
\hline$b^{*}$ & $13(4) a$ & $20(3) c$ & $17(2) b$ \\
\hline Croma & $48(28) a$ & $90(4) b$ & $60(19) \mathrm{a}$ \\
\hline Tono & $95(7) b$ & $76(4) a$ & $105(27) \mathrm{c}$ \\
\hline Fuerza fractura $(\mathrm{N})$ & $2,4(0,7) b$ & $5,2(1,7) c$ & $0,6(0,3) a$ \\
\hline Distancia (mm) & $6(2) a$ & $12(2) b$ & $7(4) a$ \\
\hline Pendiente (Ff/distancia) & $0,44(0,16) b$ & $0,43(0,09) b$ & $0,08(0,03) a$ \\
\hline
\end{tabular}

Las letras diferentes en la misma fila indican grupos significativamente diferentes según el ANOVA realizado.

Como se puede observar en la tabla 21 los resultados de todas las determinaciones son del mismo orden en los 3 productos analizados, excepto en el caso de la acidez. Para el resto de componentes y 


\section{Capítulo VI}

parámetros, en general, o bien no se observaron diferencias significativas entre muestras o bien el producto comercial mostró valores intermedios entre los escaldados por el método tradicional y por microondas.

En el caso de la acidez total se observó que el producto comercial posee un mayor contenido en ácido tartárico (339 mg/100g de muestra) que las uvas en almíbar $\mathrm{E}_{\mathrm{Mw}}$ y $\mathrm{E}_{\mathrm{T}}$ (entre 141 y $147 \mathrm{mg} / 100 \mathrm{~g}$ de muestra). Esto se debe a la presencia de un acidulante añadido al almíbar en el caso de la uva comercial, como se comenta en el apartado siguiente.

VI.5.7 Comparación de los almibares utilizados en la $\mathbf{E}_{\mathrm{MW}}, \mathbf{E}_{\mathrm{T}} \mathbf{y}$ el del almíbar comercial.

Al igual que la fruta, fueron comparados el almíbar comercial y el almíbar utilizado para el almacenamiento de las uvas $\mathrm{E}_{\mathrm{Mw}}$ y $\mathrm{E}_{\mathrm{T}}$ en cuanto a algunos parámetros como los ${ }^{\circ} \mathrm{Brix}$, la actividad del agua, el ácido tartárico, los fenoles totales y la actividad antioxidante. La tabla 22 muestra los valores obtenidos en los análisis realizados en las muestras de almíbar de dos marcas comerciales. Los resultados mostrados son el valor medio. Así mismo, aparecen los valores de las muestras procesadas en el laboratorio después de 21 días de almacenamiento. 
Tabla 22. Valores medios y desviación estándar (entre paréntesis) de los análisis en el almíbar del producto comercial así como de los productos experimentales.

\begin{tabular}{|c|c|c|c|}
\hline Análisis & Almíbar $\mathrm{E}_{\mathbf{M W}}$ & Almíbar $\mathrm{E}_{\mathbf{T}}$ & Almíbar comercial \\
\hline${ }^{\circ}$ Brix & $18,1(0,05) \mathrm{c}$ & $17(0,05) \mathrm{a}$ & $17,5(0,05) \mathrm{b}$ \\
\hline $\mathrm{aw}$ & $0,973(0,003) \mathrm{a}$ & $0,974(0,003) \mathrm{a}$ & $0,977(0,003) \mathrm{b}$ \\
\hline $\begin{array}{c}\text { Acido tartárico } \\
\text { (mg/100g de almíbar) }\end{array}$ & $160(5) \mathrm{a}$ & $151(5) \mathrm{a}$ & $335(9) \mathrm{b}$ \\
\hline $\begin{array}{c}\text { Fenoles totales (mg de } \\
\text { GAE/100g de almíbar) }\end{array}$ & $6,8(0,13) \mathrm{b}$ & $6,1(0,2) \mathrm{a}$ & $10,3(0,5) \mathrm{c}$ \\
\hline $\begin{array}{l}\text { Actividad antioxidante } \\
\text { (mg de Trolox/100g de } \\
\text { almíbar) }\end{array}$ & $11(3) \mathrm{b}$ & $4(3) \mathrm{a}$ & $26,7(0,6) \mathrm{c}$ \\
\hline
\end{tabular}
realizado.

En este caso, a excepción del contenido en sólidos solubles, los resultados obtenidos de todos los parámetros analizados fueron significativamente más altos en el almíbar comercial que en los escaldados en el laboratorio. Por una parte, hay que tener en cuenta que el almíbar comercial contiene E-330 (ácido cítrico) mientras que las no comerciales no. Esto justifica la acidez mayor del primero frente a las otras dos. Por otra parte, un mayor tiempo de contacto de la uva con el almíbar justificaría el mayor contenido en fenoles totales y actividad antioxidante observados en el producto comercial. Además, la mayor acidez del producto comercial podría haber contribuido también a la actividad antioxidante del almíbar y a evitar alguna reacción de oxidación importante en los fenoles del producto. 


\section{Capítulo VI}

\section{VI.5.8 CONCLUSIONES}

- De las tres enzimas estudiadas, la POD es la más resistente al tratamiento de escaldado tanto convencional como con microondas.

- Los tratamientos con microondas sólo resultaron efectivos si la muestra es sumergida en agua antes de aplicar el mismo.

- El tratamiento de escaldado a $100{ }^{\circ} \mathrm{C}$ durante 2 min $30 \mathrm{~s}$ y la aplicación de microondas a la muestra sumergida en agua a una potencia de $900 \mathrm{~W}$ durante $2 \mathrm{~min} 50 \mathrm{~s}$ son igualmente efectivos en cuanto a la inactivación enzimática conseguida, que fue de aproximadamente el $100 \%$ en el caso de la PPO y de entre un 70-80\% para la POD y PME. Este nivel de inactivación se consideró inicialmente como adecuado para la estabilidad de la uva en almíbar durante su almacenamiento, por lo que ambos tratamientos fueron seleccionados para el resto de este estudio.

- De todos los compuestos analizados, el escaldado únicamente afectó a la acidez de la uva, que se vio disminuida. Esto puede deberse tanto a la termolabilidad de este compuesto como a una posible lixiviación hacia el agua durante el tratamiento.

- El tratamiento de escaldado supuso, como cambio más importante relacionado con el color de las muestras, el aumento de su luminosidad, sin diferencias significativas entre los dos métodos empleados.

- El escaldado provoca un aumento de la deformabilidad de la uva, relacionado con un ablandamiento del tejido. 
- En los primeros días de almacenamiento de la uva en almíbar se observa un intercambio de agua y solutos solubles entre la fruta y el almíbar. Los cambios más importantes están relacionados con la ganancia de azúcares y la pérdida de ácido tartárico y fenoles uva. Este intercambio de compuestos se estabiliza a partir de 7 días de almacenamiento, por lo que se recomendaría este tiempo, como mínimo, para la comercialización del producto.

- En cuanto al color, con el almacenamiento se observa una disminución de la luminosidad y del ángulo de tono, lo que parece estar relacionado con un pardeamiento no enzimático de las muestras.

- A tiempos cortos de almacenamiento se observa un aumento de la dureza de la uva, que puede estar asociado a la deshidratación observada, mientras que a partir del día 15 se aprecia el ablandamiento del tejido. 
$\underline{\text { UVAS PASA }}$ 

UVA PASA

\section{UVA PASA}

\section{VII.1 JUSTIFICACIÓN}

Tradicionalmente las uvas pasas se obtienen tras la desecación del fruto al sol, con lo cual pierden gran parte del agua contenida. Las más apreciadas son las que no tienen semillas, presentan una acidez baja y son ricas en azúcares. En particular las uvas pasas son consideradas una fuente importante de fibra (Valiente et al, 1995). También es rica en potasio, calcio, magnesio, vitamina B3 y ácido ascórbico. El secado natural se realiza en aquellas regiones donde el sol así lo permite, con otoños soleados, cálidos, secos y casi sin lluvias. Las uvas son extendidas sobre el terreno en pequeñas capas de poco espesor dejándolas pasificar. En otras ocasiones los racimos se dejan sin vendimiar sobre las propias cepas e incluso realizando una torsión o corte de los sarmientos que los contienen, dejándolos que se sequen en los alambres de las espalderas (Hidalgo, 2006). El tiempo necesario para la pasificación depende de cada variedad de uva, del grado de maduración y sobre todo de las condiciones climatológicas y puede oscilar entre 8 y 10 días. Este método es barato pero existe el riesgo de deterioro debido al polvo y la infección por insectos (Pangavhane y Sawhney, 2002).

De acuerdo con Tarhan (2006), las condiciones a las que se someten las frutas durante el secado y el tiempo durante el que se mantienen almacenadas, afecta al contenido en polifenoles, ácido ascórbico y la capacidad antioxidante característica de la uva fresca. Es por ello que debe procurarse reducir los tiempos de secado y emplear temperaturas 


\section{Capítulo VII}

más bajas durante los procesos de deshidratación para, de esta forma, obtener unos productos de mayor calidad. En este sentido, se han desarrollado métodos de secado por aire que acortan el proceso. La piel de algunos frutos, como es el caso de la uva, se caracteriza por estar cubierta por una capa cerosa que disminuye su permeabilidad y dificulta por tanto la pérdida de agua (Tarhan, 2006). Es por ello que antes del secado tecnológico, a menudo se utilizan diferentes tratamientos químicos y físicos que mejoran dicha permeabilidad incrementando la velocidad de secado, mientras que al mismo tiempo permiten conservar las características físicas, químicas, nutricionales y organolépticas del producto final (Femenia et al., 1998). El aumento de la preocupación por la calidad del producto final y por los costes derivados de la producción, ha motivado diferentes investigaciones y el hecho de que la industria adopte técnicas de secado en la que se reduce la humedad mediante métodos apropiados y autorizados y que pueden combinarse para mejorar la fruta deshidratada (Zhang et al., 2006).

Como alternativa al secado natural, en este trabajo se propone el secado convectivo y el secado por microondas asistido con aire caliente, en los cuales la disminución de la humedad de los productos se controla mediante el uso de equipos o dispositivos especiales. 
UVA PASA

\section{VII.2 OBJETIVOS ESPECIFICOS}

- Puesta a punto de las condiciones de operación más adecuadas para la obtención de pasa aplicando secado por aire caliente y por microondas.

- Estudiar el efecto de los diferentes tratamientos sobre los macro y micronutrientes de la uva así como sobre su valor funcional.

- Comparar, desde el punto de vista composicional y funcional, el producto obtenido experimentalmente con el comercial.

\section{VII.3 PLAN DE TRABAJO}

1. Puesta a punto de las condiciones de operación más adecuadas para la obtención de pasa.

1.1. Aplicación de tratamientos de secado por aire caliente a $60{ }^{\circ} \mathrm{C}$ variando el tiempo hasta obtener pasas con un $30 \%$ de humedad.

1.2. Aplicación de tratamientos de secado por microondas a $0,2 \mathrm{~W} / \mathrm{g}$ variando el tiempo hasta obtener pasas con un $30 \%$ de humedad.

1.3. Aplicación de un pretratamiento con $\mathrm{NaOH}$ y selección de los tiempos de secado posterior por aire caliente y por microondas para obtener pasas con un $30 \%$ de humedad.

2. Aplicación de los tratamientos seleccionados y análisis de su efecto en la humedad, actividad del agua, ${ }^{\circ}$ Brix, azúcares y minerales mayoritarios, acidez, ácido ascórbico, pectinas, fenoles totales y actividad antioxidante. 


\section{Capítulo VII}

3. Estudio comparativo del efecto de los diferentes tratamientos aplicados en la composición de la pasa.

4. Estudio comparativo de la composición del producto comercial cpn el obtenido experimentalemente.

\section{VII.4 MATERIAL Y MÉTODOS}

\section{VII.4.1 Materia Prima}

Los experimentos fueron realizados con uva (Vitis vinífera) seleccionada de las variedades Imperial seedless y Thompson seedless adquiridas en supermercados de la ciudad de Valencia. La uva se conservó refrigerada antes de su manipulación (máximo 12 h), se enjuagó con agua destilada, se secó con papel y se separaron los granos del racimo. Inmediatamente después recibió el tratamiento de secado correspondiente. Además, se adquirió pasa comercial en un supermercado local, para compararla con la obtenida experimentalmente.

\section{VII.4.2 Procesado}

Las dos variedades de uva se sometieron a dos métodos de secado: microondas asistido con aire caliente (MW) y secado sólo por aire caliente (SAC), con la diferencia de que la uva de la variedad Imperial seedless fue sometida a un pretratamiento, que consistió en sumergirla en un baño a $95^{\circ} \mathrm{C}$ con $\mathrm{NaOH}(0.03 \%)$ durante 45 segundos, con la finalidad de acelerar el tiempo de secado. En todos los casos se fijó un nivel de humedad final del $30 \%$ para la uva deshidratada. A 
continuación, se detalla el procedimiento que se siguió para cada uno de estos tratamientos.

Para el secado con microondas se introdujeron $100 \mathrm{~g}$ de uva en un secador diseñado a nivel de laboratorio (Contreras et al, 2008) con las siguientes especificaciones técnicas:

- Velocidad máxima del aire: $4 \mathrm{~m} / \mathrm{s}$

- Temperatura máxima de secado: $100^{\circ} \mathrm{C}$.

- Potencia máxima de incidencia de las microondas: $2.000 \mathrm{~W}$.

Este equipo posee un mecanismo que permite controlar la potencia de las microondas (fijada en $0,2 \mathrm{~W} / \mathrm{g}$ ), la temperatura del aire $\left(60^{\circ} \mathrm{C}\right) \mathrm{y}$ la velocidad del aire $(1.6 \mathrm{~m} / \mathrm{s})$, así como la evolución de la masa del producto con la ayuda de una balanza analítica. Para el caso de secado por aire caliente se utilizó un secador, también diseñado a nivel de laboratorio, con mayor capacidad de muestra, con las siguientes características:

- Velocidad máxima del aire: $10 \mathrm{~m} / \mathrm{s}$

- Temperatura máxima de secado: $110^{\circ} \mathrm{C}$,

- Potencia máxima de incidencia de las microondas $1.000 \mathrm{~W}$

- Capacidad máxima de muestra: 1300 g

En este equipo se introdujeron $450 \mathrm{~g}$ de muestra $\mathrm{y}$ al igual que el microondas, este equipo permite controlar la temperatura y velocidad del aire $\left(60{ }^{\circ} \mathrm{C}, 10 \mathrm{~m} / \mathrm{s}\right)$ y la masa del producto mediante una balanza 


\section{Capítulo VII}

analítica. En todas las experiencias el peso de la muestra registrado durante el proceso permite conocer la humedad de la muestra a cada tiempo si se conoce la humedad inicial (Ec. 1, Capítulo V). Aplicando esta ecuación el proceso se detuvo cuando la muestra alcanzó el peso correspondiente a un contenido en humedad del 30\%. Los tiempos de proceso, en cada caso, fueron: SAC 5 días, MW 7,5 horas, $\mathrm{SAC}+\mathrm{NaOH}$ 34 horas y $\mathrm{MW}+\mathrm{NaOH} 4,5$ horas.

\section{VII.4.3 Análisis realizados}

Tanto a la fruta fresca como a la pasa se les midió la actividad del agua, acidez total, humedad, ${ }^{\circ}$ Brix, calcio, fósforo, magnesio, potasio, glucosa, fructosa, sacarosa, pectina total, pectina hidrosoluble, pectina oxalato-soluble, fenoles totales y la actividad antioxidante. Las determinaciones se llevaron a cabo de acuerdo a los procedimientos citados en el apartado III.2 del capítulo III de Materia Prima y Métodos de Análisis. Las determinaciones se llevaron a cabo de acuerdo a los procedimientos citados en el apartado III.2 del capítulo III de Materia Prima y Métodos de Análisis.

\section{VII.5 RESULTADOS}

Las Tablas 23 y 24 muestran los valores medios obtenidos de la $\mathrm{a}_{\mathrm{w}} \mathrm{y}$ los componentes analizados de las variedades de uva en fresco así como de las deshidratadas mediante los diferentes métodos (MW, SAC, MW + $\mathrm{NaOH}$ y $\mathrm{SAC}+\mathrm{NaOH})$. 
Tabla 23. Valores medios de actividad del agua y componentes analizados en la uva variedad Thompson seedless antes y después de cada tratamiento de secado. Entre paréntesis aparece la desviación estándar.

\begin{tabular}{|c|c|c|c|c|}
\hline \multirow{2}{*}{ Análisis } & \multicolumn{4}{|c|}{ Thompson seedless } \\
\hline & UF & MW & UF & SAC \\
\hline Humedad (g/g muestra) & $0,80(0,02)$ & $0,24(0,07)$ & $0,798(0,013)$ & $0,31(0,05)$ \\
\hline$a_{w}$ & $0,977(0,003)$ & $0,915(0,003)$ & $0,971(0,003)$ & $0,854(0,003)$ \\
\hline $\begin{array}{c}{ }^{\circ} \text { Brix } \\
\text { (g sólidos solubles } / 100 \mathrm{~g} \text { fracción } \\
\text { liquida) }\end{array}$ & $19(2)$ & $75(5)$ & $20,9(0,05)$ & $69(3)$ \\
\hline $\begin{array}{c}\text { Glucosa } \\
\text { (g/100g muestra) }\end{array}$ & $8,2(0,7)$ & $34(2)$ & $10,4(0,13)$ & $21,6(2,4)$ \\
\hline $\begin{array}{c}\text { Fructosa } \\
\text { (g/100g muestra) }\end{array}$ & $9,1(0,15)$ & $41,3(2,2)$ & $11,4(0,02)$ & $34,2(2,5)$ \\
\hline $\begin{array}{l}\text { Sacarosa } \\
\text { (g/10og muestra) }\end{array}$ & $0,36(0,06)$ & & $0,93(0,10)$ & \\
\hline $\begin{array}{c}\text { Acidez total } \\
\text { (mg AT/100g muestra) }\end{array}$ & $563(10)$ & $1847(94)$ & $388(9)$ & $974(134)$ \\
\hline $\begin{array}{l}\text { Ácido ascórbico } \\
\text { (mg/100g muestra) }\end{array}$ & $2,313(0,011)$ & $8(0,1)$ & $3.596(0,010)$ & $11,54(0,04)$ \\
\hline $\begin{array}{l}\text { Magnesio } \\
\text { (mg/100g muestra) }\end{array}$ & $6,6(0,7)$ & $15(2)$ & $7,91(0,13)$ & $18,6(1,5)$ \\
\hline $\begin{array}{c}\text { Calcio } \\
\text { (mg/100g muestra) }\end{array}$ & $7.6(0.2)$ & $13,9(1,3)$ & $9,8(0,8)$ & $18,4(1)$ \\
\hline $\begin{array}{l}\text { Potasio } \\
\text { (mg/10og muestra) }\end{array}$ & $231,3(1,1)$ & $702(11)$ & $234(6)$ & $687(3)$ \\
\hline $\begin{array}{c}\text { Fósforo } \\
\text { (mg/100g muestra) }\end{array}$ & $27,7(1,2)$ & $50(5)$ & $25(3)$ & $130(9)$ \\
\hline $\begin{array}{c}\text { PT } \\
\text { (mg de AGU/100g muestra) }\end{array}$ & $355(3)$ & $923(48)$ & $275(20)$ & $770(43)$ \\
\hline $\begin{array}{c}\text { PHS } \\
\text { (mg de AGU/100g muestra) }\end{array}$ & $14(8)$ & $500(163)$ & $55(36)$ & $74(28)$ \\
\hline $\begin{array}{c}\text { POS } \\
\text { (mg de AGU/100g muestra) }\end{array}$ & $167(32)$ & $527(108)$ & $183(53)$ & $340(252)$ \\
\hline $\begin{array}{l}\text { Fenoles totales } \\
\text { (mg de GAE/100g muestra) }\end{array}$ & $71,6(2,2)$ & $335(13)$ & $52(3)$ & $172(11)$ \\
\hline $\begin{array}{l}\text { Actividad antioxidante } \\
\text { (mg de Trolox/100g muestra) }\end{array}$ & $27,5(1,3)$ & $105(1)$ & $34(2)$ & $103(5)$ \\
\hline
\end{tabular}

AT: ácido tartárico; AGU: ácido galacturónico; GAE: ácido gálico

Como era de esperar la disminución de la humedad, provocó un aumento generalizado en los ${ }^{\circ}$ Brix y, como consecuencia, un descenso 


\section{Capítulo VII}

en la actividad del agua después de la deshidratación mediante cada uno de los métodos de secado.

Tabla 24. Valores medios de actividad del agua y componentes analizados en la variedad Imperial seedless antes y después de cada tratamiento de secado. Entre paréntesis aparece la desviación estándar.

\begin{tabular}{|c|c|c|c|c|}
\hline \multirow{2}{*}{ Análisis } & \multicolumn{4}{|c|}{ Imperial seedless } \\
\hline & UF & $\mathrm{MW}+\mathrm{NaOH}$ & $\overline{U F}$ & $\mathrm{SAC}+\mathrm{NaOH}$ \\
\hline Humedad (g/g muestra) & $0,84(0,02)$ & $0,37(0,06)$ & $0,846(0,003)$ & $0,26(0,02)$ \\
\hline$a_{w}$ & $0,973(0,003)$ & $0,793(0,008)$ & $0,972(0,003)$ & $0,820(0,003)$ \\
\hline $\begin{array}{c}{ }^{\circ} \text { Brix } \\
\text { (g sólidos solubles/100g } \\
\text { fracción liquida) }\end{array}$ & $18,7(0,05)$ & $60(5)$ & $18(0,05)$ & $60,03(0,08)$ \\
\hline $\begin{array}{c}\text { Glucosa } \\
\text { (g/100g muestra) }\end{array}$ & $6,7(0,07)$ & $27,7(1,3)$ & $6,7(0,07)$ & $26(1)$ \\
\hline $\begin{array}{l}\text { Fructosa } \\
\text { (g/100g muestra) }\end{array}$ & $8,3(0,09)$ & $28,7(5,4)$ & $8,3(0,09)$ & $28,2(0,2)$ \\
\hline $\begin{array}{l}\text { Sacarosa } \\
\text { (g/100g muestra) }\end{array}$ & $0,55(0,05)$ & & $0,55(0,05)$ & \\
\hline $\begin{array}{c}\text { Acidez total } \\
\text { (mg AT/100g muestra) }\end{array}$ & $424(7)$ & $1506(97)$ & $494(8)$ & $1598(20)$ \\
\hline $\begin{array}{l}\text { Ácido ascórbico } \\
\text { (mg/100g muestra) }\end{array}$ & $3.8(1.1)$ & $13,34(0,05)$ & $2,92(0,012)$ & $9,84(0,03)$ \\
\hline $\begin{array}{l}\text { Magnesio } \\
\text { (mg/100g muestra) }\end{array}$ & $9,2(0,3)$ & $28(2)$ & $9,2(0,3)$ & $17(1)$ \\
\hline $\begin{array}{c}\text { Calcio } \\
\text { (mg/100g muestra) }\end{array}$ & $10,18(0,12)$ & $22(3)$ & $10,18(0,12)$ & $70(12)$ \\
\hline $\begin{array}{c}\text { Potasio } \\
\text { (mg/100g muestra) }\end{array}$ & $149(3)$ & $500(12)$ & $149(3)$ & $602(10)$ \\
\hline $\begin{array}{l}\text { Fósforo } \\
\text { (mg/100g muestra) }\end{array}$ & $7,2(0,6)$ & $14(4)$ & $7,2(0,6)$ & $24,4(2,4)$ \\
\hline $\begin{array}{c}\text { PT } \\
\text { (mg de AGU/100g muestra) }\end{array}$ & $443(73)$ & 1941 (158) & $387(9)$ & $1248(21)$ \\
\hline $\begin{array}{c}\text { PHS } \\
\text { (mg de AGU/100g muestra) }\end{array}$ & 57 (3) & $406(36)$ & $55,0(1,6)$ & $150(56)$ \\
\hline $\begin{array}{c}\text { POS } \\
\text { (mg de AGU/100g muestra) }\end{array}$ & $119(50)$ & $656(87)$ & $205(17)$ & 1085 (119) \\
\hline $\begin{array}{c}\text { Fenoles totales } \\
\text { (mg de GAE/100g muestra) }\end{array}$ & $47,3(1,6)$ & $299(20)$ & $47,3(1,6)$ & $506(12)$ \\
\hline $\begin{array}{l}\text { Actividad antioxidante } \\
\text { (mg de Trolox/100g muestra) }\end{array}$ & $30,1(1,1)$ & $129(10)$ & $28,6(1,5)$ & $76(6)$ \\
\hline
\end{tabular}

AT: ácido tartárico; AGU: ácido galacturónico; GAE: ácido gálico 
Tabla 25. Valores medios de actividad del agua y componentes analizados (expresados en base de fruta fresca) en cada una de las variedades de uva deshidratadas por los dos tratamientos de secado. Entre paréntesis aparece la desviación estándar.

\begin{tabular}{|c|c|c|c|c|}
\hline \multirow{2}{*}{ Análisis } & \multicolumn{2}{|c|}{ Thompson seedless } & \multicolumn{2}{|c|}{ Imperial seedless } \\
\hline & MW & SAC & $\mathrm{MW}+\mathrm{NaOH}$ & $\mathrm{SAC}+\mathrm{NaOH}$ \\
\hline Humedad (g/g fruta fresca) & $0,19(0,05)$ & $0,31(0,05)$ & $0,39(0,04)$ & $0,25(0,01)$ \\
\hline$a_{w}$ & $0,915(0,003)$ & $0,85(0,003)$ & $0,79(0,01)$ & $0,812(0,02)$ \\
\hline $\begin{array}{c}{ }^{\circ} \text { Brix } \\
\text { (g sólidos solubles/100g } \\
\text { fracción liquida fruta fresca) }\end{array}$ & $79,3(0,03)$ & $54(0,1)$ & $60,4(0,2)$ & $72(0,1)$ \\
\hline $\begin{array}{c}\text { Glucosa } \\
\text { (g/100g fruta fresca) }\end{array}$ & $7,2(0,5)$ & $7,2(0,8)$ & $6,4(1,3)$ & $6,4(0,3)$ \\
\hline $\begin{array}{c}\text { Fructosa } \\
\text { (g/100g fruta fresca) }\end{array}$ & $8,9(0,5)$ & $11,4(1,5)$ & $7,1(0,3)$ & $6,9(0,2)$ \\
\hline $\begin{array}{c}\text { Sacarosa } \\
\text { (g/100g fruta fresca) }\end{array}$ & $\mathrm{Nd}$ & $\mathrm{Nd}$ & $\mathrm{Nd}$ & $\mathrm{Nd}$ \\
\hline $\begin{array}{c}\text { Acidez total } \\
\text { (mg AT/100g fruta fresca) }\end{array}$ & $512(26)$ & $324(43)$ & $387(25)$ & $443,7(5,5)$ \\
\hline $\begin{array}{l}\text { Ácido ascórbico } \\
\text { (mg/100g fruta fresca) }\end{array}$ & $2,14(0,02)$ & $3,9(0,01)$ & $3,3(0,01)$ & $2,73(0,01)$ \\
\hline $\begin{array}{c}\text { Magnesio } \\
\text { (mg/100g fruta fresca) }\end{array}$ & $4,1(0,6)$ & $6,2(1,3)$ & $7,2(0,5)$ & $4,8(0,2)$ \\
\hline $\begin{array}{c}\text { Calcio } \\
\text { (mg/100g fruta fresca) }\end{array}$ & $3,8(0,4)$ & $6,1(2,2)$ & $5,7(0,9)$ & $21,44(0,01)$ \\
\hline $\begin{array}{c}\text { Potasio } \\
\text { (mg/100g fruta fresca) }\end{array}$ & $193(3)$ & $228(1)$ & $129(3)$ & $167(3)$ \\
\hline $\begin{array}{c}\text { Fósforo } \\
\text { (mg/100g fruta fresca) }\end{array}$ & $14,6(1,6)$ & $44(3)$ & $3,55(1)$ & $6,8(0,6)$ \\
\hline $\begin{array}{c}\text { PT } \\
\text { (mg de AGU/100g fruta } \\
\text { fresca) }\end{array}$ & $272(14)$ & $256(14)$ & $433(97)$ & $347(6)$ \\
\hline $\begin{array}{c}\text { PHS } \\
\text { (mg de AGU/100g) }\end{array}$ & $148(48)$ & $25(9)$ & $102(9)$ & $42(16)$ \\
\hline $\begin{array}{c}\text { POS } \\
\text { (mg de AGU/100g fruta } \\
\text { fresca) }\end{array}$ & $156(32)$ & $113(84)$ & $165(22)$ & $302(33)$ \\
\hline $\begin{array}{c}\text { Fenoles totales } \\
\text { (mg de GAE/100g fruta } \\
\text { fresca) }\end{array}$ & $79(3)$ & $57,3(3,6)$ & $78(5)$ & $140,5(3,4)$ \\
\hline $\begin{array}{c}\text { Actividad antioxidante } \\
\text { (mg de Trolox/100g fruta } \\
\text { fresca) }\end{array}$ & $36,2(0,3)$ & $34,3(1,7)$ & $32(3)$ & $21,1(1,8)$ \\
\hline
\end{tabular}

AT: ácido tartárico; AGU: ácido galacturónico; GAE: ácido gálico 


\section{Capítulo VII}

Debido a la variabilidad en la composición inicial de la fruta fresca, para poder comparar entre los distintos tratamientos de deshidratación, se calculó la ganancia o pérdida en el contenido de cada compuesto, considerando la diferencia entre la cantidad del compuesto presente en $100 \mathrm{~g}$ de uva fresca y la presente en la pasa referida igualmente a $100 \mathrm{~g}$ de uva fresca. Es decir, la base de referencia para determinar los valores fue el peso de fruta fresca (Tabla 25). Además se realizó un análisis de la varianza para evaluar la significación de los cambios observados.

La figura 38 muestra el contenido en ácido tartárico y ascórbico. Ambos se ven afectados por los tratamientos, que provocan pérdidas en casi todos los casos. Para el ácido tartárico no se observaron diferencias en función del método de deshidratación empleado ni de la aplicación de pretratamiento. En cuanto al ácido ascórbico, se observa que las muestras tratadas por SAC (contrariamente a lo que ocurre con las demás) no sufrieron pérdidas en su contenido. Esto puede deberse a que la piel de la uva no padeció tanto en comparación con los otros métodos y protegió al ácido de la presencia de oxigeno. En general, y tal como era de esperar, el ácido ascórbico parece sufrir pérdidas significativas por hidrólisis y por las altas temperaturas, especialmente con la aplicación de microondas y el pretratamiento con sosa. Las mayores pérdidas observadas con la aplicación del pretratamiento, pueden verse ocasionadas por lixiviación durante el remojo y por una mayor degradación del ácido ascórbico en medios alcalinos (Fennema, 1993). Por otro lado, es bien sabido que el ácido ascórbico resulta seriamente afectado por las elevadas temperaturas, lo que justificaría la mayor 
disminución observada con la aplicación de microondas (Vikram et al., 2005).

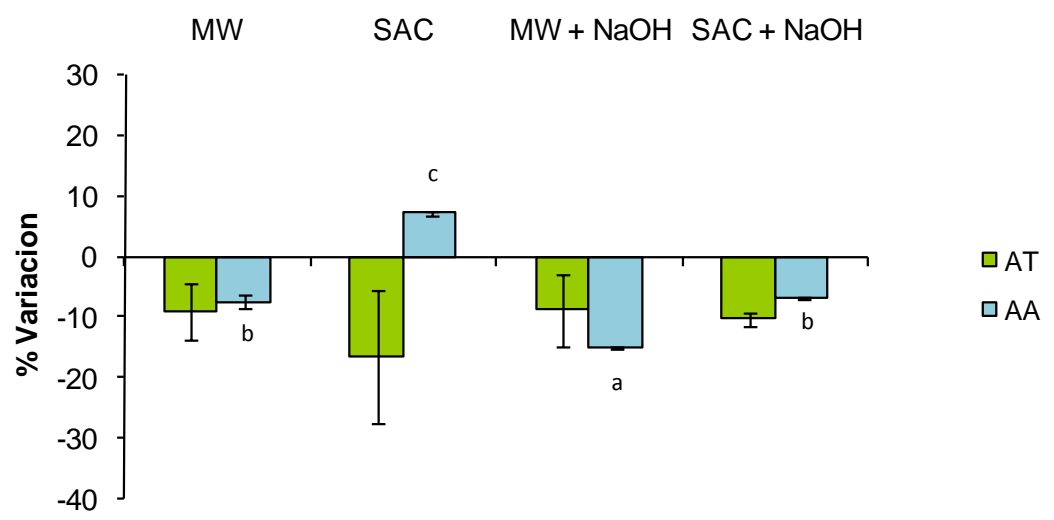

Figura 38. Porcentaje de variación en el contenido en ácido tartárico (AT) y ascórbico (AA) de la uva para cada uno de los tratamientos de secado de ambas variedades. Letras diferentes en cada compuesto indican diferencias significativas entre tratamientos.

En cuanto a los azúcares, de manera general, los tratamientos de secado provocaron una disminución en su contenido (Figura 39), siendo la sacarosa la más afectada (no detectada en la uva deshidratada) probablemente como consecuencia de su susceptibilidad a hidrolizarse por efecto de la alta temperatura. También puede observarse que la pérdida en glucosa es menor cuando se realiza el pretratamiento con $\mathrm{NaOH}$, mientras que el de la fructosa es mayor. Esto puede ser consecuencia del equilibrio ceto-enol para la fructosa en medio básico, que supone la conversión de este azúcar en su enediol y de éste en glucosa. 


\section{Capítulo VII}

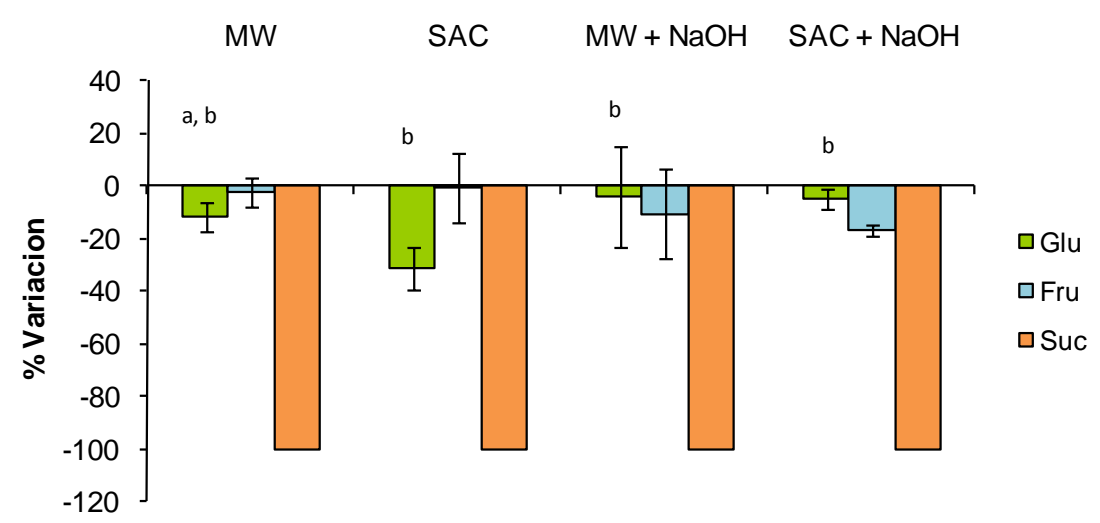

Figura 39. Porcentaje de variación en el contenido en azúcares de la uva pasa secada por aire caliente con y sin pretratamiento con $\mathrm{NaOH}$ (SAC y $\mathrm{SAC}+\mathrm{NaOH}$ ) y microondas con y sin pretratamiento con $\mathrm{NaOH}(\mathrm{MW}$ y $\mathrm{MW}+\mathrm{NaOH}$ ). Letras diferentes en cada compuesto indican diferencias significativas entre tratamientos.

En la figura 40 podemos observar el efecto de la deshidratación en los minerales cuantificados. El contenido en magnesio y calcio disminuyó significativamente en la fruta deshidratada, a excepción de aquella procesada con un pretratamiento con sosa y secada convectivamente. En este caso, el valor del calcio aumentó considerablemente. Algunos autores han observado un aumento de este mineral después del escaldado como consecuencia de la calidad de agua empleada (Fennema 1993). En el caso de las microondas, las mayores temperaturas alcanzadas por el producto junto con una posible interacción de las microondas con estas sales minerales, podían haber sido las responsables de la mayor disminución observada. En cuanto al potasio y al fósforo, los resultados parecen indicar que la aplicación de 
microondas provoca pérdidas significativas en dichos componentes, mientras que el secado por aire caliente no afecta o aumenta su contenido. La adición de sosa también afecta a estos minerales.

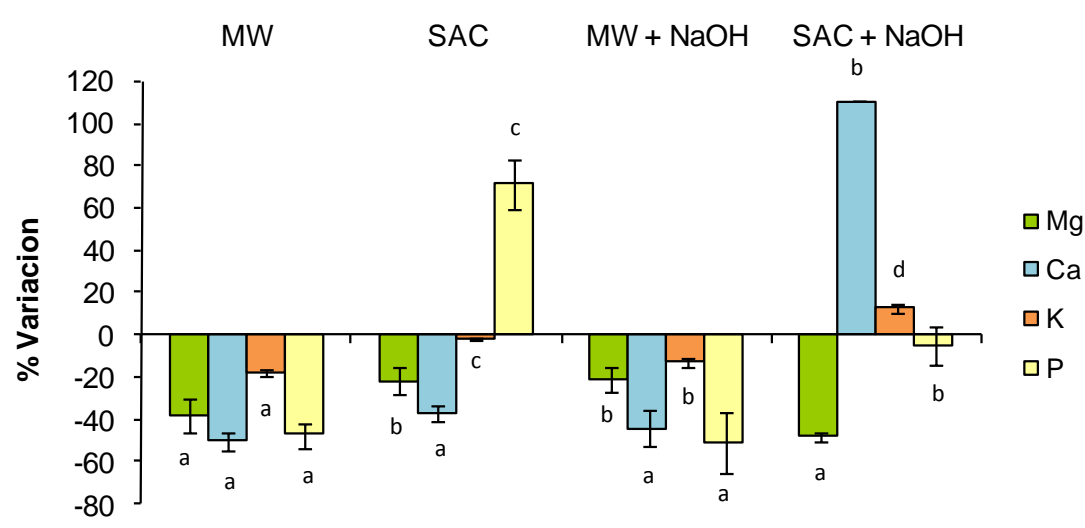

Figura 40. Porcentaje de variación en el contenido en minerales para cada uno de los tratamientos de secado de ambas variedades. Letras diferentes en cada compuesto indican diferencias significativas entre tratamientos.

Por otra parte, aunque los resultados en pectina total no muestran ninguna tendencia clara en las variaciones, los tratamientos de deshidratación provocaron la solubilización parcial de las pectinas estructurales de la uva. Este hecho se ha observado en otras frutas (Contreras et al. 2007, Torregiani et al. 1998). La aplicación de microondas supuso un mayor aumento de la fracción hidrosoluble (PHS) de la uva que el secado convectivo, lo que refleja un mayor grado de ruptura y desunión celular de las muestras deshidratadas por estos tratamientos como consecuencia de la mayor temperatura alcanzada por 


\section{Capítulo VII}

la fruta (Contreras et al., 2005). Por su parte, la fracción oxalato soluble, constituida por pectinas de menor grado de metoxilación y con capacidad para ligar calcio, también se vio afectada por los tratamientos ensayados. Cuando la fruta no se sometió a un baño de sosa, las uniones entre el calcio y estas pectinas de bajo metoxilo en la fruta deshidratada parecen haber sufrido modificaciones, tal y como muestra el descenso en la fracción oxalato soluble en estos tratamientos. Por el contrario, el pretratamiento ocasionó un efecto inverso en esta fracción péctica. La sosa podría haber demetoxilado la fracción péctica de alto metoxilo (PHS), convirtiéndola en pectinas de menor grado de metoxilación (POS), lo que justificaría que la fracción oxalato soluble aumente en la uva sometida a un baño con $\mathrm{NaOH}$ y posteriormente deshidratada (Kim et al., 1978).

A la vista de estos resultados, es posible concluir que las muestras secadas con aire caliente y sin pretratamiento son las menos afectadas mientras que las deshidratadas con microondas son las que experimentan mayores cambios en su composición péctica. Cabría esperar por tanto que la estructura celular de las primeras se haya mantenido mejor. 


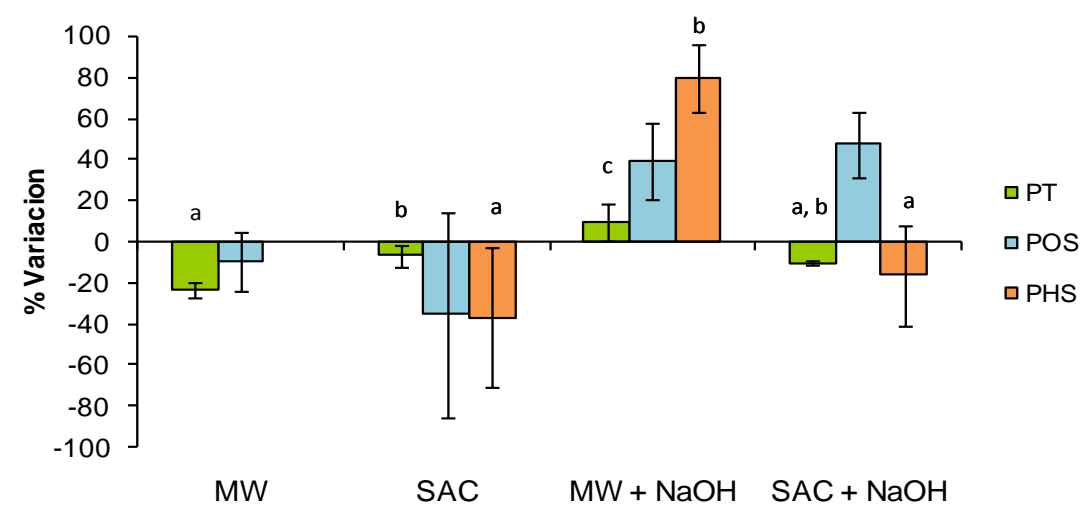

Figura 41. Porcentaje de variación en el contenido en Pectina total, pectina oxalato soluble y pectina hidrosoluble para cada uno de los tratamientos de secado de ambas variedades. Letras diferentes en cada compuesto indican diferencias significativas entre tratamientos.

La figura 42 permite observar el efecto del procesado de la uva pasa sobre la actividad antioxidante y los fenoles totales. Estas muestran en general variaciones positivas. El contenido en fenoles aumenta en la uva deshidratada, sobre todo cuando la fruta ha sido sometida al pretratamiento con sosa. La mayor facilidad en la extracción de estos compuestos como consecuencia de la alteración de la estructura durante el secado y la posible rotura de la piel durante el pretratamiento, podrían ser las responsables de los mayores valores obtenidos. La actividad antioxidante, sin embargo, no experimentó cambios en el mismo sentido que los fenoles (Figura 42). Esto puede ser debido a la baja correlación existente entre el contenido en fenoles totales, el ácido ascórbico y la capacidad antioxidante en aquellas muestras cuyo contenido en antocianos es prácticamente nulo, como es el caso de la uva blanca. De 


\section{Capítulo VII}

hecho, en determinados estudios no se ha encontrado correlación alguna entre ambos (Kuskoski et al., 2005).

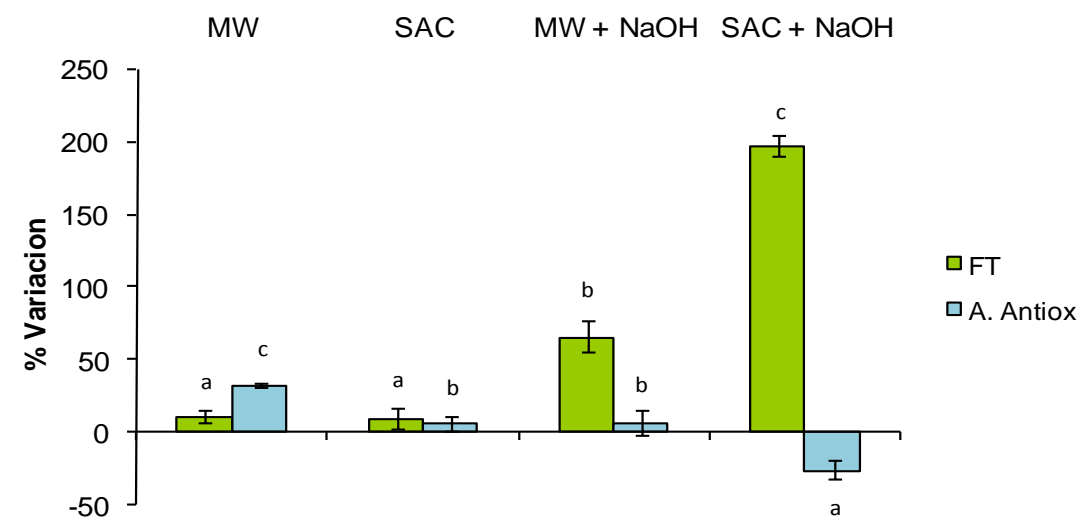

Figura 42. Porcentaje de variación en el contenido en fenoles totales (\% de GAE) y actividad antioxidante (\% de Trolox) de la uva pasa para cada uno de los tratamientos de secado de ambas variedades. Letras diferentes en cada compuesto indican diferencias significativas entre tratamientos.

\section{VII.5.1 Comparación con uva pasa comercial}

Con el objetivo de realizar una comparación entre la uva pasa obtenida experimentalmente y una pasa comercial adquirida en un supermercado local, y teniendo en cuenta que con los tratamientos ensayados se alcanzó una humedad final del producto superior a la comercial $(0,24-0,37$ frente a $0,14 \mathrm{~g}$ agua/g muestra), los valores de cada compuesto estudiado se expresaron por cantidad de materia seca (MS) de la fruta deshidratada. 
Las figuras 43 a 47 muestran los valores de los diferentes compuestos expresados en esta base de cálculo. Como puede observarse, en todos los casos excepto en el ácido ascórbico, la pasa comercial presenta un contenido de los diferentes compuesto y parámetros analizados que se encuentran en el intervalo de los encontrados para las muestras sometidas a los diferentes tratamientos. El AA fue menor en el producto comercial, probablemente como consecuencia de la mayor intensidad del tratamiento para conseguir un producto con menor humedad.

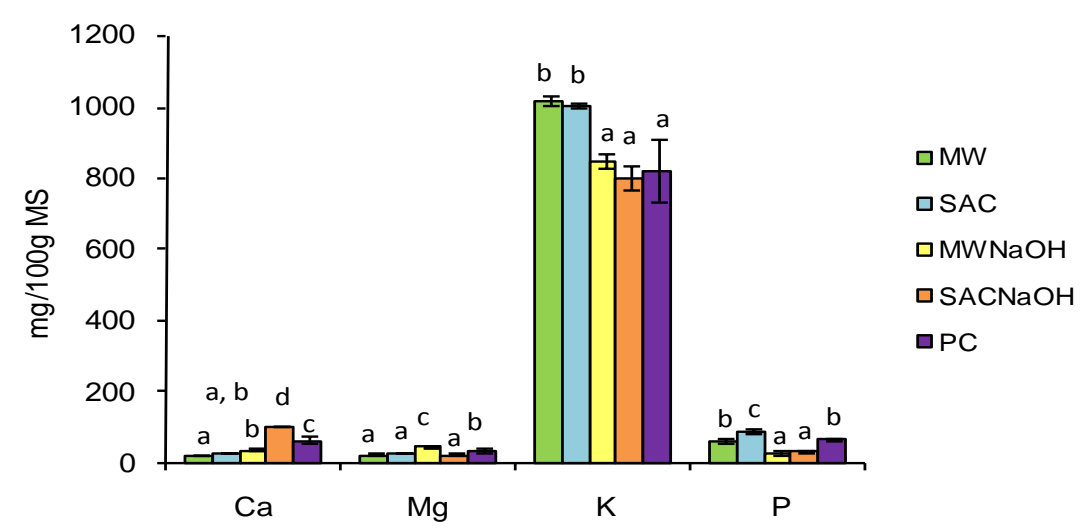

Figura 43. Valores medios y desviación estándar en el contenido en minerales de la uva pasa secada por aire caliente con y $\sin$ pretratamiento con $\mathrm{NaOH}(\mathrm{SAC}$ y $\mathrm{SAC}+\mathrm{NaOH})$, por microondas con y sin pretratamiento con $\mathrm{NaOH}(\mathrm{MW}$ y $\mathrm{MW}+\mathrm{NaOH})$ y de la uva pasa comercial. 
Capítulo VII

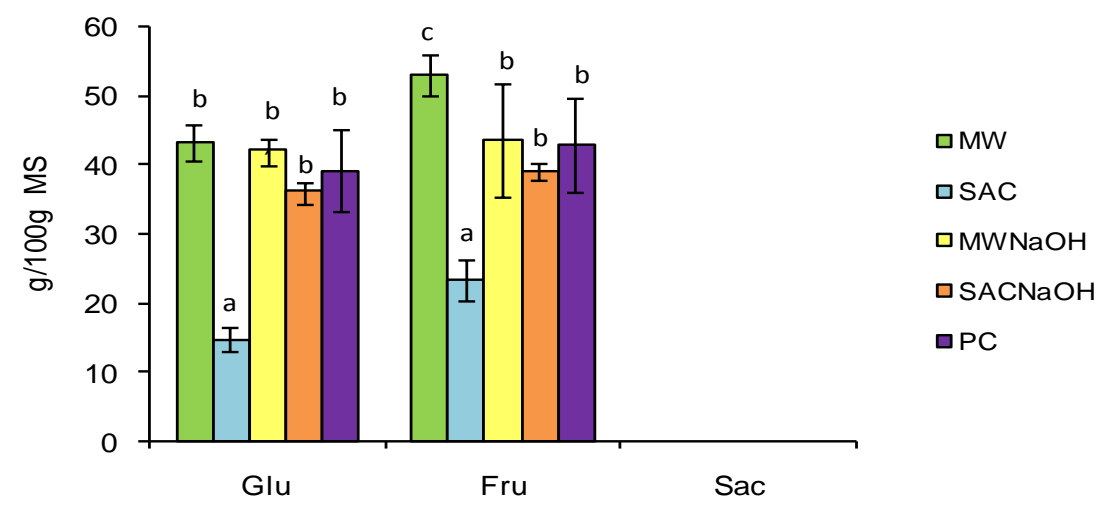

Figura 44. Valores medios y desviación estándar en el contenido en azúcares de la uva pasa secada por aire caliente con y sin pretratamiento con $\mathrm{NaOH}$ (SAC y $\mathrm{SAC}+\mathrm{NaOH})$, por microondas con y $\sin$ pretratamiento con $\mathrm{NaOH}(\mathrm{MW}$ y $\mathrm{MW}+\mathrm{NaOH}$ ) y de la uva pasa comercial.

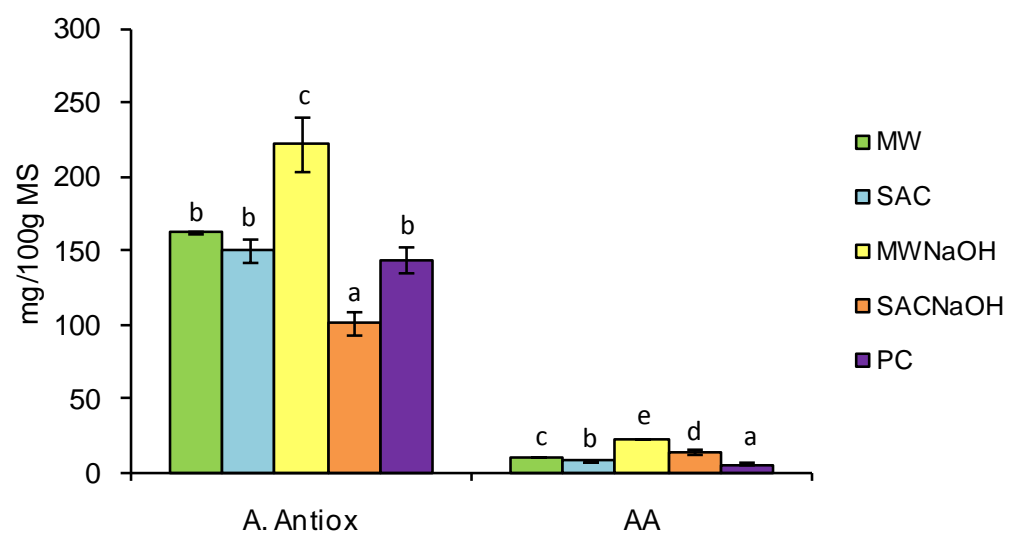

Figura 45. Valores medios y desviación estándar de la actividad antioxidante y ácido ascórbico de la uva pasa secada por aire caliente con y sin pretratamiento con $\mathrm{NaOH}(\mathrm{SAC}$ y $\mathrm{SAC}+\mathrm{NaOH})$, por 170 
microondas con y sin pretratamiento con $\mathrm{NaOH}(\mathrm{MW}$ y $\mathrm{MW}+\mathrm{NaOH})$ y de la uva pasa comercial.

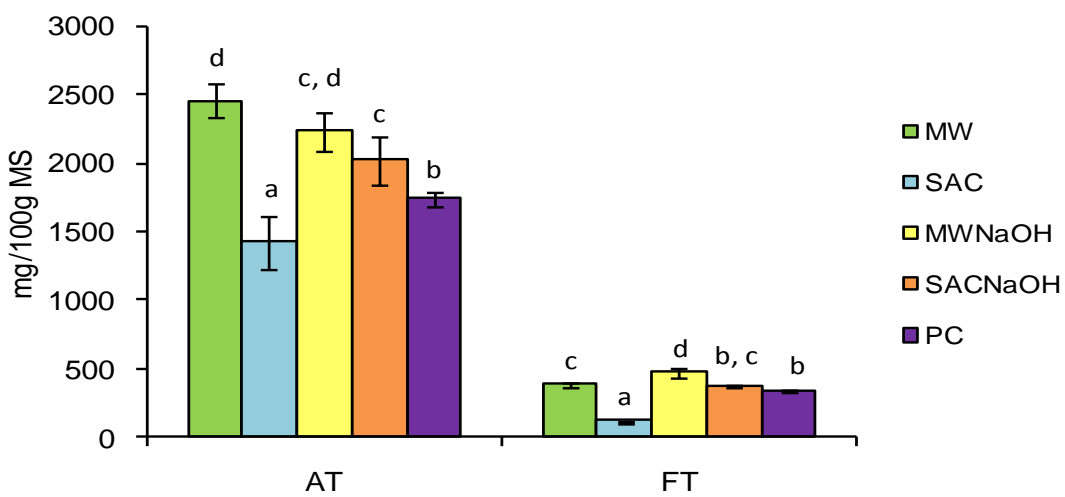

Figura 46. Valores medios y desviación estándar en el contenido en fenoles y ácido tartárico de la uva pasa secada por aire caliente con y sin pretratamiento cosn $\mathrm{NaOH}(\mathrm{SAC}$ y $\mathrm{SAC}+\mathrm{NaOH})$, por microondas con y sin pretratamiento con $\mathrm{NaOH}(\mathrm{MW}$ y $\mathrm{MW}+\mathrm{NaOH})$ y de la uva pasa comercial.

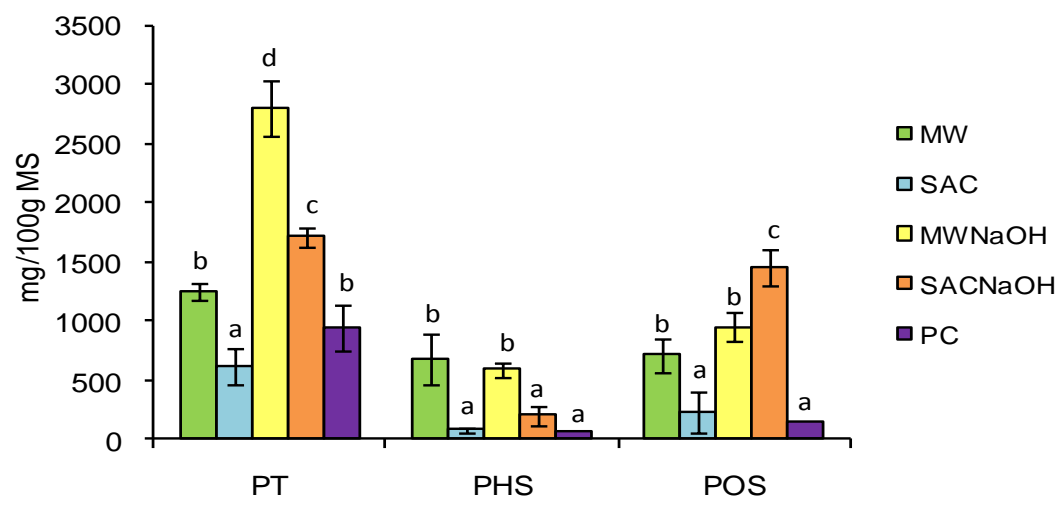

Figura 47. Valores medios y desviación estándar en el contenido en pectinas de la uva pasa secada por aire caliente con y sin pretratamiento 


\section{Capítulo VII}

con $\mathrm{NaOH}$ (SAC y $\mathrm{SAC}+\mathrm{NaOH})$, por microondas con y $\sin$ pretratamiento con $\mathrm{NaOH}(\mathrm{MW}$ y $\mathrm{MW}+\mathrm{NaOH})$ y de la uva pasa comercial.

Desde este punto de vista, parece que el proceso industrial podría sustituirse por las técnicas utilizadas experimentalmente consiguiendo un producto de similares características nutricionales/funcionales pero con tiempos de proceso optimizados, especialmente en el caso del pretratamiento y de la aplicación de microondas. Hay que recordar que los tiempos variaron entre 7,5 horas para el MW, 5 días para el SAC, 4,5 hrs para el $\mathrm{MW}+\mathrm{NaOH}$ y 34 horas para el $\mathrm{SAC}+\mathrm{NaOH}$.

\section{VII.6 CONCLUSIONES}

En todos los casos, los productos obtenidos mantienen características similares a la pasa comercial.

- El secado para la obtención de uva pasa provoca, en general, una diminución de todos los compuestos estudiados excepto de los fenoles totales, debido probablemente a su mayor facilidad de extracción por efecto de las altas temperaturas.

- El pretratamiento con $\mathrm{NaOH}$ supone mayores pérdidas de AA, de fructosa y de pectina hidrosoluble aumentando la oxalato soluble. La actividad antioxidante también disminuye cuando se aplica este pretratamiento.

- La aplicación de MW supone mayores pérdidas de AA y mayor solubilización de pectinas. Sin embargo proporciona muestras con mayor actividad antioxidante. 
UVA PASA

- En el caso de la uva blanca, no parece haber una correlación del contenido en fenoles totales y ácido ascórbico con la actividad antioxidante.

- Los métodos de secado empleados en este trabajo permiten conservar mejor el AA que el convencional. 
BIBLIOGRAFÍA 

Ahrne, L.; Prothon, F.; Funebo, T. (2003) Comparison of drying kinetics and texture effects of two calcium pretreatments before microwave-assisted dehydration of apple and potato. International Journal of Food Science and Technology. (38) 411-420.

Alexandre, B.J.L. (1997). Conservación de Alimentos. Universidad Politécnica de Valencia. 28

AOAC (1997). Official Methods of Analysis (16th ed.) Washington, DC. Association of Official Analytical Chemists.

Arthey, D.; Ashurst, P.R. (1997). Procesado de Frutas. Editorial Acribia. Zaragoza, España. 39

Barat, J.M.; Andrés, A.; Fito, P. (1998). Deshidratación osmótica de alimentos. Servicios de Publicaciones U.P.V.

Belnstein, J. (2001). The protective factors of fruit and vegetables. Food Technology International. (10) 12-14.

Bilbao, C. (2002). Estudio del secado combinado aire/microondas en manzana Granny Smith. Tesis doctoral. Universidad Politécnica de Valencia. 243

Blouin, J.; Guimbertau, G. (2005). Maduración y madurez de la uva. Ed. Mundi-Prensa. 92

Brennan, G.J. (2007). Manual del procesado de los alimentos. Ed. Acribia. Zaragoza, España. 26-29

Burnette, F.S. (1977). Peroxidase and his relationship to food flavour and quality: A review. J. Food Sci. (42) 1-6.

Cantos, E.; Espín, J.C.; Tomás-Barberán, F. (2002). Varietal differences among the polyphenol profiles of seven table grape cultivars studied by LC- 
BIBLIOGRAFÍA

DAD-MS-MS. Journal of agricultural and food Chemistry. (50) 56915696

Carbonero Z.P. (1975). Enzimas en: Complementos de bioquímica, Industrias Agrícolas: Editorial Universidad Politécnica de Madrid. 209

Carbonnell, J.V.; Contreras, P.; Carbonell, L.; Navarro, J.L. (2006). Pectin methylesterase activity in juices from mandarins, oranges and hybrids.

Cash, J.N.; Sistrunk, W,A.; Stutte, C.A. (1976) Characteristics of Concord grape polyphenoloxidase involved in juice color boos. Journal of Food Science. Chicago (41) 1398-1402

Catania, C.; Avagnina, S. (2007) La maduración de la uva. Curso superior de degustación de vinos. 2007 EEA Mendoza INTA. (18) 1-5

Chen, C.S.; Shaw, P.E.; Parish, M.E. (1993). Orange and tangerine juices. In S. Nagy, C. S. Chen, \& P. E. Shaw (Eds.), Fruit juice processing technology. Auburndale, USA: Agscience. 110-165

Contreras, C.; Esparza, M.E.; Chiralt, A.; Martínez-Navarrete, N. (2008). Influence of microwave application on convective drying: effects on drying kinetics, and optical and mechanical properties of apple and strawberry. Journal of Food Engineering. (88) 55-64

Contreras, C.; Martin, M.E.; Martínez-Navarrete, N.; Chiralt, A. (2005). Effect of vacuum impregnation and microwave application on structural changes which occurred during air-drying of apple. LWT (38) 471-477

Contreras, C.; Martin, M.E.; Martínez-Navarrete, N.; Chiralt, A. (2007). Influence of osmotic pre-treatment and microwave application on properties of air dried strawberry related to structural changes. Eur. Food Res. Technol. 499-504 
Coombe B.G. (1992). Research on development and ripening of the grape berry. Am. J. Enol. Vitic. 43 (1) 101-100.

De Pieri, T.E.; Tomé, T.C.; Clemente, E. (2003). Peroxidase (POD) and Poliphenoloxidase (PPO) in grape (Vitis Vinifera L.) Ciênc. Agrotec. Lavras. 27 (3) 635-642

Elez-Martínez, P.; Aguiló-Aguayo, P.; Martín-Belloso, O. (2006). Inactivation of orange juice peroxidase by high intensity pulsed electric fields as influenced by process parameters. Journal of the Science of Food and Agriculture. (86) 71-81

Erenturk, S.; Gulaboglu, M.S.; Gultekin, S. (2005). The effects of cutting and drying medium on the vitamin $\mathrm{C}$ content of Rose hip during drying. Journal of Food Engineering. (68) 513-518.

Escribá, B. G. (2000). Deshidratación osmótica del kiwi. Efecto crioprotector en la textura. Universidad Politécnica de Valencia.

Femenia, A.; Sánchez, E.S.; Simal, S.; Rosselló, C. (1998). Effects of Drying Pre-treatment's on the Cell Wall Composition of Grape Tissues. Journal of Agricultural and Food Chemistry. (46) 271-276.

Fennema, O. (1993). Química de los alimentos. Editorial Acribia, S. A. Zaragoza. 102-108

Fito, P.; Chiralt, A. (1995). An update on vaccum osmotic dehydration. In G. V. Barbosa-Cánovas \& J. Welti-Chanes (Eds), Food preservatión by moisture control. Fundamentals and applications. Lancaster, PA: Technomic Publishing Co. 351-372 
Fito, P.; Chiralt, A.; Barat, J.M; Andrés, A.; Martínez-Monzó, J.; MartínezNavarrete, N. (2001) Vacumm impregnation for development of new dehydrated products. Journal of Food Engeneering (49) 297-302.

Fruit \& food log. http://www.fruitfoodlog.com.br/grapes-sugraone.htm [Consulta: 3-nov-2009]

Fundación Eroski. http://frutas.consumer.es/documentos/frescas/uva/intro.php [consulta: 4-Nov-09]

Funebo, T.; Ahrne, L.; Prothon, F.; Kidman, S.; Langton, M.; Skoldebrand, C. (2002) Microwave and convective dehydration of ethanol treated and frozen Apple-physical properties and drying kinetics. International Journal of food science and technology. (37) 603-614.

Genina, P. (2002). Deshidratación osmótica: alternativa para conservación de frutas tropicales. Avance y Perspectiva, (21) 321-324.

Gowen, A.A.; Abu-Ghannam, N.; Frias, J. M.; Barat, J. M.; Andres, A.; Oliveira, J.C. (2006). Comparative Study of Quality Changes Occurring on Dehydration and Rehydration of Cooked Chickpeas (Cicer Arietinum L.) Subjected to Combined Microwave-Convective and Convective Hot Air Dehydration. Journal of Food Science. (71) 282-289.

Greve, L.C.; McArdle, R.N.; Gohlke, J.; Labatich, J.M. (1994) The impact of heating on carrot firmness: Changes in cell wall components. Journal of Agricultural and Food Chemistry (42) 2900-2906

Heddleson R.A.; Doores, S. (1994) Factors affecting microwave heating of foods and microwaves induced destruction of food borne pathogens- a review. Journal of food protection. 57 (11), 1025-1037 
Hendrix, C.M.; Redd, J.B. (1995). Chemistry and technology of citrus juices and by-products. In P. R. Ashurst (Ed.), Production and packaging of non-carbonated fruit juices and fruit beverages. New York, USA: Chapman \& Hall. 53-87

Hidalgo, L. (2002) Tratado de viticultura general. 3ra Editorial Mundi-Prensa. Madrid, España. 12-35.

Holsdsworth, S.D. (1988). Conservación de frutas y hortalizas. Editorial Acribia, Zaragoza, España. 25

Jun Yang.; Timothy, E.M.; Rui Hai Liu. (2009). Phytochemical profiles and antioxidant activities of wine grapes. Food Chemistry. (116) 332-339.

Kaur, C.; Kapoor, H.C. (2001). Antioxidants in fruits and vegetables - the millenniums's health. International Journal of Food Science and Technology, 36 (7), 703-725.

Kidmose, U.; Martens, H.J. (1999) Changes in texture, microstructure and nutritional quality of carrot slices during blanching and freezing. Journal of the science of food and agriculture, 79 (12), 1747-1753

Kim, W.J.; Smit, C.J.B.; Rao, V.N.M. (1978). Demethylation of pectin using acid and ammonia. Journal of Food Science. 43 (1) 74.

Kimball D.A. (1999) Citrus Processing. A complete guide, $2^{\text {nd }}$ Ed. Kluver Academic/Plenum Publishers, New York. 117-125

King, A.; Young, G. (1999). Characteristics and occurrence of phenolic phytochemicals. Journal of the American Dietetic Association, 99 (2) 213-218. 
Kitner, P.K.; Van Buren, P.J. (1982). Carbohydrate interference and its correction in pectin analysis using the m-hydroxydiphenyl method. Food science. (47) 756-764 .

Klein, B.P.; Kurilich, A.C. (2000). Processing effects of dietary antioxidants from plant foods. HortScience, 35(4), 580-584.

Kuskoski, M.E.; Asuero, A.G.; Troncoso, A.M.; Manzini-Filho, J.; Fett, R. (2005). Aplicación de diversos métodos químicos para determinar actividad antioxidante en pulpa de frutos. Ciencia y Tecnología de Alimentos. 25(4) 726-732.

Lambretch, H.S. (1995) Sulfite substitutes for the prevention of enzymatic browning in foods. In C. Y. Lee, \& J.R. Whitaker (Eds) Enzymatic browning and its prevention. USA: American Chemical Society. 240250

Li Ni.; Lin, D.; Barret D.M. (2005) Pectin methyl esterase catalized firming effects on low temperature blanched vegetables. Journal of Food Engineering. (70) 546-556.

Li, B.B.; Smith, B.; Hossain M.M. (2006). Extraction of phenolics from citrus peels I. Solvent extraction method. Separation Purification Technology, (48) 182-188.

Lin, S.; Brewer, M.S. (2005) Effects of blanching method on the quality charachteristics on frozen peas. Journal of Food Quality. (28) 350-360.

Martin, M.E. (2002). Utilización de microondas en el secado por aire caliente de manzana (variedad Granny Smith). Influencia del pretratamiento por impregnación al vacío. Tesis doctoral. Universidad Politécnica de Valencia. 
Martínez-Navarrete, N., Camacho, M.M., García-Martínez, E., Martin-Esparza, M.E. (2007). Development of gel products containing fruit pieces using osmotic treatments without byproducts generation. Focus on food engineering research and developments. Ed.: F. Columbus. Nova Science Publishers In. 307-337.

Mataix, V.J. (1998). Tabla de composición de alimentos. Universidad de Granada. 137

Mathew, A.G.; Parphia, H.A. (1971) Food browning as a polyphenol reaction advances in food research. (19) 75-145

Maxcheix, J.J.; Fleuriet, A.; Billot, J. (1990) The main phenolics of fruits. In fruit phenolics. Boca Ratón, Fl: CRC Press 1-98

Mayer, A.M.; Harel, E. (1979) Polyphenoloxidases in plants. Phytochemistry. (18) $193-215$

McEvily A.J.; Iyengar, R.; Otwell, S. (1992). Inhibition of enzymatic browning in foods and beverages. Critical review in food science and nutrition. 32 (3) $253-273$.

Mclellan K,M.; Robinson D.S. (1984) Heat stability of peroxidase from orange. Food Chemistry,Brking, (13) 139-147.

Ming-Liu.; Xiu-Qi-Li.; Weber, C.; Chang-Yong-Lee.; Brown, J.; Rui-Hau-Liu. (2002). Antioxidant and antiproliferative activities of raspberries. Journal of Agricultural and Food Chemistry, 50(10) 2926-2930.

Morton, L.W.; Caccetta, R.A.; Puddey, I.B.; Croft, K.D. (2000). Chemistry and biological effect of dietary phenolic compounds: relevance to cardiovascular disease. Clinical and Experimental Pharmacology and Physiology, (27) 152-159. 
Nuñez-Delicado, E.; Serrano-Megías, M.; Pérez-López, A.J.; López, Nicolas, J.M. (2007) Characterization of polyphenoloxidase from Napoleon Grape. Food Chemistry. (100) 108-114

Nutrition Data. C2009, http://www.nutritiondata.com/facts/fruits-and-fruitjuices/1920/2 [Consulta: 6-nov-09]

Pangavhane, D.R.; Sawhney, R. L. (2002). Review of research and development work on solar dryers for grape drying. Energy conversion management (43) 45-61.

Peiró, R.; Díaz, V.M.C.; Camacho M.M.; Martínez-Navarrete, N. (2006) Micronutrient flow to the osmotic solution during the grapefruit osmotic dehydration Journal of Food Engineering, 74 (3) 299-307.

Peiró-Mena, R.; Camacho, M.M.; Martínez-Navarrete, N. (2007). Compositional and physicochemical changes associated to successive osmodehydration cycles of pineapple (Ananas comusus). Journal of Food Engineering. (79) 842-849.

Pérez, F. (1998) La uva de mesa. Editorial Agroguías. Mundi-Prensa. Madrid.

Philippon, J. (1984). Méthodes de blanchiment-refrodissement des legumes destines la congêlation. Science des Aliments. (4) 523-550

Piotrowski, D.; Lenart, A.; Wardzynski, A. (2004). Influence of osmotic dehydration on microwave-convective drying of frozen strawberries. Journal of food Engineering, (65) 519-525.

Ponne, C.T.; Van Remmen, H.H.J.; Bartels, P.V. (1991). Application of electromagnetic energy in processing of whole potatoes. Voedingsmiddelentechnologie. 24 (21) 44-46.

Primo, Y.E. (1998). Química de los alimentos. Ed Síntesis. Madrid. 232-278 
Prior, R.L.; Guohua-Cao, (2000). Antioxidant phytochemicals in fruits and vegetables: diet and health implications. HortScience, 35(4) 588-592.

Prothon, F.; Ahrné, L.; Funebo, T.; Kidman, S.; Langton, M.; Sjoholm, I. (2001) Effects of combined osmotic and microwave dehydration of apple on texture, microstructure and regydration charachteristics. Lebensmittel Wissenschaft and Technologie, (34) 95-101.

Raghavan, G.S.V.; Silveira, A.M. (2001) Shrinkage characteristics of strawberries osmotically dehydrated in combination with microwave drying. Drying technology, 19 (2) 405-414.

Ramaswany, H.; Van de Voort, F.R. (1990) Microwave application in food processing. Canadian Institute of Food Science and Technology Journal. 23(1) $17-23$

Rapeanu, G.; Ann, V.L.; Chantal, S.; Hendrickx, M. (2006) Biochemical Characterization and process stability of polyphenoloxidase extracted from Victoria Grape. Food Chemistry. (94) 253-261

Re, R.; Pellegrini, N.; Proteggente A.; Pannala N.; Yang M.; Rice-Evans C. (1999). Antioxidant activity applying an improved ABTS radical cation decolorization assay. Free Radical Biology \& Medicine. (26) 1231-1237.

Rexova-Benkova, L.; Marcovich, O. (1976) Pectic enzymes. In R. S. Tipson and D.Horton (Eds) Advanced in Carbohydrate Chemistry and Biochemistry. New York, London: Academic Press. (33) 323-385

Reynier, A. (1989). Manual de viticultura. Editorial Mundi-prensa. Madrid España.

Richardson, T.; Hyslop, D.B. (1985) Enzymes. In O. R. Fennema (Ed) Food chemistry, 2nd Ed. USA: Marcel Dekker. 371-476 
BIBLIOGRAFÍA

Rui-Hai-Liu. (2003). Health benefits of fruit and vegetables are from additive and synergistic combinations of phytochemicals. American Journal of Clinical Nutrition, 78(3) 517S-520S.

Salunkhe, D.K.; Kadam, S.S. (1995). Handbook of fruit science and technology. Ed. Board. New York, USA. 22

Sapis, J. C.; Macheix J. J.; Cordonier, R.E. (1983) The browning capacity of grapes. Changes in polyphenol oxidase activities during development and maturation of fruits. Journal of Agricultural and Food Chemistry. (31) $342-345$

Selman, J.D. (1987) The Blanching Process in, Developments in Food Processing- 4, ed. St. Thorne, Elsevier, Applied Science, London. 205249.

Severini C.; De pilli, T.; Baiano, A.; Mastrocola, D.; Massini, R. (2001) Study of preventing enzymatic browning of potato by microwave blanching. Sciences des aliments. 21(2) 149-160

Siddiq, M.; Sinha, N.K.; Cash, J.N. (1992). Characterization of polyphenoloxidase from Stanley plums. Journal of Food Science, Chicago. 57 (5) 1177-1179.

Snir, R.; Koehler P.E.; Sims, K.A.; Wicker, L. (1996) Journal of Food Science. (61) 379-382

Stolle-Smiths, T.; Beekhuizen, J. G.; Recourt, K.; Voragen, A.G. J.; Van Dijk, C. (1997) Changes in pectic hemicellulosic polymers of green beans (Phaseolus Vulgaris L.) during industrial processing. Journal of Agricultural and Food Chemistry. (45) 4790-4799 
Tarhan, S. (2006). Selection of chemical and thermal pretreatment combination for plum druing at low moderate drying air temperatures. Journal of Food Engineering. (79) 255-260.

Tijskens L.M.M.; Rodis P.S.; Hertog M.L.A.T.M.; Proxenia N.; Van Dijk C. (1999). Activity of pectin methyl esterase during blanching of peaches. Journal of Food Engineering. (39) 167-177

Tomás-Barberán, F.A. (2003). Los polifenoles de los alimentos y la salud. Alimentación, nutrición y salud, 10 (2) 41-53.

Torregiani, D.; Forni, E.; Maestrelli, A.; Quadri, F. (1998) Influence of osmotic dehydration on texture and pectic composition of kiwifruit slices. Drying Technology 17 (7 \& 8) 1378-1397.

Torringa, E.; Esveld, E.; Scheewe, I.; Van den Berg, R.; Bartels, P. (2001) Osmotic dehydration as a pretreatment before combined microwave-hot air-drying of mushrooms. Journal of food Engineering, (49) 185-191.

Valero, E.; Varón, R.; Carmona, G.F. (1988) Characterization of polypenoloxidase from Airen grape. Journal of Food Science. Chicago (53) $1482-1485$.

Valero, R.E. (1993) Caracterización cinética de la polifenoloxidasa de uva Airen. Servicio de publicaciones de la Universidad de Castilla-La Mancha. 57-67

Valiente, C.; Arrigori, E.; Esteban, R.; Arnado, R. (1995) Grape Pomace as a potential food fiber. Journal of food science. 60 (4) 818-820

Velioglu, Y.S.; Mazza, G.; Gao, L.; Oomah, B.D. (1998). Antioxidant activity and total phenolics in selected fruits, vegetables and grain products. Journal of Agricultural and Food Chemistry, 46 (10) 4113-4117. 
Venant, B.; Pourrat, A.; Pourrat, H.; Gross, D.; Bastide, P.; Bastide, J. (1988). Chem. Pharm. Bull. (36) 828.

Vikram, V.B.; Ramesh, M.N.; Prapulla, S.G. (2005). Thermal degradation kinetics of nutrients in orange juice heated by electromagnetic and conventional methods. Journal of Food Engineering. 69 (1) 31-40.

Viña, Z.S.; Olivera D.F.; Marani, C.M.; Ferreyra R.M.; Mugridge, A.; Chaves A.R.; Mascheroni, R.H. (2007). Quality of Brussels sprouts (Brassica oleracea L. gemmifera DC) as affected by blanching method. Journal of food engineering. (80) 218-225.

Waladkhani, A.; Clemens, M.R. (1998). Effect of dietary phytochemicals on cancer development (review). International journal of molecular medicine, (1) 747-753.

Walker, J.R.L. (1995) Enzymatic browning in fruits. In C. Y. Lee, \& J. R. Whitaker (Eds), Enzymatic browning and its prevention. USA: American Chemical Society. 8-22

Wargovich, M.J. (2000). Anticancer properties of fruits and vegetables. HortScience, 35(4) 573-575.

Whitaker, J.R. (1972). Principles of enzymology for the food science. New York Marcel Dekker Inc.

Winkler, A. (1965) Viticultura. Editorial Continental. México.

Wolfe, K.; Xianzhong, W.; Rui-Hai-Liu. (2003). Antioxidant activity of apple peel. J. Agric. Food Chem. 51(3) 609-614.

Yokotsuka, K.; Shimizu, T. (1991) Polyphenoloxidase from six matre grape varieties and their activities towards various phenols. Journal of Fermentation Bioengineering. Osaka (71) 156-162. 
Yu, L.; Reitmeieir, C,A.; Love, M.H. (1996). Strawberry Texture and Pectin Content as affected by Electrón Beam Irradiation. Journal of food science. 844-846.

Zhang, M.; Tang, J.; Mujumdar, A.S.; Wang, S. (2006). Trends in microwaverelated drying of fruits and vegetables. Food Science \& Technology (17) 524-534. 